University of Massachusetts Amherst

ScholarWorks@UMass Amherst

Masters Theses 1911 - February 2014

2011

Multidimensional Modeling of Condensing Two-Phase Ejector

Flow

Michael F. Colarossi

University of Massachusetts Amherst

Follow this and additional works at: https://scholarworks.umass.edu/theses

Part of the Heat Transfer, Combustion Commons

Colarossi, Michael F., "Multidimensional Modeling of Condensing Two-Phase Ejector Flow" (2011).

Masters Theses 1911 - February 2014. 672.

Retrieved from https://scholarworks.umass.edu/theses/672

This thesis is brought to you for free and open access by ScholarWorks@UMass Amherst. It has been accepted for inclusion in Masters Theses 1911 - February 2014 by an authorized administrator of ScholarWorks@UMass Amherst. For more information, please contact scholarworks@library.umass.edu. 
MULTIDIMENSIONAL MODELING OF CONDENSING TWO-PHASE EJECTOR FLOW

A Thesis Presented

by

MICHAEL COLAROSSI

Submitted to the Graduate School of the

University of Massachusetts Amherst in partial fulfillment

of the requirements for the degree of

MASTER OF SCIENCE IN MECHANICAL ENGINEERING

September 2011

Mechanical and Industrial Engineering 
(C) Copyright by Michael Colarossi 2011

All Rights Reserved 


\section{MULTIDIMENSIONAL MODELING OF CONDENSING TWO-PHASE EJECTOR FLOW}

A Thesis Presented

by

MICHAEL COLAROSSI

Approved as to style and content by:

David Schmidt, Chair

Stephen de Bruyn Kops, Member

Ashwin Ramasubramaniam, Member

Donald Fisher, Department Head

Mechanical and Industrial Engineering 


\section{ACKNOWLEDGMENTS}

I would like to thank my advisor, Professor David Schmidt, for all of his support throughout my entire time as a graduate student. His helpful insight and advice kept me motivated to complete my thesis. I would also like to thank the other members of my committee, Profs. de Bruyn Kops and Ramasubramaniam, for their input on my thesis

project. Also, thanks to Dr. Bergander for the collaboration on my research.

Thanks go to the National Science Foundation, STTR Phase II Project No. 0822525 and the Department of Energy, under Award Number DE-FG36-06GO16049 for sponsoring this research and providing financial support.

Thank you to everyone I worked with in the CFD lab, for helping me whenever I needed advice and for making the lab an enjoyable place to work. 


\author{
ABSTRACT \\ MULTIDIMENSIONAL MODELING OF CONDENSING TWO-PHASE EJECTOR \\ FLOW \\ SEPTEMBER 2011 \\ MICHAEL COLAROSSI, B.S., CLARKSON UNIVERSITY \\ M.S.M.E., UNIVERSITY OF MASSACHUSETTS AMHERST \\ Directed by: Professor David Schmidt
}

Condensing ejectors utilize the beneficial thermodynamics of condensation to produce an exiting static pressure that can be in excess of either entering static pressure. The phase change process is driven by both turbulent mixing and interphase heat transfer. Semi-empirical models can be used in conjunction with computational fluid dynamics (CFD) to gain some understanding of how condensing ejectors should be designed and operated.

The current work describes the construction of a multidimensional simulation capability built around an Eulerian pseudo-fluid approach. The transport equations for mass and momentum treat the two phases as a continuous mixture. The fluid is treated as being in a non-thermodynamic equilibrium state, and a modified form of the homogenous relaxation model (HRM) is employed. This model was originally intended for representing flash-boiling, but with suitable modification, the same ideas could be used for condensing flow. The computational fluid dynamics code is constructed using the open-source OpenFOAM library. Fluid properties are evaluated using the REFPROP database from NIST, which includes many common fluids and refrigerants. 
The working fluids used are water and carbon dioxide. For ejector flow, simulations using carbon dioxide are more stable than with water. Using carbon dioxide as the working fluid, the results of the validation simulations show a pressure rise that is comparable to experimental data. It is also observed that the flow is near thermodynamic equilibrium in the diffuser for these cases, suggesting that turbulence effects present the greatest challenge in modeling these ejectors. 


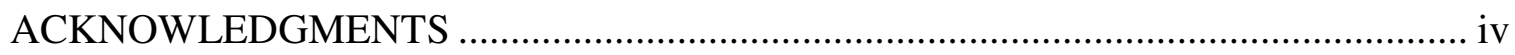

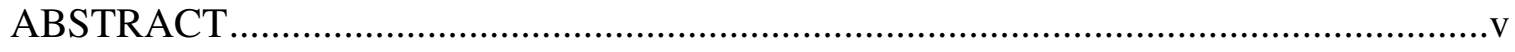

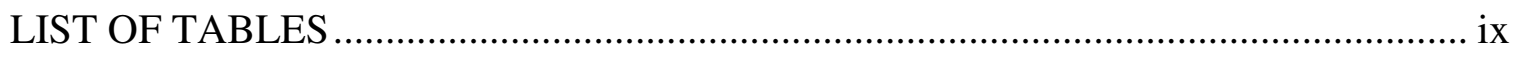

LIST OF FIGURES ……………………………………………………………...

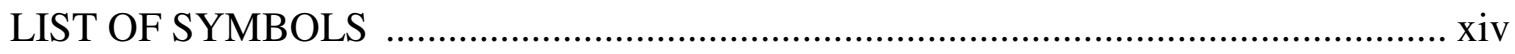

\section{CHAPTER}

1. INTRODUCTION AND LITERARY BACKGROUND ............................................

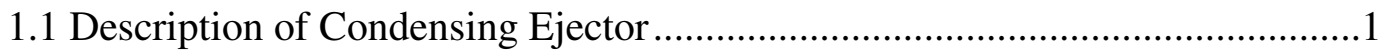

1.2 Application of Condensing Ejector...................................................................2

1.3 Early Experimental Work on Condensing Ejectors ..........................................

1.4 Modeling of Two-Phase Flow ...................................................................6

1.5 Using CFD to Model Flow in a Nozzle .........................................................

1.5.1 CFD of Two-Phase Flow through a Nozzle .........................................

1.5.2 Ejector Flow Studies Using CFD .......................................................

1.6 Use of Carbon Dioxide in a Refrigeration Cycle with an Ejector ....................17

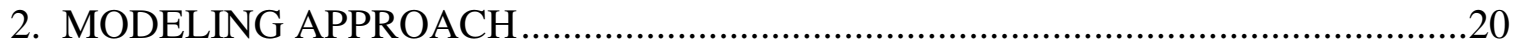

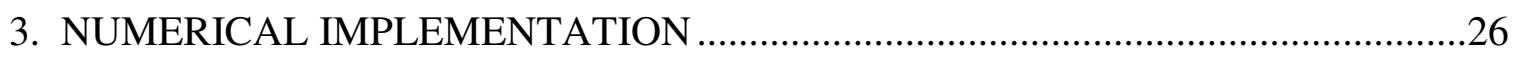

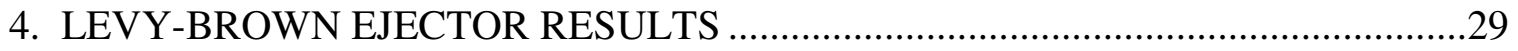

4.1 Levy-Brown Condensing Ejector ……………...........................................29

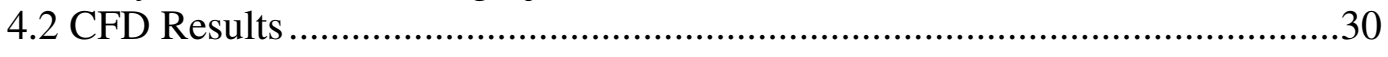

4.2.1 Water as Working Fluid...................................................................30

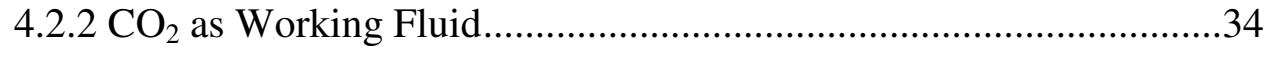

5. NAKAGAWA EJECTOR RESULTS …………………………………………......

5.1 Nakagawa et al. Two-Phase $\mathrm{CO}_{2}$ Ejector Cycle ……....................................40 
5.2 Results

5.2.1 Model Validation

5.2.2 CFD Results ................................................................47

5.3 Mesh Quality.......................................................................................... 51

5.4 Comparison of Different Turbulence Models.............................................53

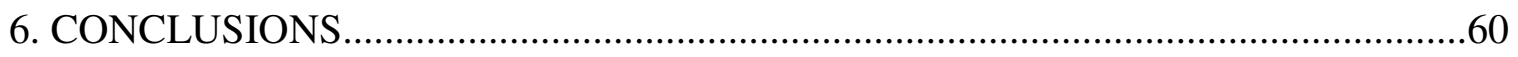

APPENDIX: PRESSURE PROFILE FOR ALL CFD VALIDATION CASES ..............63

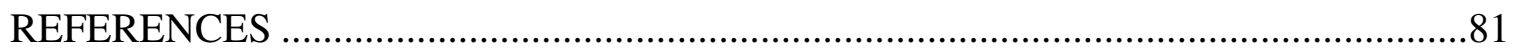




\section{LIST OF TABLES}

Table

Page

5.1. Pressure recovery difference between experimental and CFD results for varying gas cooler pressures of (a) $9.5 \mathrm{MPa}$, (b) $10 \mathrm{MPa}$, and (c) $10.5 \mathrm{MPa}$

5.2: Effect on pressure recovery when varying the turbulent Schmidt number for cases with gas cooler pressure set to $10 \mathrm{MPa}$

5.3. Using the realizable k-epsilon turbulence model, pressure recovery difference between experimental and CFD results for varying gas cooler pressures of (a) $9.5 \mathrm{MPa}$, (b) $10 \mathrm{MPa}$, and (c) $10.5 \mathrm{MPa}$

5.4. Using the RNG k-epsilon turbulence model, pressure recovery difference between experimental and CFD results for varying gas cooler pressures of (a) $9.5 \mathrm{MPa}$, (b) 10 $\mathrm{MPa}$, and (c) $10.5 \mathrm{MPa}$

5.5. Using the k-omega SST turbulence model, pressure recovery difference between experimental and CFD results for varying gas cooler pressures of (a) $9.5 \mathrm{MPa}$, (b) 10 $\mathrm{MPa}$, and (c) $10.5 \mathrm{MPa}$ 


\section{LIST OF FIGURES}

Figure

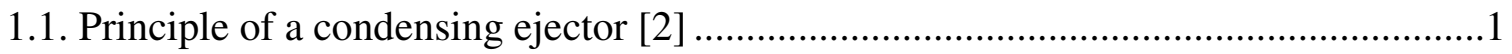

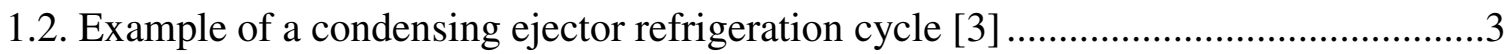

1.3. An oblique shock is observed in the Laval nozzle used in Senoo and White [32] .......9

1.4. Nozzle that was modeled in Menegay [8]. Saturated liquid flows through the motive nozzle and vapor flows in from the suction nozzle..................................................... 10

1.5. Experimental steam ejector cycle used in Sriveerakul et al. [12] ............................13

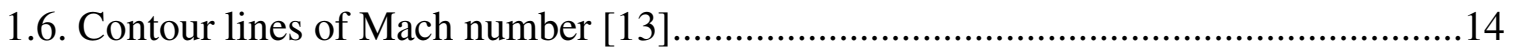

1.7. $\mathrm{CO}_{2}$ refrigeration system with ejector, and corresponding $\mathrm{p}$-h diagram [42]...........18

4.1. Two-dimensional representation of nozzle used by Levy and Brown [16] ..............29

4.2. Pressure distribution through ejector. Top picture is mirrored over the centerline axis

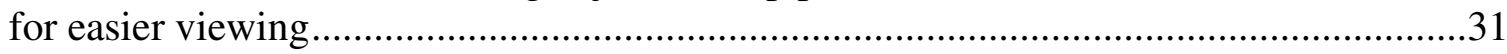

4.3. Velocity in the ejector (mirrored over centerline axis). As the two streams mix, there is a steady decrease in velocity as the flow moves across the nozzle...

4.4. In these two pictures, vapor mass fraction, $x$, is shown in the top half, and equilibrium vapor mass fraction, $\bar{x}$, is shown in the bottom half. The scale is adjusted in the second picture to better show the vapor mass fraction in the diffuser.

4.5. The highest value of viscosity is in the mixing section, when the liquid and vapor streams begin to mix

4.6. Mass fraction of vapor, $x$, is shown in the top half of the figure and the equilibrium mass fraction of vapor, $\bar{x}$, is shown in the bottom half

4.7. Rate of phase change (mirrored over centerline axis). Negative values indicate that more condensation needs to occur to reach thermodynamic equilibrium

4.8. Pressure profile throughout the nozzle (mirrored over centerline axis). The pressure

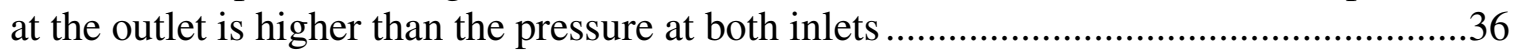

4.9. Velocity profile throughout the nozzle (mirrored over centerline axis) ....................36 
4.10. Turbulent viscosity is shown in this figure (mirrored over centerline axis). Mixing can be seen along the splitter in the constant area section, and also near the outlet..........37

4.11. Velocity along the midpoint of the diffuser for varying outlet pressure..................38

4.12. The boundary condition on the pressure at outlet is varied, and the effect on the instantaneous mass fraction of vapor and equilibrium mass fraction of vapor is investigated

5.1. Mesh for the $5 \mathrm{~mm}$ mixing section length case with the boundaries labeled, and a close-up image of the inlets and mixing section

5.2. CFD results of pressure recovery for different mixing section lengths at varying gas cooler pressure. The $15 \mathrm{~mm}$ ejector type has the greatest predicted pressure rise, both when the IHX is used and when not used

5.3. Pressure profile throughout the nozzle. Only the top half of the nozzle is modeled in the simulation, but the image is mirrored over the horizontal axis for easier viewing ......48

5.4. Comparison of CFD to experimental results of pressure profile across the nozzle....48

5.5. Instantaneous quality, $x$, shown on the top half of the nozzle and equilibrium quality, $\overline{\mathrm{x}}$, is mirrored on the bottom half. The flow is near thermodynamic equilibrium in the diffuser section

5.6. Velocity profile in the nozzle (mirrored over horizontal axis). The motive nozzle flow quickly decelerates in the mixing section.....

5.7. Stream lines show recirculation along the top wall of the mixing section. The stream lines are colored by velocity .50

5.8. Turbulent kinematic viscosity is shown here (mirrored over horizontal axis), with the greatest amount of viscosity occurring in the mixing section.

5.9. Difference in pressure in the mixing section of the ejector with the $5 \mathrm{~mm}$ mixing section for varying cell count. The coarser mesh with 6145 cells is on top and the mesh with 12,645 cells is on the bottom

5.10. Using the realizable k-epsilon turbulence model, CFD results of pressure recovery for different mixing section lengths at varying gas cooler pressure

5.11. Using the RNG k-epsilon turbulence model, CFD results of pressure recovery for different mixing section lengths at varying gas cooler pressure

5.12. Using the k-omega SST turbulence model, CFD results of pressure recovery for different mixing section lengths at varying gas cooler pressure. 
A.1. Pressure through the ejector, comparing four turbulence models against experimental data. $5 \mathrm{~mm}$ mixing section length case without the IHX. Gas cooler pressure $=9.5 \mathrm{MPa}$

A.2. Pressure profile for $5 \mathrm{~mm}$ mixing section length case with the IHX. Gas cooler pressure $=9.5 \mathrm{MPa}$

A.3. Pressure profile for $15 \mathrm{~mm}$ mixing section length case without the IHX. Gas cooler pressure $=9.5 \mathrm{MPa}$

A.4. Pressure profile for $15 \mathrm{~mm}$ mixing section length case with the IHX. Gas cooler pressure $=9.5 \mathrm{MPa}$

A.5. Pressure profile for $25 \mathrm{~mm}$ mixing section length case without the IHX. Gas cooler pressure $=9.5 \mathrm{MPa}$

A.6. Pressure profile for $25 \mathrm{~mm}$ mixing section length case with the IHX. Gas cooler pressure $=9.5 \mathrm{MPa}$

A.7. Pressure profile for $5 \mathrm{~mm}$ mixing section length case without the IHX. Gas cooler pressure $=10 \mathrm{MPa}$

A.8. Pressure profile for $5 \mathrm{~mm}$ mixing section length case with the IHX. Gas cooler pressure $=10 \mathrm{MPa}$

A.9. Pressure profile for $15 \mathrm{~mm}$ mixing section length case without the IHX. Gas cooler pressure $=10 \mathrm{MPa}$

A.10. Pressure profile for $15 \mathrm{~mm}$ mixing section length case with the IHX. Gas cooler pressure $=10 \mathrm{MPa}$

A.11. Pressure profile for $25 \mathrm{~mm}$ mixing section length case without the IHX. Gas cooler pressure $=10 \mathrm{MPa}$

A.12. Pressure profile for $25 \mathrm{~mm}$ mixing section length case with the IHX. Gas cooler pressure $=10 \mathrm{MPa}$

A.13. Pressure profile for $5 \mathrm{~mm}$ mixing section length case without the IHX. Gas cooler pressure $=10.5 \mathrm{MPa}$

A.14. Pressure profile for $5 \mathrm{~mm}$ mixing section length case with the IHX. Gas cooler pressure $=10.5 \mathrm{MPa}$

A.15. Pressure profile for $15 \mathrm{~mm}$ mixing section length case without the IHX. Gas cooler pressure $=10.5 \mathrm{MPa}$ 
A.16. Pressure profile for $15 \mathrm{~mm}$ mixing section length case with the IHX. Gas cooler pressure $=10.5 \mathrm{MPa}$.

A.17. Pressure profile for $25 \mathrm{~mm}$ mixing section length case without the IHX. Gas cooler pressure $=10.5 \mathrm{MPa}$.

A.18. Pressure profile for $25 \mathrm{~mm}$ mixing section length case with the IHX. Gas cooler pressure $=10.5 \mathrm{MPa}$ 


\section{LIST OF SYMBOLS}

$\mu_{\mathrm{t}}$

$v_{t}$

$\rho$

$\rho_{1}$

$\rho_{\mathrm{v}}$

$\tau$

$\phi$

$\phi \mathrm{v}$

$\psi$
Enthalpy $\left(\mathrm{J} \mathrm{kg}^{-1}\right)$

Pressure $(\mathrm{Pa})$

Saturated pressure $(\mathrm{Pa})$

Turbulent Prandtl number

Turbulent Schmidt number

Time (s)

Velocity $\left(\mathrm{m} \mathrm{s}^{-1}\right)$

Vapor mass fraction

Equilibrium vapor mass fraction

Vapor volume fraction

Timescale (s)

Viscosity $\left(\mathrm{kg} \mathrm{m}^{-1} \mathrm{~s}^{-1}\right)$

Turbulent kinematic viscosity $\left(\mathrm{m}^{2} \mathrm{~s}^{-1}\right)$

Density $\left(\mathrm{kg} \mathrm{m}^{-3}\right)$

Liquid density $\left(\mathrm{kg} \mathrm{m}^{-3}\right)$

Vapor density $\left(\mathrm{kg} \mathrm{m}^{-3}\right)$

Stress tensor $(\mathrm{Pa})$

Mass flux $\left(\mathrm{kg} \mathrm{m}^{-2} \mathrm{~s}^{-1}\right)$

Volume flux $\left(\mathrm{m} \mathrm{s}^{-1}\right)$

Dimensionless pressure difference 


\section{CHAPTER 1}

\section{INTRODUCTION AND LITERARY BACKGROUND}

\subsection{Description of Condensing Ejector}

The condensing ejector is a two-phase jet device in which a fluid in a liquid state or in the two-phase region is mixed with its vapor phase, producing a mixed stream with a pressure that is higher than the pressure of either of the two inlet streams [1]. Figure 1.1 presents the predicted behavior of a condensing ejector.

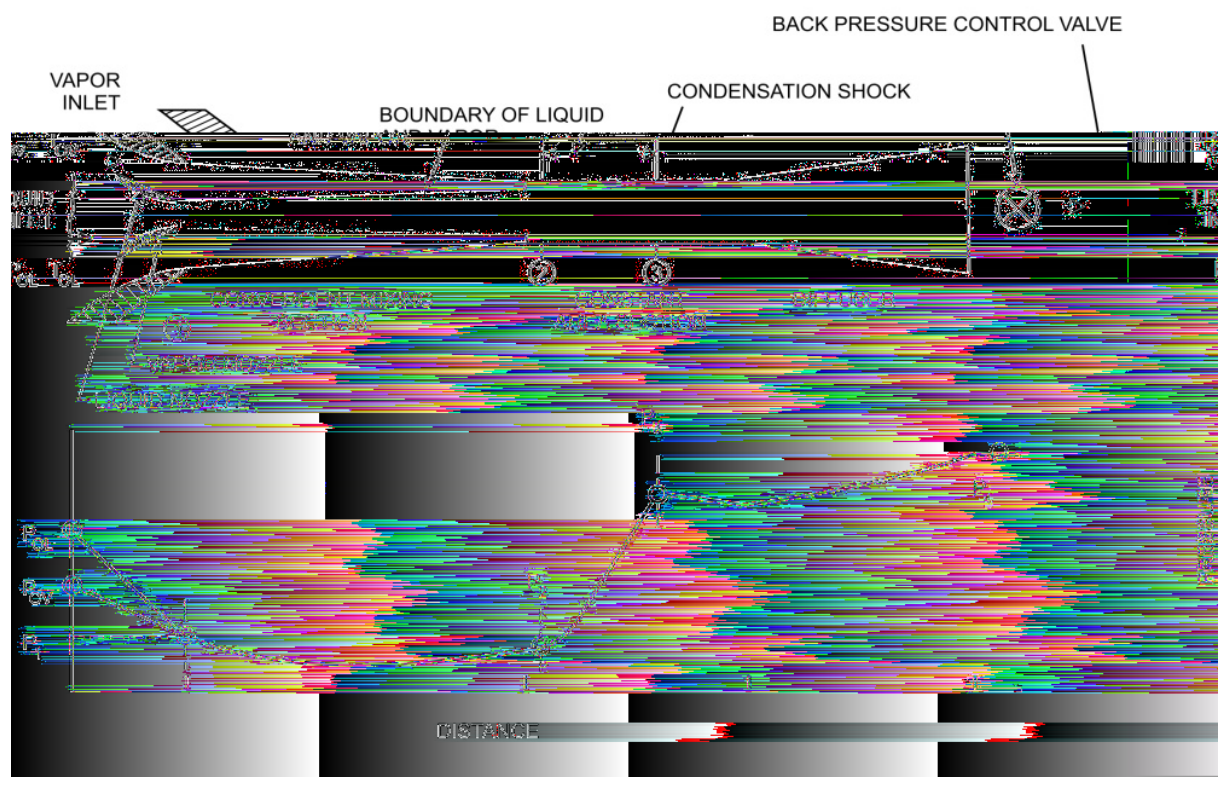

Figure 1.1. Principle of a condensing ejector [2].

As can be seen from the picture, liquid and vapor enter the nozzle and mix in the converging section. The liquid inlet is the motive inlet that drives the nature of the flow, and the vapor inlet is the suction inlet. The high relative velocity between the suction and motive streams produces a high heat transfer value and vapor phase condensation rate. This condensed vapor adds to the momentum flux of the motive stream. The pressure 
rises due to lowering the velocity of the motive and suction streams and the mass flow balance is maintained by a sudden change of density (condensation). The main objective of this project is to model the flow inside a condensing ejector using Computational Fluid Dynamics (CFD).

A CFD analysis is employed to overcome the limitations of a simple control volume analysis and to provide an input to design methodology of the condensing ejector. The simulations will be used to predict the flow for various boundary conditions and different fluids (in these cases, water and carbon dioxide). This can also provide the basis for the design methods of other equipment operating on two-phase flow, including condensing ejectors, pumps, heat exchangers, jet compressors, and diffusers.

\subsection{Application of Condensing Ejector}

The two-phase condensing ejector that is being modeled in this work could potentially be put into a refrigeration cycle. A typical refrigeration cycle consists of a compressor, condenser, expansion valve, and evaporator. In a standard cycle, refrigerant enters the compressor as a saturated vapor and is compressed to a higher pressure and temperature. This superheated vapor moves through the condenser and is cooled to a saturated liquid state. At this stage, heat is rejected from the system. Next, the liquid goes through the expansion valve where there is a significant reduction in pressure. This reduction in pressure allows for evaporation to occur at a lower temperature. Lastly, the low-pressure liquid moves through the evaporator. Here, the refrigerant absorbs heat released from the condenser and results in a cooling of the surrounding environment. The evaporated refrigerant continues to the compressor and repeats the cycle again. 
Having an ejector placed in the cycle could potentially reduce the amount of work required by the compressor, resulting in an increased efficiency. Figure 1.2 shows a proposal configuration of a condensing ejector within a refrigeration cycle [3].

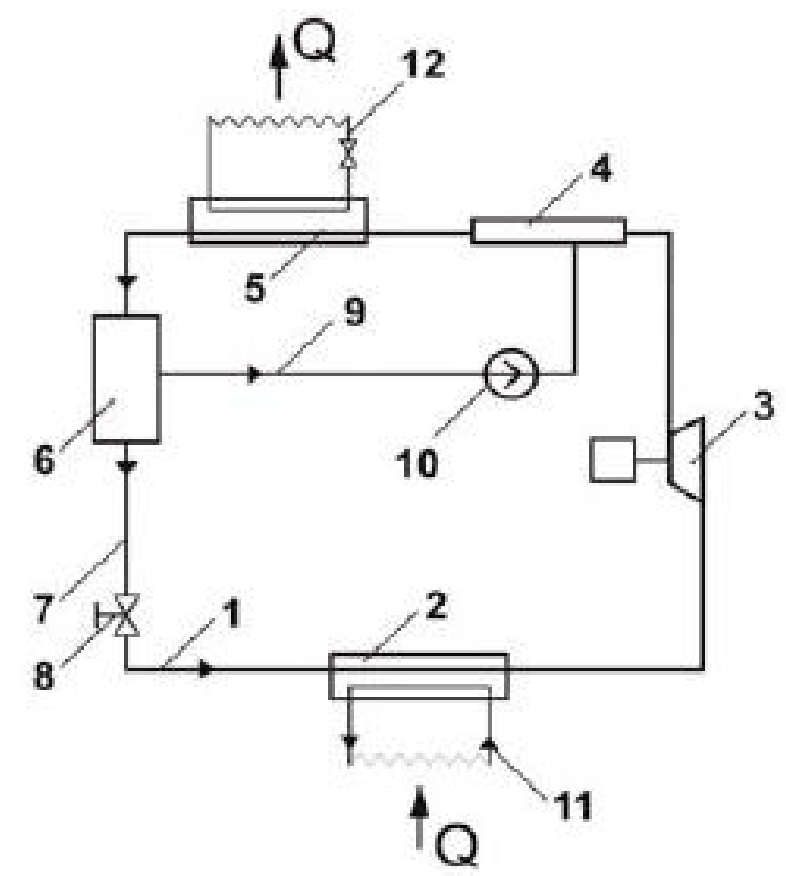

Figure 1.2: Example of a condensing ejector refrigeration cycle [3].

In this refrigeration cycle [3], (1) is the main piping circuit, which contains the evaporator (2), compressor (3), ejector (4), condenser (5), separator tank (6), intermediate heat exchanger (7), and expansion valve (8). The additional liquid line (9) circulates the liquid from the separator (6) and moves it through the pump (10), and continues back to the ejector (4). The evaporator (2) absorbs heat from the source (11), and the condenser (5) is connected to the heat sink (12) [3].

Earlier work using a single-phase ejector resulted in a theoretical improvement of 16 percent and an experimental improvement of 4 percent [4]. Bergander [3] expected a theoretical improvement of 38 percent and observed an experimental improvement of 16 percent when using a two-phase ejector with R22 as the working fluid. The improvement 
in efficiency is based upon the type of refrigerant, design of the cycle, and the design of the ejector nozzle. Specifically looking at the ejector, the operating conditions and nozzle geometry have a significant role in the effectiveness of the refrigeration cycle. This will be discussed later in the chapter.

\subsection{Early Experimental Work on Condensing Ejectors}

The condensing ejector has a long history going back to the early 1900's [5], but there are still questions of how to correctly model the flow and to determine the best nozzle shape. Experiments have been done to analyze thermodynamic properties throughout the nozzle and how the vapor and liquid phases interact before and after the potential shock wave [6] [7]. Analytical models have been made to better describe the experimental results. In the past few decades, CFD has been used to describe two-phase flow through nozzles, with some work particularly looking at the condensing ejector [814].

A key feature of two-phase flow is that the speed of sound is much lower than for a pure liquid or pure gas. Fisenko [15] shows that the sonic speed of an equal mix of liquid and gas, by volume, is less than one tenth of the sonic speed of a pure gas. Even when a mixture has a high percentage of one of the phases, the speed of sound is still significantly lower. With this known, this author mentions how less energy is necessary to reach the speed of sound in a two-phase mixture [15].

Miguel and Brown [1] designed a condensing ejector for two-phase flow. They also provided analytical results that matched well with their experiments. The analytical solution assumed that it was steady, incompressible flow, and that there was complete 
condensation of the vapor at the end of the constant-area mixing section. The nozzle that was used had a converging mixing section followed by a constant-area mixing section and then a diffusing section after the condensation shock occurs.

Different designs for condensing ejectors would be studied. Levy and Brown [16] designed a nozzle that only had a constant-area section for mixing of the liquid and vapor streams, followed by a diffusing section. Experiments looked at the effect of changing the inlet liquid velocity. Tests were done with the back pressure valve open, even though in most applications the condensing ejector must operate with a high back pressure or with the back pressure valve closed. This was done because it was easier to examine the interactions between the liquid and vapor streams. From the experiments, it was noticed that there was liquid jet breakup in the mixing section and was most prominent for the lower inlet liquid velocities $(25 \mathrm{ft} / \mathrm{s}, 7.62 \mathrm{~m} / \mathrm{s})$. Complete condensation occurred with the high liquid inlet velocity stream $(88.5 \mathrm{ft} / \mathrm{s}, 27.0 \mathrm{~m} / \mathrm{s})$, but not with the intermediate $(35.8$ $\mathrm{ft} / \mathrm{s}, 10.9 \mathrm{~m} / \mathrm{s}$ ) and low velocity liquid streams.

The efficiency of the condensing ejector is currently non-ideal, and there has been work that predominantly looks at the efficiency of the ejector cycle and possible ways to improve it [17] [18] [19]. Kermani et al. [19] studied the thermodynamic loss for condensing steam flow through a converging-diverging nozzle. A CFD model was constructed to get the results, where it was seen that most of the losses were caused by nucleation and also the temperature change through the shock. Trela et al. [17] noticed similar results with experimental testing of a condensing injector (liquid is pumped into the mixing chamber for an injector, where as it is sucked into the mixing chamber for an ejector), with irreversible losses around the shock wave and in the mixing chamber. 


\subsection{Modeling of Two-Phase Flow}

Previous works have looked at modeling turbulent flow for two-phase mixtures, having mixed results overall [8] [20] [21]. The mixing of the liquid and vapor phases causes a high amount of turbulence. A simple model to describe this is a turbulent mixing length [20]. So far, this has not led to a sufficient turbulence model [8]. Avetissian et al. [21] analyzes the effects of turbulence on the spontaneous condensation of steam in a de Laval nozzle. In the analysis, a standard k-epsilon and a modified kepsilon turbulence model were used. The k-epsilon was modified to account for the modulation of turbulence due to droplets, and it was assumed that the expression for the eddy viscosity coefficient is a function of the turbulence production-to-turbulence ratio [21]. It was concluded that the modified k-epsilon model was better at predicting twophase flow through a de Laval nozzle. The authors noticed that the standard k-epsilon model can incorrectly predict the disappearance of a steady condensation shock for a nozzle with a low level of inlet turbulence [21]. At very high-level inlet turbulence, steady shock and the shock waves of spontaneous condensation disappear with either model [21].

White [22] compares three different modeling methods for wet-steam flow. In particular, the size distributions and the growth of the liquid phase are compared for flow through a one-dimensional supersonic nozzle. The author looks at a mixed EulerianLagrangian method, a fully Eulerian method, and a method based on moments of the droplet field [22]. It was concluded that the moment-based method was efficient and would be most practical for two-dimensional and three-dimensional calculations. The fully Eulerian calculations did have some error but required less CPU time. The 
Eulerian-Lagrangian method had accurate results, at a cost of longer computational time [22]; this method has also been used for modeling flow through de Laval nozzles and turbine blades [23]. In a later work, White used Reynolds-averaged Navier-Stokes equations to calculate wet-steam flow [24]. Both steady and unsteady flows were looked at for various nozzle geometries. For one of the unsteady cases, asymmetric oscillation modes were observed, which previously were only noticed in moist air [24].

For interphase mass transfer, Bilicki and Kestin [25] look at the homogeneous relaxation model (HRM) for one-dimensional, vaporizing two-phase flows. HRM is a modified version of the homogeneous equilibrium model (HEM), where a differential term is added to the mass, momentum, and energy equations, and a relaxation equation is added. The authors suggest that the HRM model is a better model than the HEM. When calculating critical velocity, as the void fraction approaches zero (saturated liquid), for the HRM the critical velocity approaches the speed of sound for a liquid while for the HEM the critical velocity is of the magnitude of $1 \mathrm{~m} / \mathrm{s}$ [25]. Also, the HEM can underestimate critical mass-flow rates up to $20 \%$. Because of these reasons, it can be nearly impossible to calculate flow parameters for a two-phase mixture at high velocity using the HEM [25]. A modified form of the HRM is used in the work presented here.

\subsection{Using CFD to Model Flow in a Nozzle}

\subsubsection{CFD of Two-Phase Flow through a Nozzle}

CFD has been used to simulate two-phase flow, with some work being done for flow through a condensing ejector (mostly one-dimensional modeling for condensing ejector simulations). This sub-section will look at studies that did not specifically examine the condensing ejector cycle, or the condensing ejector. Clerc et al. [26] used 
CFD to simulate flow through nuclear reactor cores. The simulations had liquid and vapor streams interacting in a converging-diverging nozzle. A covolume method is used because it supports the use of unstructured meshes and variable density flows. According to the authors [26], this is the first time where this modeling method is used for nuclear thermal-hydraulics. From the preliminary results, the covolume method shows a similar efficiency to traditional sub-channel analysis, but there is a possibility for refinement in the future [26].

Richter [27] modeled one-dimensional flow through a short tube or nozzle. He used a separated flow model where the conservation equations were written for each phase. Harrell [28] wrote a computer program for a one-dimensional model of flow in the mixing section of an ejector. The model divides the flow into a jet core of droplets and vapor, and an annular suction flow. A pressure rise in the mixing section and diffuser is predicted, supporting previous experimental results [28].

The study of shocks has not only been tested using liquid-water and vapor-water as the working fluids, but also with other mixtures such as liquid-water and air [29] [30]. For flow through a nozzle, the air bubbles are a non-condensing component, but act similarly to water-vapor in that injecting the air into the liquid flow at high speeds causes the overall flow to accelerate. In Albagli and Gany [30], choking conditions with supersonic velocity at the exit were seen with an air and liquid-water mixture. It was also noticed that wall friction caused a significant decrease in energy and velocity of the flow.

Young [31] used CFD to simulate non-equilibrium, steady flows of wet steam in two-dimensional and three-dimensional turbine cascades. A time-marching solution is used to solve the mixture equations in an Eulerian reference frame. The author noticed a 
difference between the computational and experimental results, attributing it to the high level of unsteady flow seen in turbines, which is difficult to model [31]. Senoo and White [32] used numerical techniques to simulate unsteady wet steam flow through a de Laval nozzle and through a turbine. A finite volume method based on an approximate Riemann solver is used to solve the conservation equations for two-phase compressible flow [32]. The vapor is assumed to be a perfect gas, and the wetness is low enough (less than $15 \%$ ) that the volume of the liquid droplets can be ignored [32]. Oblique shock waves and a pressure increase due to condensation are noticed. Figure 1.3 shows where the shock occurs in the de Laval nozzle and the resulting change in direction of the flow.

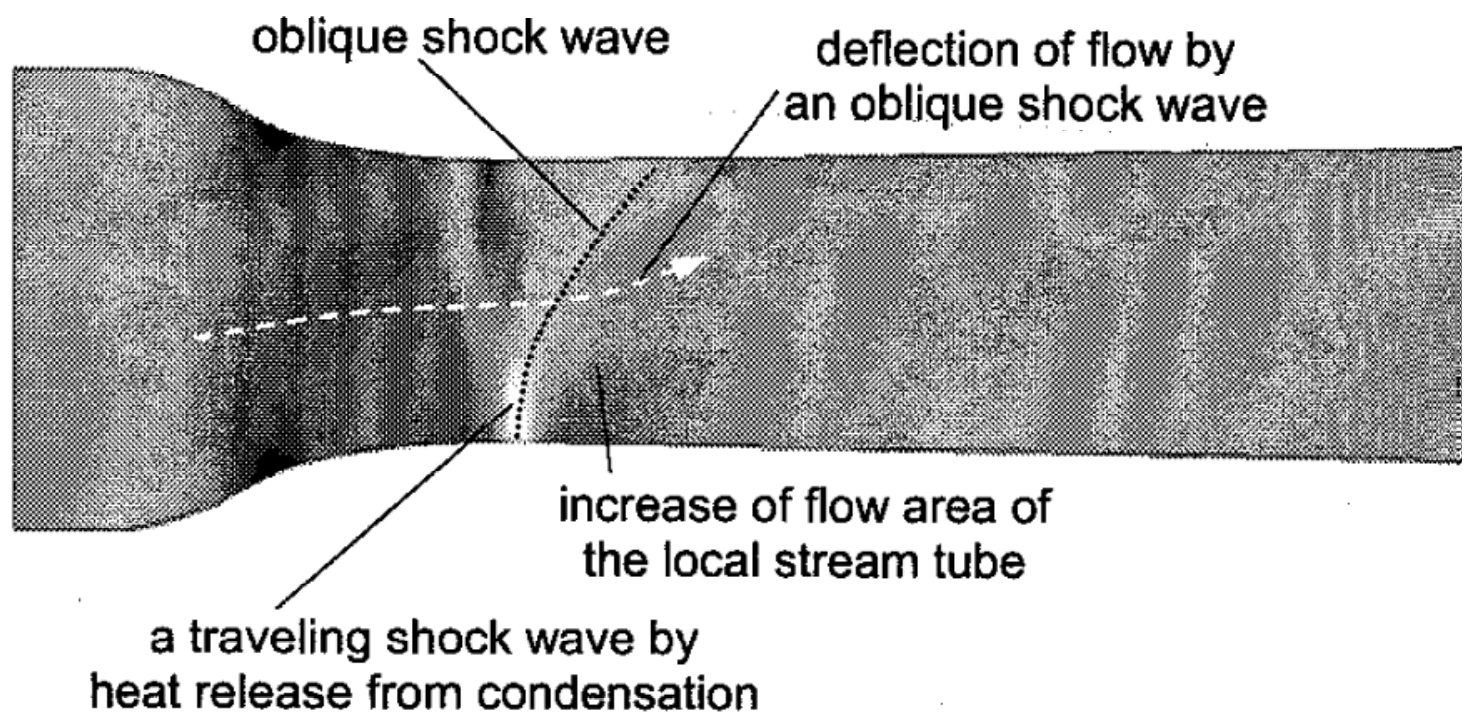

Figure 1.3: An oblique shock is observed in the de Laval nozzle used in Senoo and White [32].

\subsubsection{Ejector Flow Studies Using CFD}

There has been some work done with CFD that directly deals with the condensing ejector cycle, and more specifically just the ejector. Menegay [8] used CFD to simulate 
two-phase flow through a condensing ejector. The nozzle used has a constant-area mixing section, and is shown below in Figure 1.4.

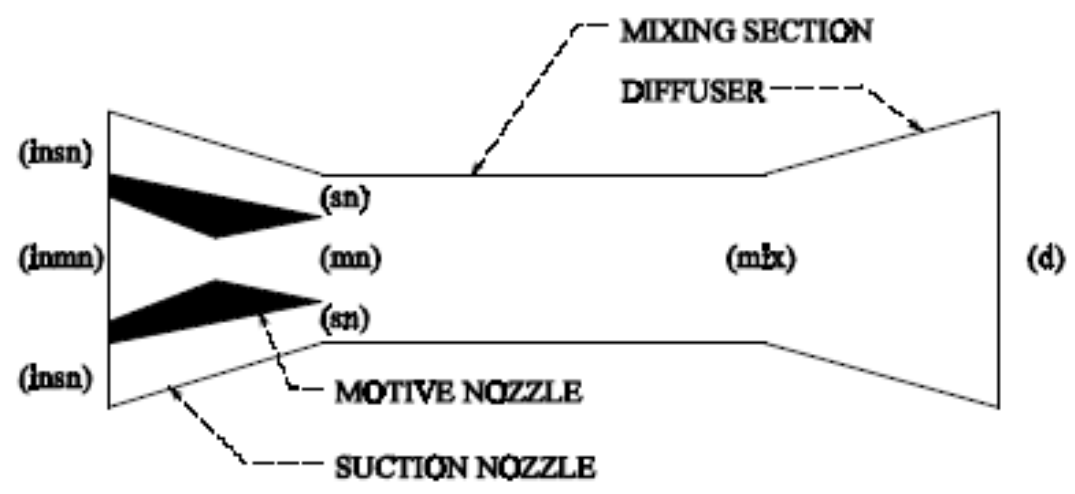

Figure 1.4: Nozzle that was modeled in Menegay [8]. Saturated liquid flows through the motive nozzle and vapor flows in from the suction nozzle.

A constant-area mixing section is chosen instead of a constant-pressure mixing section because with the homogeneous equilibrium model (HEM) that is implemented in the modeling, constant-area mixing results in slightly higher performance. Menegay [8] describes the problems with the HEM and how the methods lead to poor ejector designs and thus poor cycle performance. This model was chosen mainly for its simplicity, but it unfortunately does not accurately represent the complexity of the flow [8]. Menegay and Kornhauser [4] also noticed the relatively small coefficient of performance (COP) improvement when using the HEM on an ejector compared to the standard refrigeration cycle; for one case, a 3.6 percent increase was observed. With the same conditions for an ideal (isentropic) ejector, a 16.2 percent increase was calculated [4].

Realizing the problems that come with the HEM, they suggest a semi-parabolic two-fluid model instead to better describe flow through an ejector [8]. An EulerianEulerian formulation is used that has a total of eight equations; two for mass conservation equations (one for each phase), two energy equations, two stream-wise momentum 
equations, and two cross-stream momentum equations. The equations are parabolized to simplify the system of equations. This can be done because the cross-stream velocity is assumed to be negligible compared to the stream-wise velocity and the cross-stream gradients are much greater than the stream-wise gradients. Also, pressure can be shown to depend mainly on the stream-wise direction, allowing the use of a marching solution that significantly reduces the computational time needed [8]. The determination of droplet and bubble size is based on the Weber number. This term is included in the equations for calculating interfacial drag and heat transfer [8].

More recently (within the last decade), CFD simulations looking at flow (both single-phase and two-phase) through an ejector have become more complex in the aspect of modeling [9-13]. More sophisticated turbulence models have been used to better predict the flow and compressibility effects have been added too. By having turbulence predictions in the conservation equations, this causes the primary and secondary streams to mix in the constant area section, where a shock (or series of shocks) can occur. Compressibility is considered because of the supersonic flow of the vapor and also because it is the driving force for an accurate condensation shock to occur in the nozzle [9] [10].

Bartosiewicz et al. [9] looked at how different turbulence models would affect the performance of a steam ejector. Other authors in the past have used k-epsilon models in their work, but there was no justification to the use of a particular model and no experimental validations [33] [34] [35]. For this particular work, superheated R142b was the working fluid at both inlets, with the fluid at the primary inlet having a greater temperature than the fluid at the secondary inlet. Favre averaged Navier-Stokes 
equations were used for compressible, steady state flow, for an axisymmetric nozzle [9]. Using the conditions described in Bartosiewicz et al. [9], the k-omega-SST turbulence model resulted in the greatest possible nozzle efficiency compared to the standard kepsilon model and the RNG model. The authors conclude that there is still a need to integrate experimental work with the CFD results in order to determine the most appropriate turbulence model [9].

Sriveerakul et al. [12] determined that the realizable k-epsilon model was the best choice for their ejector (with different nozzle geometry and operating conditions). The authors' justification is that this model is able to predict a more accurate spreading rate of a round jet [12]. This was tested for a steam ejector, where the fluid at both inlets are saturated vapor, with the primary fluid being much hotter. A diagram of the experimental refrigeration cycle used is shown in Figure 1.5. From the figure, it is seen how the liquid in the receiver tank is pumped to either the evaporator or the boiler, with the boiler providing the primary fluid moving through the ejector. 


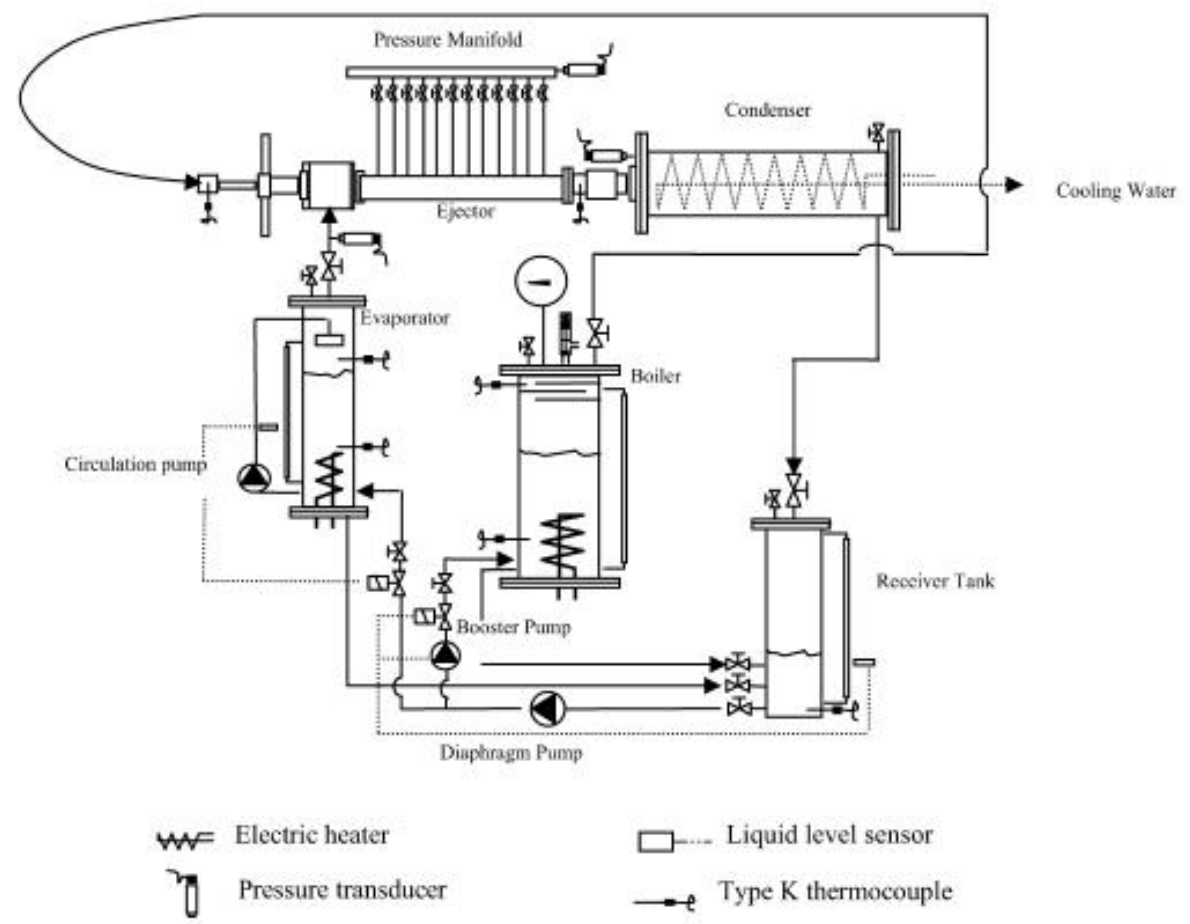

Figure 1.5: Experimental steam ejector cycle used in Sriveerakul et al. [12].

The CFD simulation package Fluent was used to simulate the flow through the ejector [12]. Water vapor was used as the working fluid, and was treated as an ideal gas. The authors [12] state that this is an unrealistic assumption, but it has been shown before that the ideal gas model can produce similar results to a real gas model [36]. The CFD calculations of the entrainment ratio, the ratio of the mass flow rate of the secondary fluid to the mass flow rate of the primary fluid, and critical back pressure were close in comparison to experimental results for numerous nozzle geometries and inlet temperatures.

With the compressibility terms modeled, there is an expectation of a "shock-train" in the constant area section [9]. A "shock-train" contains a series of shocks and multiple pressure peaks, along with a pressure rise at the end of the set of shocks. Bartosiewicz et 
al. [9] describes this phenomenon, but the ejector used in their CFD simulation had a constant area section that was too small to produce this series of shocks. Simulating the "shock-train" was not a key part of that work, but the authors had a plan to look at this in the future.

Using the same experimental setup and ejector geometries for the steam ejector in [12], Sriveerakul et al. [13] did notice a series of oblique shocks and expansion waves in the mixing chamber, and refers to it was a "diamond wave." This is in Figure 1.6, along with other important characteristics seen in the ejector. The contour lines of Mach number are pictured, and it shows that the flow is supersonic until reaching the diffuser, where there is a set of secondary oblique shocks.

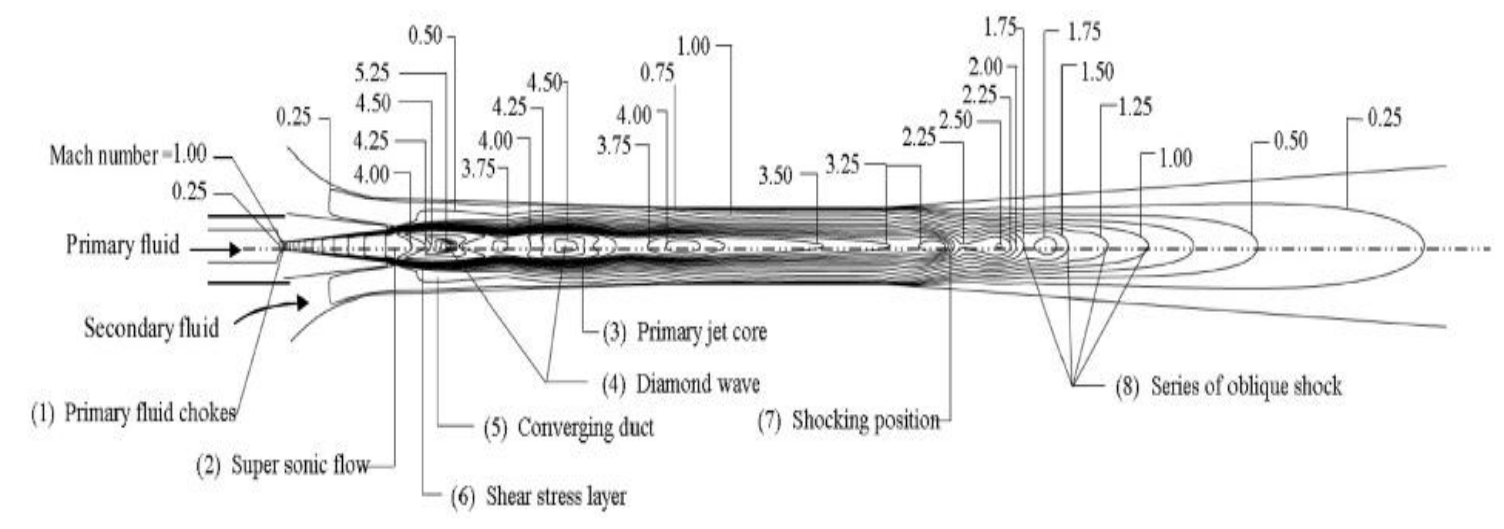

Figure 1.6: Contour lines of Mach number [13].

Besides turbulence and compressibility effects, ejector geometry has an effect on the nozzle performance. Authors have attempted to determine an optimal nozzle shape that will result in a high rate of performance [9] [10] [11] [13]. 
It was discussed earlier in Bartosiewicz et al. [9] how a small constant area mixing section would result in the absence of a shock-train. Sriveerakul et al. [13] concludes that changing the length of the mixing section of the ejector has little effect on the entrainment ratio, but it does change the shape of the oblique shocks. With a longer mixing section, the streams become more uniform, which cause the oblique shocks to be flatter [13]. A longer mixing section will also result in a greater pressure loss because of the viscous boundary layer along the wall, and the stronger shock wave [13].

Rusly et al. [10] primarily focused on the effects of using different nozzle geometries. The authors used a combined ejector-vapor compression system, which contains an ejector sub-cycle and a vapor-compression sub-cycle. There is an intercooler that provides the interaction between the sub-cycles. The vapor from the vaporcompression cycle rejects heat to (and evaporates) the liquid refrigerant from the ejector cycle [10]. Using CFD to specifically look at the ejector flow, the entrainment ratio was calculated for the simulations and compared to previous experimental work [37], with reasonable agreement seen between the results. The diameter of the constant area section was thought to be the most influential parameter on ejector performance due to its direct proportion with the secondary flow area. It is also noted that the constant area diameter can be increased to improve ejector performance, but at a certain diameter the shock disappears [10].

Varga et al. [11] also used CFD to attempt to determine optimal nozzle geometry, and noticed that the nozzle efficiency was only slightly affected by increasing the mixing section diameter. These conclusions were based on different operating 
conditions, and it is noted that the operating conditions do have a significant effect on how the flow in the nozzle will behave [10] [11].

Sriveerakul et al. [13] compares a constant-area mixing section and a converging mixing section. There is a lower entrainment ratio with a converging section because less secondary fluid can move through the nozzle. The Mach number of the primary fluid is greater with a converging mixing section [13]. The shock positions are also different between the two nozzles.

In Sriveerakul et al. [13], when the primary nozzle area is increased, there is a lower entrainment ratio since less secondary fluid can enter the mixing section. This causes the second series of oblique shocks to be stronger and closer to the end of the diffuser.

Also considered important was the nozzle exit distance relative to the constant area entrance. In the results of Rusly et al. [10], moving the nozzle exit distance 1.5 times further away from the constant area duct (compared to the base model) resulted in a better ejector performance.

Changing the pressure values at the inlets and the outlet has a significant effect on fluid flow. When the downstream pressure is increased, this will move the second series of oblique shocks further upstream, closer to the first series [13]. Because of this, the secondary fluid is no longer choked. If the primary fluid pressure is increased, the Mach number of the primary stream does not change, which is expected for supersonic compressible flow [13]. This also increases the mass flow rate of the primary fluid, thus decreasing the entrainment ratio. If the secondary fluid pressure is increased, the overall momentum is increased and the position of the shock wave moves downstream [13]. 
An assumption that has been used by several authors is treating the vapor as an ideal gas [10] [12] [32] [38] [39]. This allows for simplicity in modeling the two-phase flow, but at a cost of obtaining less than perfect results. This assumption can be used for preliminary results, and some authors mention using real gas equations in their future work [12]. Grazzini et al. [14] compares the ideal gas model to the saturated vapor model and the metastable (not in thermodynamic equilibrium) vapor model for a two-stage steam ejector. It is seen that the ideal gas model underestimates the nozzle exit pressure by about 35 percent when compared to the metastable model. Also, the ideal gas model predicted the lowest rate of condensation [14].

\subsection{Use of Carbon Dioxide in a Refrigeration Cycle with an Ejector}

The working fluid for most of the results presented in this thesis is carbon dioxide. In recent years, $\mathrm{CO}_{2}$ has become a more prevalent refrigerant because of its low global warming potential and zero ozone depletion potential [40].

Several authors have experimentally studied the condensing ejector refrigeration cycle with carbon dioxide as the working refrigerant where the fluid is above the critical point before entering the motive nozzle [40 - 45]. None of these authors reported observing a shock in the ejector. An example of this type of cycle along with a corresponding $\mathrm{p}$-h diagram can be seen in Figure 1.7 [42]. This specific ejector cycle has the option of using a heat exchanger, which lowers the temperature of the super-critical fluid before entering the motive nozzle. When the flow from the motive nozzle and suction nozzle meet in the mixing section, both streams are in the two-phase region. 
Within the ejector, there is a pressure rise, which leads to a more efficient cycle as compared to a standard cycle without an ejector.
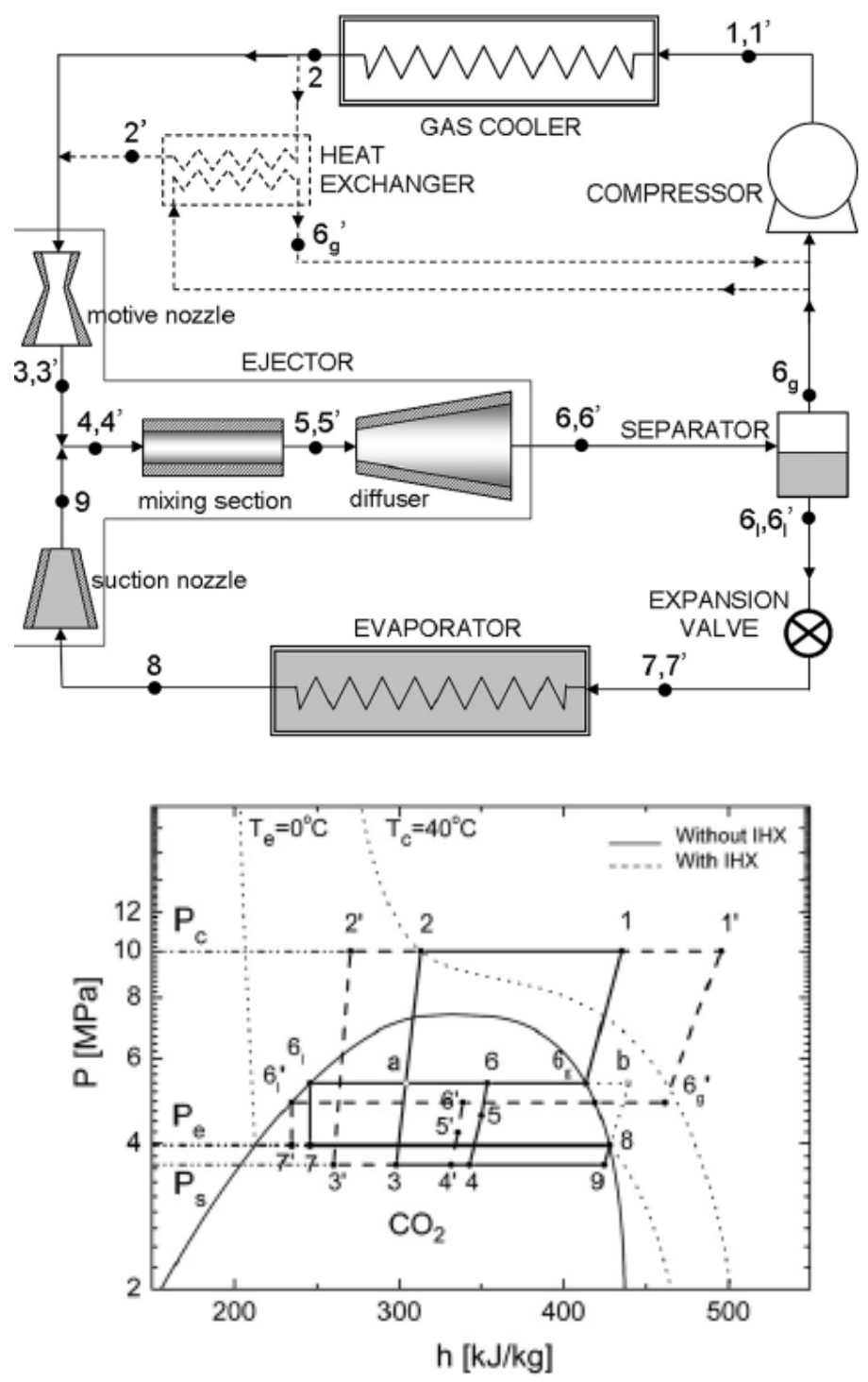

Figure 1.7. $\mathrm{CO}_{2}$ refrigeration system with ejector, and corresponding $\mathrm{p}$-h diagram [42].

$\mathrm{Li}$ and Groll [46] presented numerical results for a $\mathrm{CO}_{2}$ ejector system that looked at the effect of entrainment ratio and pressure drop at the nozzle inlets, and also saw a $16 \%$ overall COP improvement compared to a basic cycle for air-conditioning applications. 
Most studies have looked at the overall cycle, but there has been some experimental work that analyzes the flow within the ejector nozzle [42]. In the experiments in this paper [42], the effect of the length of the mixing section was tested. Thermocouples were placed inside the mixing section and diffuser, and the pressure values were calculated at each point. The pressure recovery was able to be determined from this data. It was seen that the ejector with the $15 \mathrm{~mm}$ mixing section length (compared to the $5 \mathrm{~mm}$ mixing section and the $25 \mathrm{~mm}$ mixing section) had the highest pressure recovery, and also the highest COP. 


\section{CHAPTER 2}

\section{MODELING APPROACH}

Overall, from the previous works, numerous authors have looked at how an ejector can be utilized in a refrigeration cycle. There is much that is still unknown, especially how the fluid mixes in the mixing section of the ejector. In most of the work presented here, the ejector being modeled uses carbon dioxide as the working fluid. Compared to other refrigerants, there have been relatively fewer numerical studies looking at $\mathrm{CO}_{2}$ flow through an ejector. The modeling method here is based on treating the fluid as being in a state of non-thermodynamic equilibrium, and a modified form of the homogeneous relaxation model (HRM) will be presented.

For the condensing flow simulation, the two phases are treated as a single fluid with combined transport equations; this is known as the "pseudo-fluid" approach. The equations for the conservation of mass, momentum, and enthalpy are given below.

$$
\begin{gathered}
\frac{\partial \rho}{\partial t}+\nabla \cdot \phi=0 \\
\frac{\partial \rho U}{\partial t}+\nabla \cdot(\phi U)=-\nabla p+\nabla \cdot \overrightarrow{\vec{\tau}} \\
\frac{\partial \rho h}{\partial t}+\nabla \cdot(\phi h)-\nabla \cdot\left(\frac{\mu_{t}}{\operatorname{Pr}_{t}} \nabla h\right)=\frac{\partial p}{\partial t}+U \cdot \nabla p
\end{gathered}
$$

In these equations, $\phi$ is the mass flux and $\tau$ is the stress tensor. A form of the enthalpy equation is used instead of the energy equation. In the enthalpy equation, a diffusive term is included in lieu of conduction. In this term, $\mu_{t}$ is the turbulent viscosity calculated from the k-epsilon turbulence model and $P r_{t}$ is the turbulent Prandtl number. 
Cebeci [47] shows how the enthalpy equation can be derived and how the diffusion term in the energy equation can be put in terms of viscosity, Prandtl number, and enthalpy.

An equation of state would be necessary to close the system. In the case of twophase flow, the condensation process involves mixing and heat transfer between the phases, and there is no direct method to calculate this. Also, the two-phase mixture is not in thermodynamic equilibrium. To bring the mixture towards equilibrium, a modified form of the HRM is used. The model was originally used for flash-boiling cases [48], but with some modifications the same idea can be applied for condensing flow.

The homogeneous relaxation model is based on a linearized expansion proposed by Bilicki and Kestin [25]. The equation for the total derivative of quality, the mass fraction of vapor, is shown in Eqn. 4.

$$
\frac{D x}{D t}=\frac{\bar{x}-x}{\Theta}
$$

The derivative shows the relaxation of the instantaneous quality, $\mathrm{x}$, compared to the equilibrium quality, $\bar{x}$, over the timescale, $\Theta$. The formula suggested by DownarZapolski et al. [49] for the timescale is shown below in Eqn. 5.

$$
\Theta=\Theta_{o} \alpha^{a} \psi^{b}
$$

The values for $\Theta_{0}$, a, and $b$ were determined by best-fit values of flashing experiments of water [49]. The values for the low-pressure correlation, when the upstream pressure is less than $10 \mathrm{bar}$, are $\Theta_{0}=6.51 \cdot 10^{-4}[\mathrm{~s}], \mathrm{a}=-0.257$, and $\mathrm{b}=-2.24$. The variable $\alpha$ is the vapor volume fraction and $\psi$ is a dimensionless pressure difference represented in Eqn. 6. Though the current application is beyond the intended use of this empiricism, it serves as a starting point for further investigation. 


$$
\psi=\left|\frac{p_{\text {sat }}-p}{p_{\text {sat }}}\right|
$$

For a variable density flow, the divergence of the velocity field is non-zero.

$$
-\rho \nabla \cdot U=\frac{D \rho}{D t}
$$

By expanding this total derivative of density via the chain rule, the change in density is split into contributions of Mach effects, density variations due to concentration differences, and thermal expansion effects (Eqn. 8).

$$
\frac{D \rho}{D t}=\left.\frac{\partial \rho}{\partial p}\right|_{x, h} \frac{D p}{D t}+\left.\frac{\partial \rho}{\partial x}\right|_{p, h} \frac{D x}{D t}+\left.\frac{\partial \rho}{\partial h}\right|_{p, x} \frac{D h}{D t}
$$

As shown in the above equation, density is a function of pressure, quality, and enthalpy [25]. The first term on the right-hand side of Eqn. 8 represents the density change due to compressibility. The middle term represents the change in density due to phase change. The last term is omitted because of the negligible effect on the change in density due to change in enthalpy as compared to change in density due to phase change and compressibility. With this assumption, the divergence of velocity is given by Eqn. 9 .

$$
\nabla \cdot U=-\frac{1}{\rho}\left(\left.\frac{\partial \rho}{\partial p}\right|_{x, h} \frac{D p}{D t}+\left.\frac{\partial \rho}{\partial x}\right|_{p, h} \frac{D x}{D t}\right)
$$

A generalized form of the momentum equation is shown below in Eqn. 10, where $a_{p}$ is the diagonal coefficient of the momentum equation matrix and $H(U)$ is the offdiagonal terms caused by convection and diffusion with neighboring cells plus source terms.

$$
a_{p} U_{p}=H(U)-\nabla p
$$


The divergence of this equation is taken and combined with Eqn. 9.

$$
\left.\frac{\partial \rho}{\partial p}\right|_{x, h} \frac{\partial p}{\partial t}+\left.\frac{\partial \rho}{\partial p}\right|_{x, h}(U \cdot \nabla p)+\rho \nabla \cdot\left(\frac{H}{a_{p}}\right)-\rho \nabla \frac{1}{a_{p}} \nabla p+\left.\frac{\partial \rho}{\partial x}\right|_{p, h} \frac{D x}{D t}=0
$$

The HRM model is an empiricism that has been tuned to represent flash boiling [48]. The current application to rapid condensation represents an extension of the model beyond its original intent. One should certainly expect that some adjustment of the model is required.

In the current application, a number of changes were made to the classic HRM model. To achieve the amount of mixing between the motive and suction streams that has previously been observed experimentally, turbulent mixing terms have been introduced into transport equations for quality, momentum and enthalpy. This approach has been employed previously in the $\sum-Y$ model [50] to predict the turbulent atomization of a liquid jet using a similar pseudo-fluid Eulerian framework. This approach assumes that at high Reynolds and Weber numbers, the scales at which turbulent mixing occurs are separate from those of the bulk fluid motion, allowing the turbulent mixing and generation of interfacial surface area to be resolved through classical turbulence closures. The calculation of Reynolds stresses are modeled through a k-epsilon model while the turbulent mixing of motive and suction streams is characterized by a turbulent diffusion hypothesis. In the results that will be presented, the k-epsilon turbulence models used are the standard, RNG (Renormalization Group), and realizable models; the k-omega SST (shear stress transport) model is also used. The equations and the constant values for each model can be found in the Fluent User's Guide [51]. The values for k and epsilon that are specified at the inlets and the outlet are based on turbulent intensity and velocity 
magnitude, and a zero gradient boundary condition is applied at the walls. The value for $k$ is calculated by Eqn. 12, where $I$ is the turbulent intensity set near $5 \%$.

$$
k=1.5\left(I * U_{\text {avg }}\right)^{2}
$$

The initial value for epsilon is calculated such that the resulting eddy viscosity is approximately two orders higher in magnitude than the molecular viscosity. Turbulent viscosity, $\mu_{t}$, is shown in Eqn. 13.

$$
\mu_{t}=C_{\mu} * \rho * \frac{k^{2}}{\varepsilon}
$$

A transport equation from the $\sum-\mathrm{Y}$ model that is used to calculate quality is added to the HRM model and is shown below in Eqn. 15. In the $\sum-\mathrm{Y}$ model, $\mathrm{Y}$ is the liquid mass fraction; vapor mass fraction, $\mathrm{x}$, is substituted in to Eqn. 15, with Eqn. 14 showing the relation of $\mathrm{Y}$ to $\mathrm{x}$.

$$
\begin{gathered}
Y=1-x \\
\frac{\partial \rho x}{\partial t}+\nabla \cdot(\phi x)-\nabla \cdot\left(\frac{\mu_{t}}{S c_{t}} \nabla x\right)=\rho \frac{D x}{D t}
\end{gathered}
$$

For all of the CFD cases, the turbulent Schmidt number, $S c_{t}$, was set to 0.9, which is within an acceptable range for $\mathrm{CO}_{2}$ [52] [53] [54].

According to Eqn. 5, the timescale of phase change becomes infinite at zero void fraction. This represents that the change in quality over time will equal zero. For condensing flows, a similar behavior should be present for the case of unity void fraction. An extra term was added to Eqn. 5 to provide symmetry of phases, so that $\Theta$ approaches infinity at both $\alpha=0$ and $\alpha=1$, and the modified equation is shown in Eqn. 16 .

$$
\Theta=\Theta_{o} \alpha^{a} \psi^{b}(1-\alpha)^{a}
$$


Also, the timescale was bounded, both from above and below, in order to avoid numerical instability and floating point exceptions.

For simplicity in the numerical simulation, a relationship is found between the vapor mass fraction, $\mathrm{x}$, and the vapor volume fraction, $\alpha$, in terms of density. From simple derivations, the formula for $\alpha$ in terms of density is shown below in Eqn. 17.

$$
\alpha=\frac{\rho_{l}-\rho}{\rho_{l}-\rho_{v}}
$$

Similarly, the formula for $\mathrm{x}$ is in terms of density is shown in Eqn. 18.

$$
x=\frac{\frac{1}{\rho_{l}}-\frac{1}{\rho}}{\frac{1}{\rho_{l}}-\frac{1}{\rho_{v}}}
$$

By finding a common denominator for both parts of the fraction in Eqn. 18, vapor mass fraction is equivalent to:

$$
x=\frac{\frac{\rho-\rho_{l}}{\rho_{l^{*} \rho}}}{\frac{\rho_{v^{-}} \rho_{l}}{\rho_{l^{*} \rho_{v}}}}
$$

Simplifying Eqn. 19, vapor mass fraction equals:

$$
x=\frac{\rho-\rho_{l}}{\rho_{v}-\rho_{l}} * \frac{\rho_{v}}{\rho}
$$

This is the same as writing:

$$
x=\alpha * \frac{\rho_{v}}{\rho}
$$




\section{CHAPTER 3}

\section{NUMERICAL IMPLEMENTATION}

A benefit of the pressure equation (11) is that most of the terms are linear in relation to pressure. An incompressible formulation can be established, and Schmidt et al. [55] used this form in a two-step projection method on a staggered mesh approach. This method was used for their two-dimensional structured grid solver. In order to apply this model to a variable density, compressible, two-dimensional solution and for an unstructured, general polyhedral mesh, a collocated variable approach is applied in the current model.

For each time step, the first step is to find the solution of the mass conservation equation using the volumetric velocity flux, $\phi_{v}$, from the previous time step (Eqn. 22).

$$
\frac{\partial \rho}{\partial t}+\nabla \cdot\left(\phi_{v} \rho\right)=0
$$

The resulting density is interpolated to cell faces and multiplied by the volumetric flux to define a predictor for the mass flux, $\phi$. Thermodynamic variables, such as the equilibrium quality, are then updated using the new density.

The enthalpy equation, shown below in Eqn. 23, is then solved.

$$
\frac{\partial \rho h}{\partial t}+\nabla \cdot(\phi h)-\nabla \cdot\left(\frac{\mu_{t}}{\operatorname{Pr}_{t}} \nabla h\right)=\frac{D p}{D t}
$$

Using the equilibrium vapor mass fraction determined via Eqn. 22, the transport equation for vapor mass fraction can be solved. This is given in Eqn. 24 .

$$
\frac{\partial \rho x}{\partial t}+\nabla \cdot(\phi x)-\nabla \cdot\left(\frac{\mu_{t}}{S c_{t}} \nabla x\right)=\rho\left(\frac{\bar{x}-x}{\theta}\right)
$$


An adjusted form of the PISO (Pressure Implicit with Splitting of Operators) algorithm [56] is used to calculate the pressure and velocity implicitly. First, the velocity field is predicted using a lagged pressure. The equation for predicted velocity, $\mathrm{U}^{0}$, is given below in Eqn. 25.

$$
\frac{\partial \rho U^{0}}{\partial t}+\nabla \cdot\left(\phi U^{0}\right)=-\nabla p^{n}+\nabla \cdot\left\{\mu_{\mathrm{t}}\left[\nabla U^{0}+\left(\nabla U^{0}\right)^{T}\right]\right\}
$$

This equation represents three linear systems of equations, for the three components of velocity, with the nonlinear velocity terms lagged in the mass flux term. Velocity is solved implicitly and the pressure gradient is treated as an explicit source term.

Eqn. 10 is used to determine an updated velocity flux, $\phi^{*}$, via Jacobi inversion dividing the off-diagonal terms by the diagonal coefficients (Eqn. 26).

$$
\phi^{*}=\frac{H(U)}{a_{p}}
$$

The non-linearity of the last term in Eqn. 11, the term representing the phase change model, is treated semi-implicitly with respect to pressure through the use of a secant method, as seen in Eqn. 28, where the term $M$ in Eqn. 28 is shorthand for the phase-change model, seen in Eqn. 27.

$$
\begin{aligned}
& \left.M \equiv \frac{\partial \rho}{\partial x}\right|_{p, h} \frac{\bar{x}-x}{\Theta} \\
& \left.\frac{1}{\rho} \frac{\partial \rho}{\partial p}\right|_{x, h}\left(\frac{\partial \rho p}{\partial t}+\nabla \rho p^{k+1} U\right)+\rho \nabla \cdot \phi^{*}-\rho \nabla \cdot \frac{1}{a_{p}} \nabla p^{k+1}+\nabla \cdot\left(\frac{\mu_{t}}{S c_{t}} \nabla x\right)+M\left(p^{k}\right) \\
& +\frac{\partial M}{\partial p}\left(p^{k+1}-p^{k}\right)=0
\end{aligned}
$$


The previous and current PISO iterations are represented by the superscripts " $\mathrm{k}$ " and "k +1 ", respectively. Solution of Eqn. 27 yields a pressure that will give a velocity field approximately satisfying the continuity equation. Multiple PISO iterations can be performed to account for the non-linearity of the momentum equation. Typically, four to eight $\mathrm{PISO} /$ secant iterations are employed, and the solution of the pressure equation is necessary for every iteration. For the full pressure equation, a geometric/algebraic multigrid solver is used. Once the pressure equation is solved, the pressure field is used to correct the fluxes and the time step is finished.

Fluid properties are obtained using REFPROP (Reference Fluid Thermodynamic and Transport Properties Database) from the NIST (National Institute of Standards and Technology) database [57]. Given two thermodynamic inputs, REFPROP calls its necessary subroutines to calculate the thermodynamic and transport properties requested by the user. The user selects two thermodynamic properties to use as inputs and selects an appropriate range and step size. For the current work being completed, pressure and enthalpy are the two inputs. The properties calculated at these specified points are arranged in a table format. Properties can be calculated for many fluids, including mixtures; in this case the working fluid is carbon dioxide.

The structure for solving these equations is provided by OpenFOAM, which allows rapid construction of CFD codes in an object-oriented framework [58]. OpenFOAM also provides a message passing interface (MPI) that can run decomposed cases in parallel. Solvers written with OpenFOAM are compatible with fully threedimensional general polyhedral meshes. 


\section{CHAPTER 4}

\section{LEVY-BROWN EJECTOR RESULTS}

\subsection{Levy-Brown Condensing Ejector}

The nozzle being modeled in the CFD simulations is one that has been used in experiments by Levy and Brown [16], and is shown below in Figure 4.1. The experimental work uses water as the working fluid.

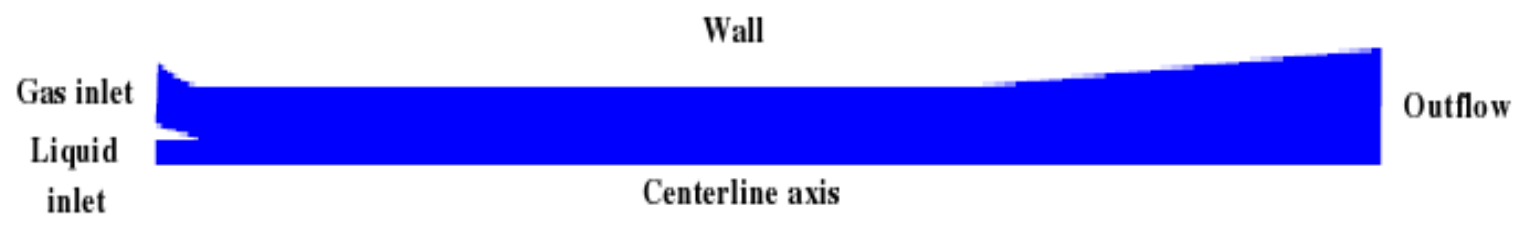

Figure 4.1: Two-dimensional representation of nozzle used by Levy and Brown [16].

This nozzle acts as a condensing ejector for two-dimensional flow of a fluid. The image in Fig. 4.1 is axisymmetric across the centerline axis.

For these simulations, saturated vapor enters through the annular channel and saturated liquid enters axially. As the saturated liquid and saturated vapor flow past the splitter (the wall between the mixing section entrances of the liquid and vapor streams), the two streams start to mix. Within the diverging part of the nozzle there is an expectation of a shock wave that leads to increased mixing and circulation of the two streams, according to Levy and Brown [16]. In the experimental work, the precise location and size of the shock wave has been difficult to determine [16]. 


\subsection{CFD Results}

\subsubsection{Water as Working Fluid}

The velocity at the gas inlet is set to Mach 1 and the velocity at the liquid inlet is set to $30 \mathrm{~m} / \mathrm{s}$, which are values used by Levy and Brown [16]. The outlet boundary condition on the velocity gradient is set to zero. Fixed uniform densities of $0.59 \mathrm{~kg} / \mathrm{m} 3$ at the gas inlet and $997.1 \mathrm{~kg} / \mathrm{m} 3$ at the liquid inlet are imposed. Zero pressure gradient boundary conditions are specified at the inlets. At the outlet, the pressure is set to a value of 4 bar. The realizable k-epsilon turbulence model is applied, with standard wall functions applied near the walls. All walls are adiabatic.

This simulation presented here was run for 0.075 seconds of simulated time, and the flow was able to reach steady state. In general, most of the simulations were unstable and led to floating point exceptions. The region where most of the instability occurred was around the splitter wall. One way to make the simulations more stable is to treat the fluid flow as incompressible. For this case shown here, the compressibility term in the modeling equations were not included.

Figure 4.2 shows the pressure distribution through the nozzle. Though there is a slight pressure increase at the beginning of the mixing section and the beginning of the diffuser, the pressure at the outlet does not have a significant increase compared to the inlet pressure because of the pressure drop that occurs in most of the mixing section. The outlet pressure is only greater than the liquid inlet pressure. Looking at just the constant area mixing section and diffuser section, the minimum pressure is at the end of the constant area section. 


\section{$\begin{array}{cccc}\text { Pressure (Pa) } \\ 4.6 e+05 & 3.8 e+05 & 4.2 e+05 \quad 4.4 e+05\end{array}$}

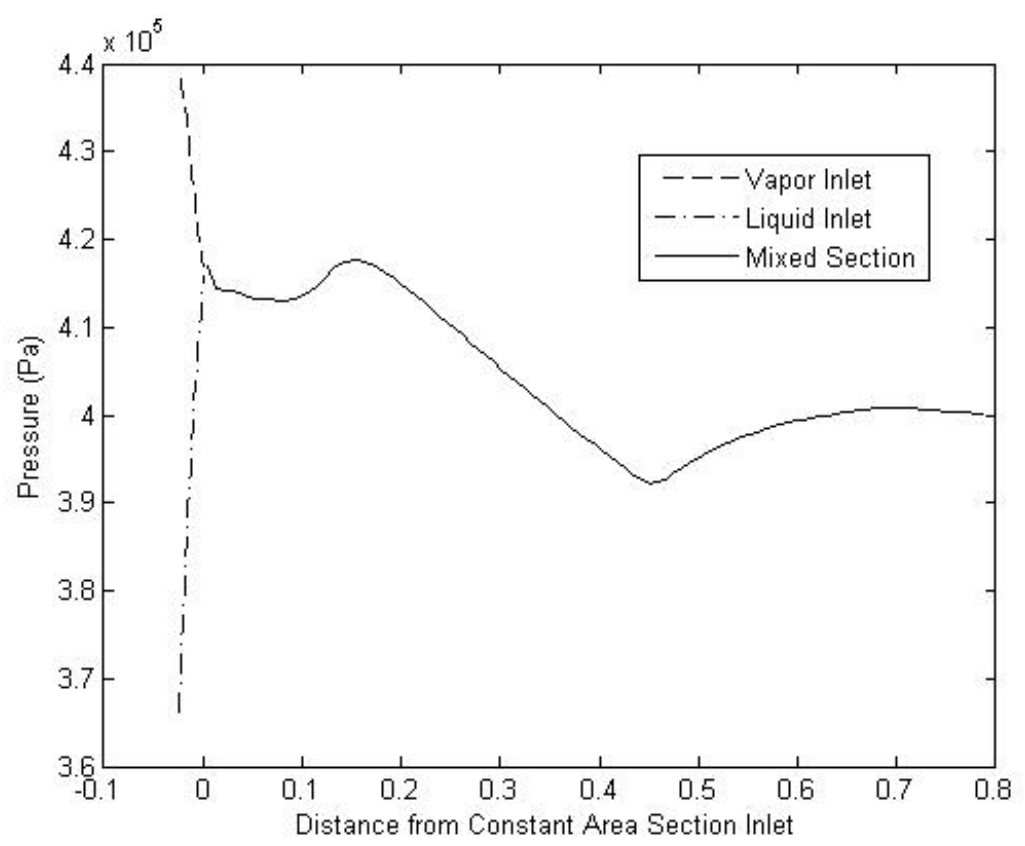

Figure 4.2: Pressure distribution through ejector. Top picture is mirrored over the centerline axis for easier viewing.

The velocity magnitude profile is shown in Figure 4.3. There is no condensation shock seen in the simulation, but there is a gradual decrease in velocity as the fluids mix and move through the ejector. The vapor flow velocity increases from the inlet to the beginning of the mixing section and then decreases when starting to mix with the liquid flow. In the diffuser section there is an increase in density, which results in a continuing deceleration of the fluid. The flow at the outlet is sub-sonic. 


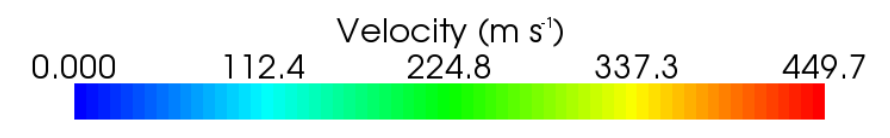

Figure 4.3. Velocity in the ejector (mirrored over centerline axis). As the two streams mix, there is a steady decrease in velocity as the flow moves across the nozzle.

Figure 4.4 shows that there is noticeable mixing between the vapor and liquid streams, and that by the nozzle exit the flow is mostly liquid, but has not completely condensed. This mixing is caused by the high enthalpy of the gas mixing with the low enthalpy of the liquid. This mixing predisposes the vapor to condense by lowering its temperature. Around the centerline the mass fraction of vapor is very close to zero, while along the top wall of the vapor stream area the mass fraction of vapor is close to 0.02 . The equilibrium mass fraction at the outlet is zero. The flow does not reach thermodynamic equilibrium by the outlet. 


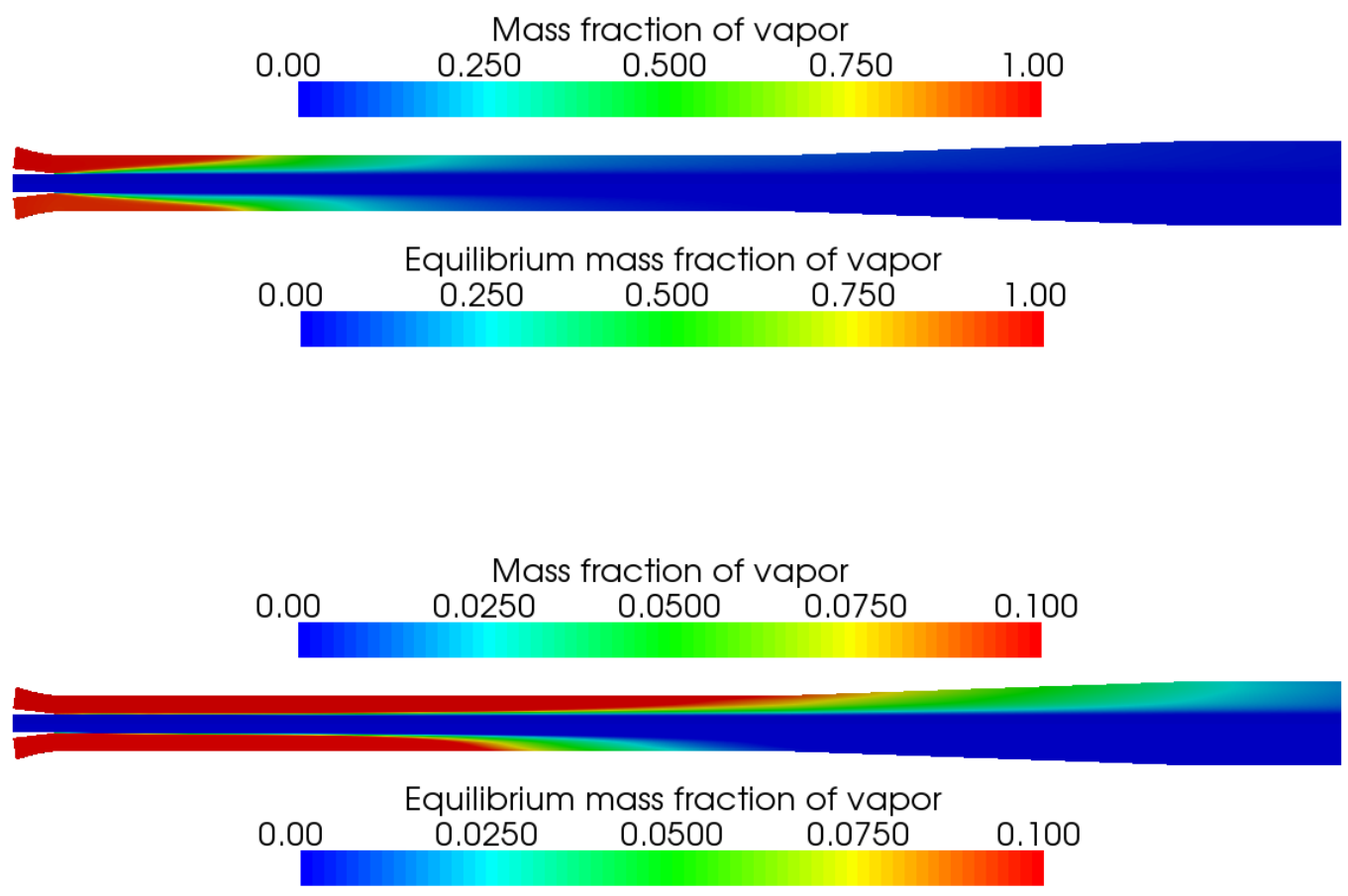

Figure 4.4. In these two pictures, vapor mass fraction, $x$, is shown in the top half, and equilibrium vapor mass fraction, $\bar{x}$, is shown in the bottom half. The scale is adjusted in the second picture to better show the vapor mass fraction in the diffuser.

The turbulent viscosity is shown in Figure 4.5. The greatest value of viscosity is in the mixing section along the splitter axis, somewhat downstream of where the vapor and liquid streams meet. This is expected, since this is where most of the mixing between streams occurs. As the flow becomes more homogeneous, the turbulent viscosity decreases.

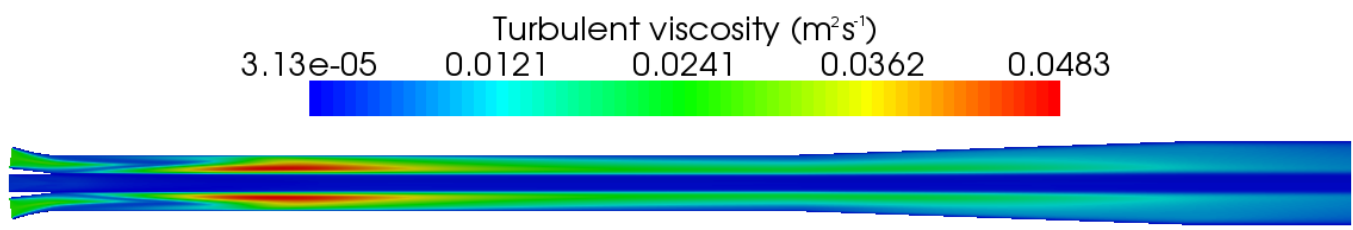

Figure 4.5. The highest value of viscosity is in the mixing section, when the liquid and vapor streams begin to mix. 


\subsection{2 $\mathrm{CO}_{2}$ as Working Fluid}

Since using water can lead to numerical instability, the working fluid used for the cases in this sub-section is carbon dioxide. Stated earlier in Chapter $1, \mathrm{CO}_{2}$ has become a more commonly studied refrigerant [40 - 45]. Besides being a more practical refrigerant than water for current applications, using carbon dioxide as the working fluid leads to more stable simulations. The highest rate of instability is at the splitter, where the vapor and liquid streams meet. The ratio of liquid density to vapor density of water is about 1000. For the pressure values used in this sub-section, the ratio of liquid density to vapor density of $\mathrm{CO}_{2}$ is around 50. This results in a much lower density gradient at cells where the liquid and vapor flow interact. Also, because of the greater stability, compressibility can be included in the modeling equations.

For the initial case shown (Figs. $4.6-4.10$ ), the velocity at the saturated vapor inlet is set to Mach $1\left(221 \mathrm{~m} \mathrm{~s}^{-1}\right)$ and the velocity at the saturated liquid inlet is set to 150 $\mathrm{m} \mathrm{s}^{-1}$. At both of the inlets, the pressure gradient is set to zero. Fixed uniform densities of $23.0 \mathrm{~kg} \mathrm{~m}^{-3}$ at the vapor inlet and $1150 \mathrm{~kg} \mathrm{~m}^{-3}$ at the liquid inlet are applied. At the outlet, a non-reflecting pressure boundary condition of $2.5 \mathrm{MPa}$ is imposed and the velocity gradient is zero. The realizable k-epsilon turbulence model is used, with standard wall functions applied near the walls. All walls are adiabatic.

The simulations were run for 0.1 seconds of simulated time, and the flow was able to reach steady state. The nozzle is reflected around the centerline axis for better clarity in showing the results (Figs. $4.6-4.10$ ). Fig. 4.6 shows the mixing between the vapor and liquid streams. By the nozzle exit the flow is mostly liquid, but has not completely condensed. Figure 4.7 shows the rate of phase change, the difference between the 
instantaneous quality and the equilibrium quality divided by the timescale, $\Theta$. At points where $\mathrm{x}$ is greater than $\overline{\mathrm{x}}$, further condensation will have to occur over time to reach thermodynamic equilibrium. This is seen in the diffuser and across the top wall of the whole ejector. The equilibrium quality is greater than the instantaneous quality along the liquid stream line in the mixing section, before it completely mixes with the vapor stream.

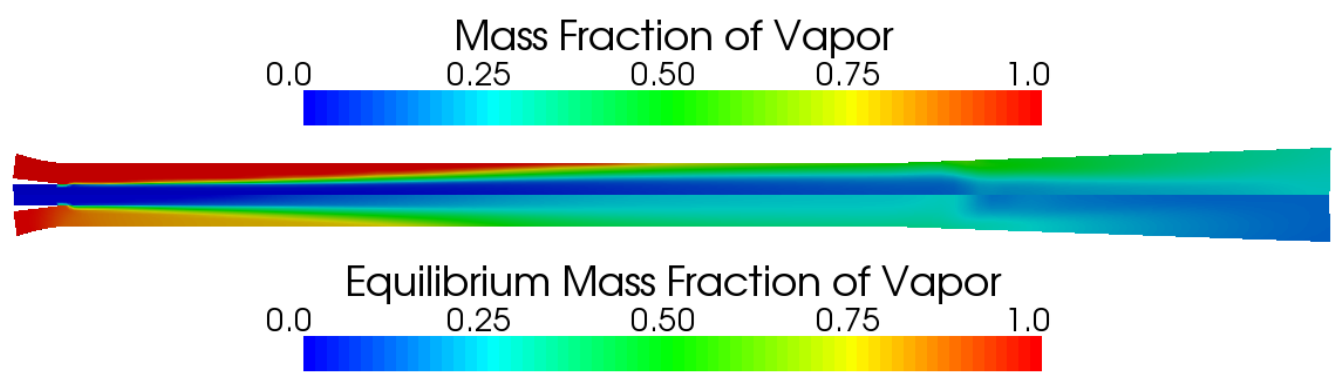

Figure 4.6. Mass fraction of vapor, $\mathrm{x}$, is shown in the top half of the figure and the equilibrium mass fraction of vapor, $\overline{\mathrm{x}}$, is shown in the bottom half.

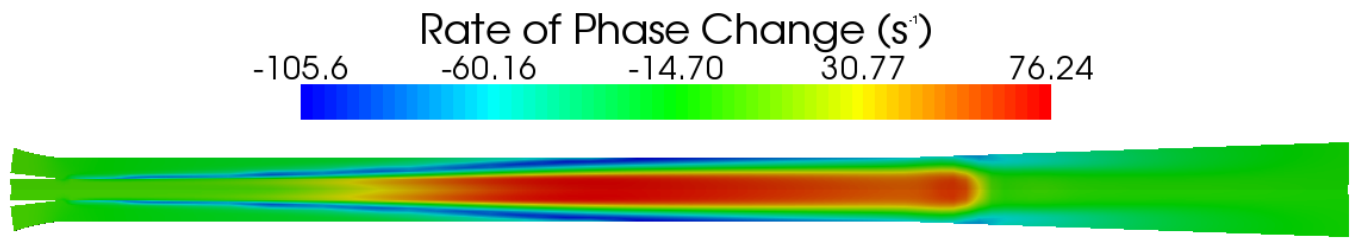

Figure 4.7. Rate of phase change (mirrored over centerline axis). Negative values indicate condensation, positive values indicate vaporization.

Pressure shows a noticeable increase, as shown in Fig. 4.8. The pressure at the outlet is greater than the pressure at both inlets; slightly higher than the pressure at the vapor inlet, and much higher than the pressure at the liquid inlet. This is to be expected for an efficient condensing ejector. Similar to the results in the last sub-section, the 
pressure reaches a minimum around the end of the mixing section and then the pressure increases rapidly in the diffuser.

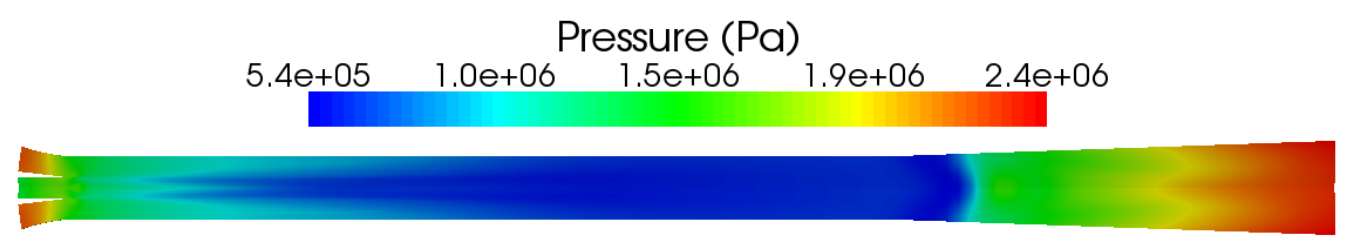

Figure 4.8. Pressure profile throughout the nozzle (mirrored over centerline axis). The pressure at the outlet is higher than the pressure at both inlets.

Fig. 4.9 shows the deceleration that accompanies the pressure increase and condensation. Near the beginning of the diffuser there is a rapid decrease in velocity. There is an increase in the vapor velocity shortly after the inlet, but the velocity gradually decreases when moving through the constant-area section after starting to mix with the liquid stream. The velocity in the diffuser is lower along the top wall than along the centerline axis.

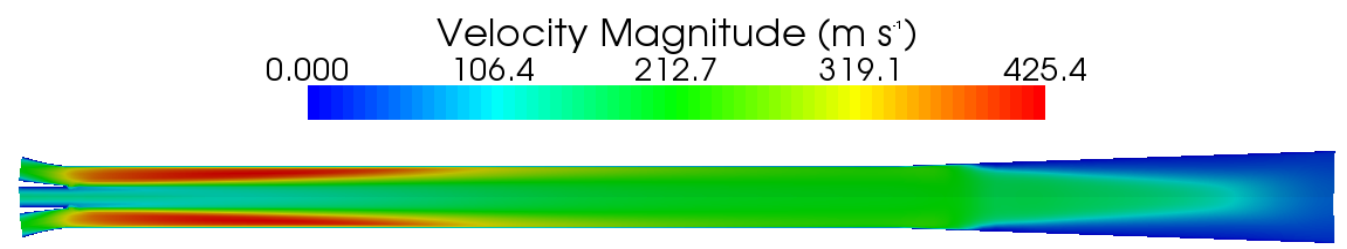

Figure 4.9. Velocity profile throughout the nozzle (mirrored over centerline axis).

Fig. 4.10 shows the effective turbulent viscosity, $v_{t}$. As expected, the greatest amount of mixing occurs within the mixing layer near the splitter, where the two inlet streams meet. Turbulent viscosity is at a maximum shortly before the midpoint of the mixing section. The flow is also turbulent near the exit of the nozzle. This corresponds with the decrease in the velocity in the diffuser. 


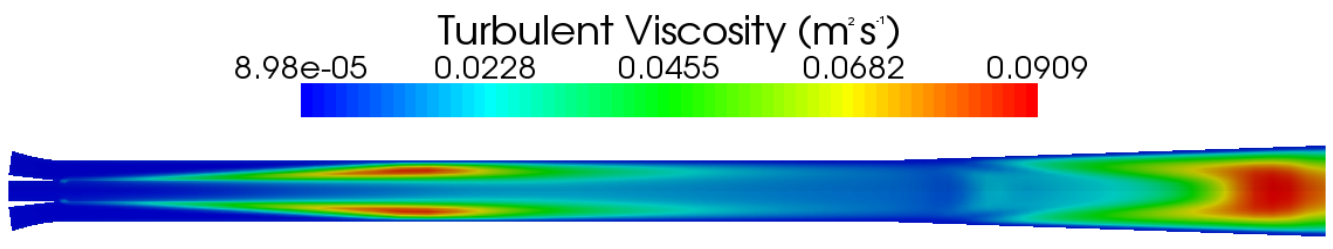

Figure 4.10. Turbulent viscosity is shown in this figure (mirrored over centerline axis). Mixing can be seen along the splitter in the constant area section, and also near the outlet.

Changing the operating pressure at the outlet was also investigated. The boundary conditions stated earlier in this section remained the same, while the outlet pressure was varied from 1.5 MPa to 2.7 MPa. The velocity profile was looked at, and also the mass fraction of vapor. In Fig. 4.11, it can be seen that as the outlet pressure is increased, the point of rapid deceleration of the flow is more upstream. The maximum velocity in the diffuser is greatest at the lowest set outlet pressure in this study. Despite the lack of a condensation shock, this is similar to what is seen in Sriveerakul et al. [13], where the shocking position (which leads to a sudden decrease in velocity) is further upstream for higher back pressure.

The mass fraction of vapor and the equilibrium mass fraction of vapor at the outlet are lower for higher outlet pressure (Fig. 4.12), with an increase in pressure having a greater effect on $\overline{\mathrm{x}}$. This can be expected for $\overline{\mathrm{x}}$ since it is dependent on pressure (and also enthalpy). The instantaneous mass fraction of vapor is also affected by pressure; an increase in pressure while keeping enthalpy constant will result in a lower density, and thus a greater value of $x$. 


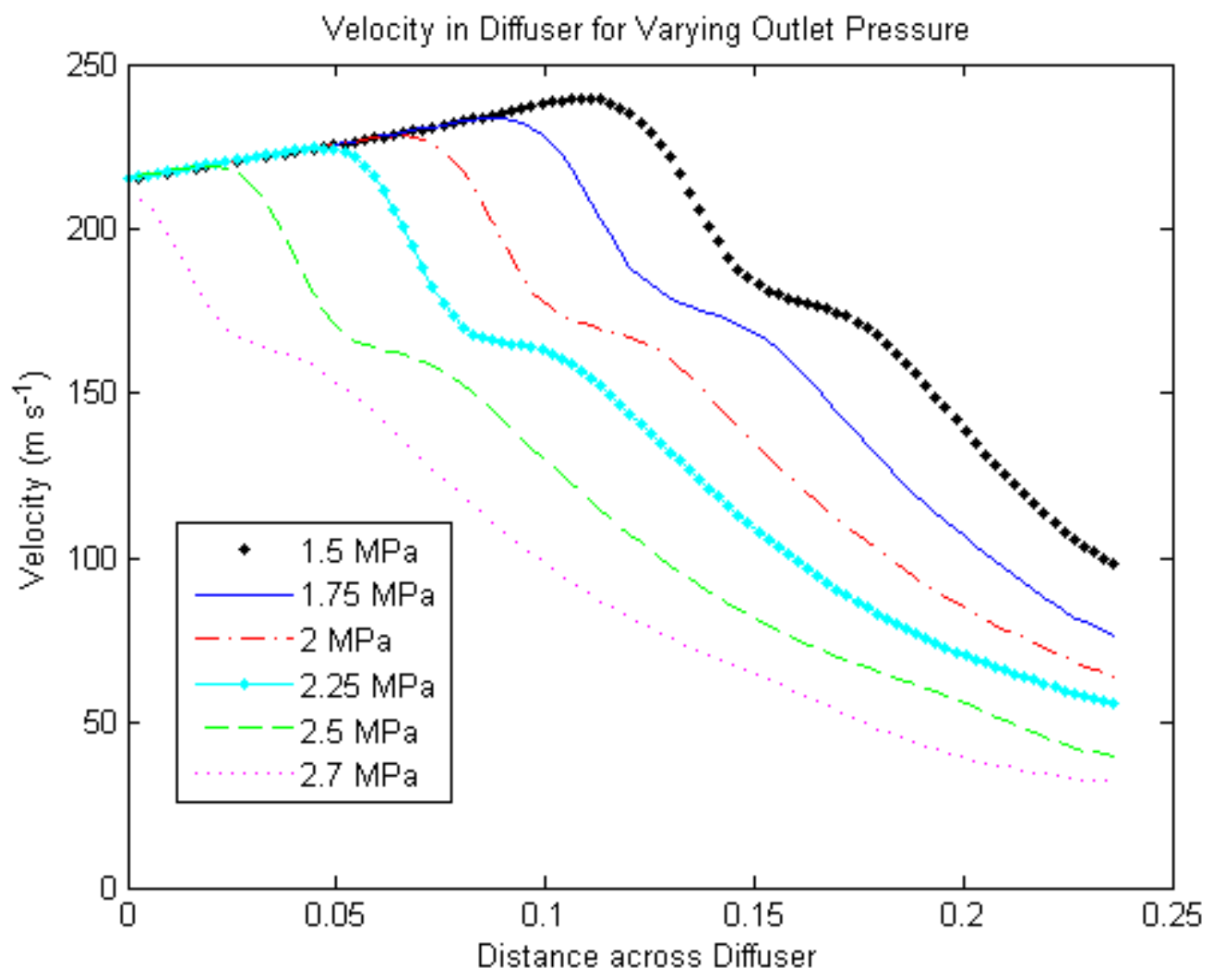

Figure 4.11. Velocity along the midpoint of the diffuser for varying outlet pressure. 


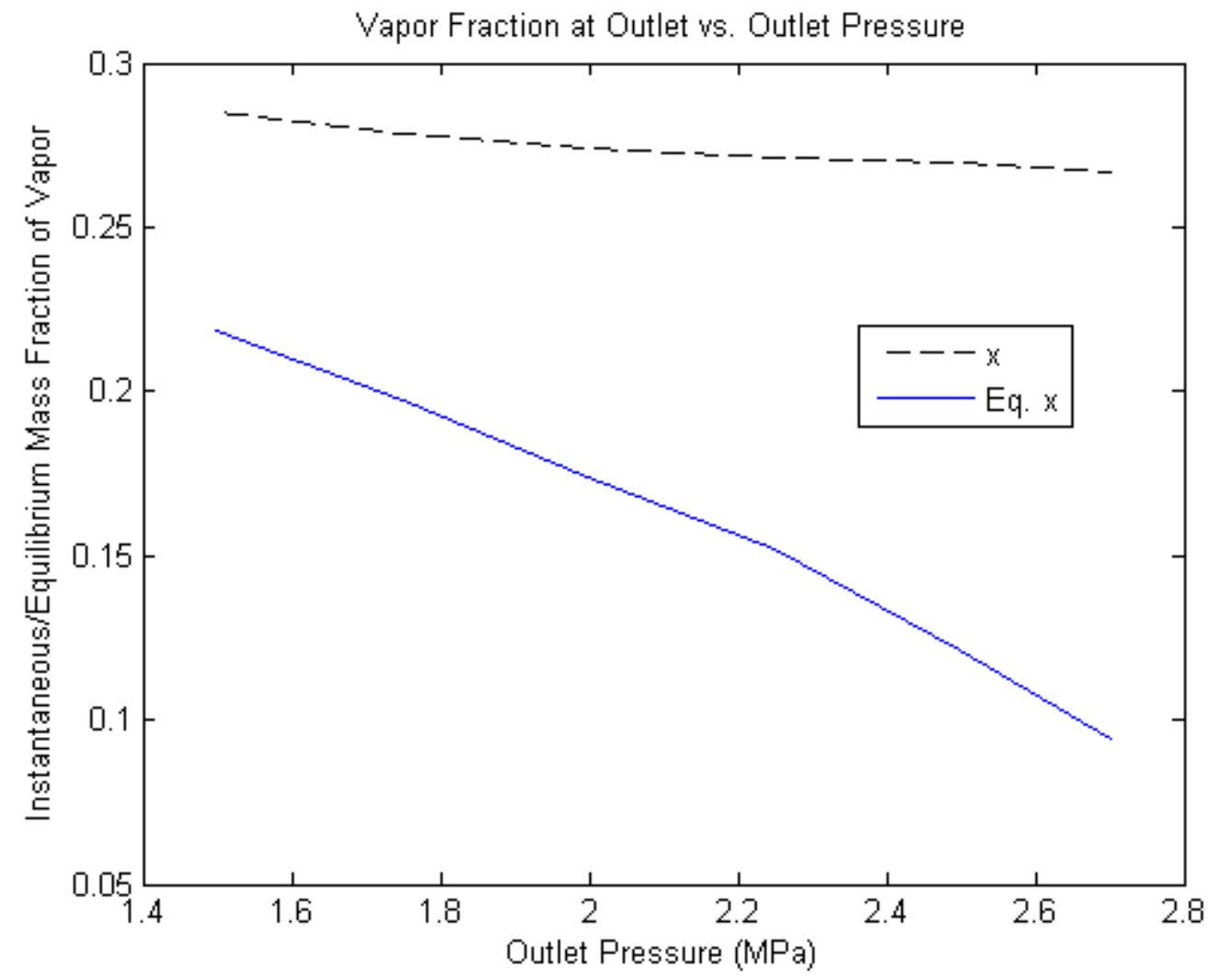

Figure 4.12. The boundary condition on the pressure at outlet is varied, and the effect on the instantaneous mass fraction of vapor and equilibrium mass fraction of vapor is investigated. 


\section{CHAPTER 5}

\section{NAKAGAWA EJECTOR RESULTS}

\subsection{Nakagawa et al. Two-Phase $\mathrm{CO}_{2}$ Ejector Cycle}

The ejector being modeled is described in Nakagawa et al. [42]. The work in that paper not only looks at the overall refrigeration cycle, but also what specifically occurs in the ejector nozzle through experimental study. Because this paper uses carbon dioxide as the working refrigerant and has data on the flow in the ejector, this work is a good choice for comparison to the CFD model presented here. A diagram of the ejector refrigeration cycle used in the work by Nakagawa et al. [42], along with a corresponding p-h diagram, is shown in Figure 1.7.

The full nozzle dimensions can be found in Nakagawa et al. [42], and the dimensions of the parts modeled in the CFD mesh are stated here. The width at the exit of the motive nozzle is $0.8 \mathrm{~mm}$. Three different mixing section lengths were investigated $(5,15$, and $25 \mathrm{~mm})$, each with a width of $2.5 \mathrm{~mm}$. The diffuser length is $30.5 \mathrm{~mm}$, with a width of $2.5 \mathrm{~mm}$ at the beginning and $8 \mathrm{~mm}$ at the outlet. For the $5 \mathrm{~mm}$ and $15 \mathrm{~mm}$ mixing section lengths, a supplementary piece with a width of $8 \mathrm{~mm}$ was attached to the end of the diffuser so the total length of the ejector was $55.5 \mathrm{~mm}$. Along with analyzing the effect of different mixing section lengths, the effect of using an internal heat exchanger (IHX) was also investigated. The use of an IHX lowers the temperature of the super-critical fluid exiting the gas cooler. This results in the fluid having a lower enthalpy in the motive nozzle. 


\subsection{Results}

\subsubsection{Model Validation}

For each of the three nozzle designs (for the different mixing section lengths), a 2D quad mesh of 6100 to 6750 cells $(6145$ cells for the nozzle with the $5 \mathrm{~mm}$ mixing section; 6549 for the $15 \mathrm{~mm}$; 6741 for the $25 \mathrm{~mm}$ ) was made. Figure 5.1 shows the mesh for the ejector with a $5 \mathrm{~mm}$ mixing section with the parts of the ejector labeled, and a close-up of the mesh at the inlets and mixing section. Only the top half of the nozzle was modeled because of axi-symmetry. At the inlets, a mass flow rate is specified based on the experimental results in Nakagawa et al. [42], and a zero gradient pressure boundary condition is applied. At the walls, a slip condition is applied. At the outlet, the velocity gradient is set to zero, and a non-reflecting pressure boundary condition is imposed. For each case, the value of the outlet pressure is set to what was determined in the experimental results. Exit pressure is specified at the outlet to help ensure a well-posed problem. Using the exit pressure value, the pressure at the inlets is predicted. Density at the inlets and outlet are calculated based on the pressure and enthalpy. The density is updated at the inlets for every time step as pressure changes. The enthalpy at the motive inlet is calculated based on the pressure and temperature of the gas cooler in the experimental work, and the efficiency of the ejector; the enthalpy at the suction nozzle inlet can be determined from the pressure and temperature in the evaporator. All walls are adiabatic. 

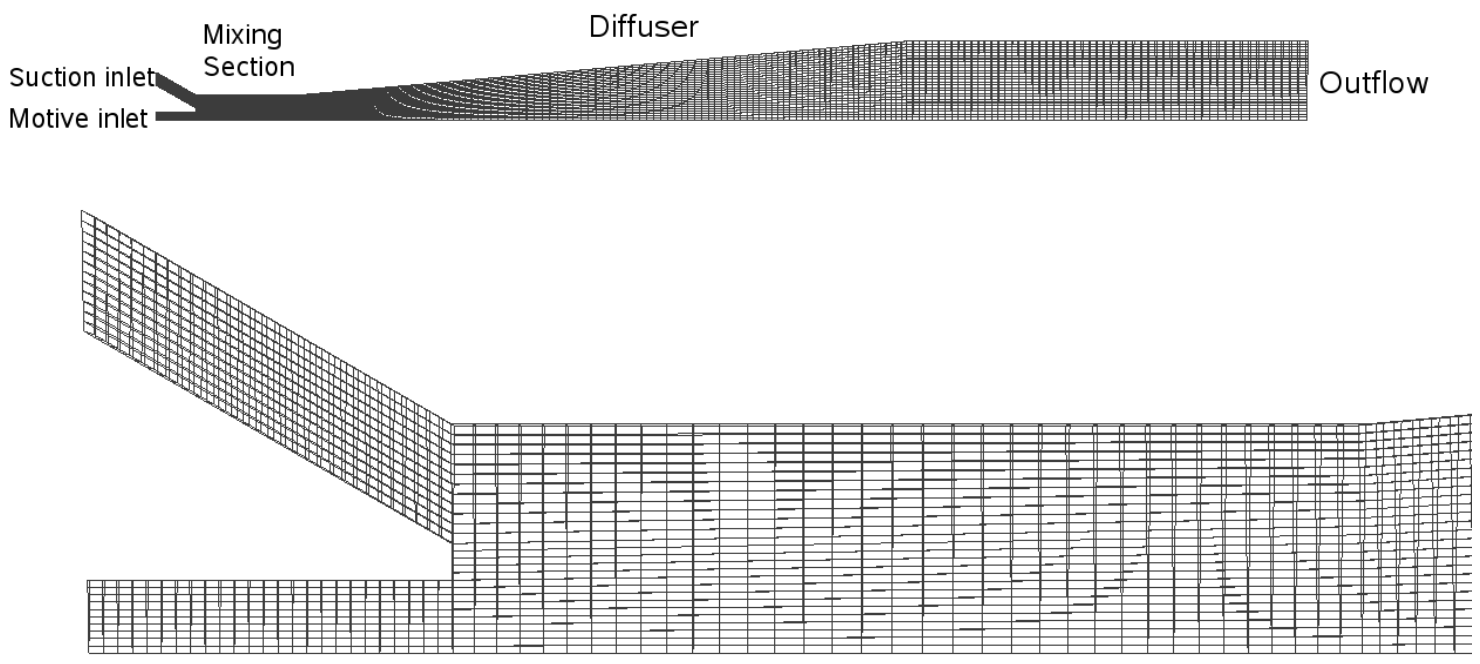

Figure 5.1. Mesh for the $5 \mathrm{~mm}$ mixing section length case with the boundaries labeled, and a close-up image of the inlets and mixing section.

The simulations were run up to 0.08 seconds of simulated time, and were all able to reach steady state. Cases were run for the three different mixing section lengths (simulating both the use of an IHX and also without it), and for varying gas cooler pressure. The three gas cooler pressures chosen were 9.5, 10, and 10.5 MPa, which were also tested in the experiments. The flow is super-critical at these pressures, but is in the sub-critical two-phase region when entering the mixing section. The temperature at the gas cooler is $42{ }^{\circ} \mathrm{C}$ and the temperature at the evaporator is $2{ }^{\circ} \mathrm{C}$.

A key characteristic of an ejector is the pressure rise at the outlet. This pressure rise is what leads to an increase in the COP of this refrigeration cycle, as compared to a standard cycle. For all of the cases simulated, the pressure recovery is shown in Figure 5.2. The pressure recovery is the difference in the pressure at the outlet to the pressure at the start of the mixing section. The pressure values are taken along the top wall of the ejector, which was also done in the experiments by Nakagawa et al. [42]. As can be seen 
from Fig. 5.2, the nozzle with the $15 \mathrm{~mm}$ mixing section length outperformed the other two ejector designs for both the use of an IHX and without. The nozzle with the $25 \mathrm{~mm}$ mixing section length has a slightly lower pressure recovery for all cases. The pressure rise in the nozzle with the $5 \mathrm{~mm}$ mixing section length is significantly lower than the other two ejector types (for when the IHX is used and also when not used), and this is especially noticed when the gas cooler pressure is higher.

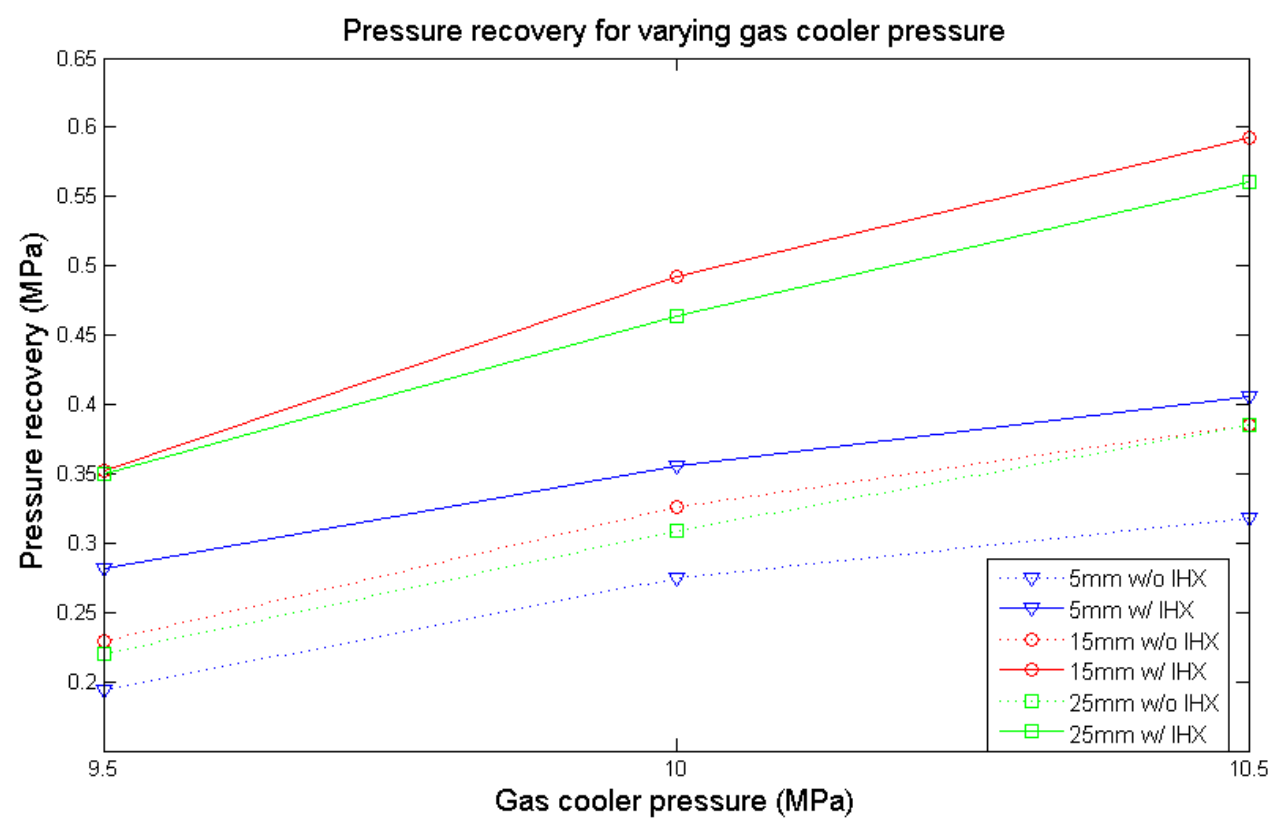

Figure 5.2. CFD results of pressure recovery for different mixing section lengths at varying gas cooler pressure. The $15 \mathrm{~mm}$ ejector type has the greatest predicted pressure rise, both when the IHX is used and when not used.

These pressure recoveries have a similar trend with the experimental results in Nakagawa et al. [42], where the $15 \mathrm{~mm}$ mixing section has the best performance and the pressure recovery increases as the gas cooler pressure increases. The only exception in the experimental results is the $5 \mathrm{~mm}$ mixing section with the IHX, where pressure recovery slightly decreases when increasing the gas cooler pressure from $10 \mathrm{MPa}$ to 10.5 MPa. The CFD results predict a steady increase in pressure rise for this case, similar to 
what is seen with the other ejector types. The comparison of CFD to experimental results, for pressure recovery for each of the cases is shown in Table 5.1 a-c. The experimental setup did not have a thermocouple placed directly at the beginning of the mixing section to measure the pressure (the entire flow in the ejector is in the two-phase region, so a temperature value can only have one corresponding pressure value), but did shortly after (2.2 $\mathrm{mm}$ for the $5 \mathrm{~mm}$ mixing section; $3 \mathrm{~mm}$ for the $15 \mathrm{~mm} ; 4 \mathrm{~mm}$ for the 25 $\mathrm{mm}$ ). Pressure recovery was determined as the difference between the pressure at the outlet to the pressure at the first thermocouple in the mixing section. From Table $5.1 \mathrm{a}-\mathrm{c}$, it is noticed that the CFD results under-predict pressure recovery for the cases that do not use the IHX, and over-predict recovery for the cases with the IHX with the exception of the $15 \mathrm{~mm}$ and $25 \mathrm{~mm}$ types when the gas cooler pressure is set to $9.5 \mathrm{MPa}$. The worst CFD results (based on percent error) are the cases with the $5 \mathrm{~mm}$ mixing section and the use of the IHX. This is because the CFD results predict a gradual increase in pressure recovery as gas cooler pressure increases (similar to all the other cases) while the experimental results do not. The ejector types with the CFD results closest to the experiments are the $5 \mathrm{~mm}$ mixing section without the IHX and the $25 \mathrm{~mm}$ mixing section with the IHX. The average percent error of all the cases is $18.6 \%$. For the initial CFD results this is promising and there are a few sources of error that could be accounted for and improved upon. 
Table 5.1: Pressure recovery difference between experimental and CFD results for varying gas cooler pressures of (a) $9.5 \mathrm{MPa}$, (b) $10 \mathrm{MPa}$, and (c) $10.5 \mathrm{MPa}$.

\begin{tabular}{|c|c|c|c|c|c|}
\hline & \multicolumn{5}{|c|}{ Gas cooler pressure $=9.5 \mathrm{MPa}$} \\
\hline Mixing section length $(\mathrm{mm})$ & IHX? & Pressure increase (MPa) & & \\
\hline & & Nakagawa et al. & CFD & difference & \% error \\
\hline 5 & no & 0.265 & 0.210 & 0.055 & 20.755 \\
\hline 5 & yes & 0.240 & 0.270 & -0.030 & -12.500 \\
\hline 15 & no & 0.375 & 0.253 & 0.122 & 32.533 \\
\hline 15 & yes & 0.397 & 0.339 & 0.058 & 14.610 \\
\hline 25 & no & 0.365 & 0.237 & 0.128 & 35.068 \\
\hline 25 & yes & 0.393 & 0.353 & 0.040 & 10.178 \\
\hline
\end{tabular}

\begin{tabular}{|c|c|c|c|c|c|}
\hline (b) & \multicolumn{5}{|c|}{ Gas cooler pressure $=10 \mathrm{MPa}$} \\
\hline Mixing section length (mm) & IHX? & Pressure increase (MPa) & & \\
\hline & & Nakagawa et al. & CFD & difference & $\%$ error \\
\hline 5 & no & 0.291 & 0.275 & 0.016 & 5.498 \\
\hline 5 & yes & 0.256 & 0.336 & -0.080 & -31.250 \\
\hline 15 & no & 0.448 & 0.334 & 0.114 & 25.446 \\
\hline 15 & yes & 0.443 & 0.468 & -0.025 & -5.643 \\
\hline 25 & no & 0.432 & 0.329 & 0.103 & 23.843 \\
\hline 25 & yes & 0.454 & 0.450 & 0.004 & 0.881 \\
\hline
\end{tabular}

\begin{tabular}{|c|c|c|c|c|c|}
\hline & \multicolumn{5}{|c|}{ Gas cooler pressure $=10.5 \mathrm{MPa}$} \\
\hline Mixing section length (mm) & IHX? & Pressure increase (MPa) & & \\
\hline & & Nakagawa et al. & CFD & difference & $\%$ error \\
\hline 5 & no & 0.313 & 0.308 & 0.005 & 1.597 \\
\hline 5 & yes & 0.254 & 0.380 & -0.126 & -49.606 \\
\hline 15 & no & 0.496 & 0.377 & 0.119 & 23.992 \\
\hline 15 & yes & 0.487 & 0.561 & -0.074 & -15.195 \\
\hline 25 & no & 0.472 & 0.402 & 0.070 & 14.831 \\
\hline 25 & yes & 0.480 & 0.537 & -0.057 & -11.875 \\
\hline
\end{tabular}


The choice of turbulence model has an effect on the flow, especially in the mixing section where the two streams meet. The standard k-epsilon model is used for the simulations presented here. Other Reynolds-averaged Navier-Stokes (RANS) turbulence models, such as the realizable k-epsilon model, and the RNG model and the k-omega SST model will be examined in section 5.4. Large-eddy simulation (LES) turbulence models are also a possibility for future work.

Another possible source of error could be from the boundary conditions, most importantly at the motive nozzle inlet. The velocity and density of the motive nozzle flow have the most significant effect on the pressure recovery in the ejector. The mass flow rates measured in the experiments are specified at the inlets in the CFD cases, so a change in density will also result in a change in velocity. Density is calculated from the pressure and enthalpy at the inlets; this assumes that the fluid is in thermodynamic equilibrium. This is the best assumption that can be made based on the information given in the experiments. The difference between the instantaneous quality and the equilibrium quality will be minor, but a slight difference will have a small but noticeable effect on pressure recovery.

Adjusting some of the constants, particularly the turbulent Schmidt number and turbulent Prandtl number, can have an impact on pressure recovery. For all of the CFD cases, the turbulent Schmidt number was set to 0.9 and the turbulent Prandtl number was set to 0.9 , both within an acceptable range for $\mathrm{CO}_{2}$ [52] [53] [54]. Different turbulent Schmidt numbers within the acceptable range determined in Koeltzsch [59] and Tominaga [60] were investigated. Table 5.2 shows how changing the turbulent Schmidt number has an effect on pressure recovery (for the cases with the gas cooler pressure set 
to $10 \mathrm{MPa}$ ). Looking at $S c_{t}$ values of 0.4 and 0.9 , for the cases with the $5 \mathrm{~mm}$ mixing section length ejector the change in pressure recovery was $2.2 \%$ and $3.4 \%$, without and with the IHX, respectively, and for the cases with the $15 \mathrm{~mm}$ and $25 \mathrm{~mm}$ mixing section length ejectors there was a pressure recovery difference of only $\pm 1 \mathrm{kPa}$. While changing the turbulent Schmidt number can affect the pressure rise in the nozzle, the difference is not too significant.

Table 5.2: Effect on pressure recovery when varying the turbulent Schmidt number for cases with gas cooler pressure set to $10 \mathrm{MPa}$.

\begin{tabular}{|c|c|c|c|c|}
\hline \multirow{2}{*}{\multicolumn{2}{|c|}{}} & \multicolumn{3}{|c|}{ Turbulent Schmidt number } \\
\cline { 3 - 5 } & 0.4 & 0.625 & 0.9 \\
\hline Mixing section length (mm) & IHX? & \multicolumn{3}{|c|}{ Pressure recovery (MPa) } \\
\hline 5 & no & 0.281 & 0.278 & 0.275 \\
\hline 5 & yes & 0.368 & 0.361 & 0.356 \\
\hline 15 & no & 0.325 & 0.326 & 0.326 \\
\hline 15 & yes & 0.492 & 0.492 & 0.492 \\
\hline 25 & no & 0.309 & 0.309 & 0.309 \\
\hline 25 & yes & 0.463 & 0.464 & 0.464 \\
\hline
\end{tabular}

\subsubsection{CFD Results}

The CFD results show the distribution of the pressure rise. Figure 5.3 shows the pressure throughout the nozzle (the nozzle is reflected about the horizontal axis for clarity). The case presented here, and for the other figures in this sub-section, is the 25 mm mixing section length with the IHX and the gas cooler pressure at $10 \mathrm{MPa}$. It can be seen that most of the pressure recovery occurs in the mixing section and the beginning of the diffuser section. Also, the pressure becomes almost constant near the end of the mixing section, but has a pressure increase at the beginning of the diffuser. This was also noticed in the experiments of Nakagawa et al. [42] for the cases with the ejector that had 
the $25 \mathrm{~mm}$ mixing section. Figure 5.4 shows the comparison of the pressure profile from the CFD case compared to the experimental results for the same operating conditions and nozzle geometry. Even though both cases predict the same pressure recovery in the nozzle, the CFD results predict a higher pressure recovery in the mixing section, and less of a recovery in the diffuser section.

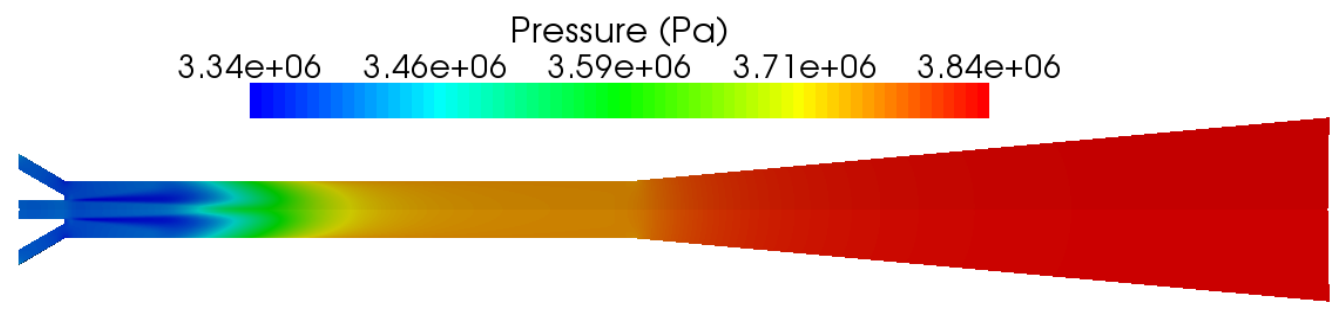

Figure 5.3. Pressure profile throughout the nozzle. Only the top half of the nozzle is modeled in the simulation, but the image is mirrored over the horizontal axis for easier viewing.

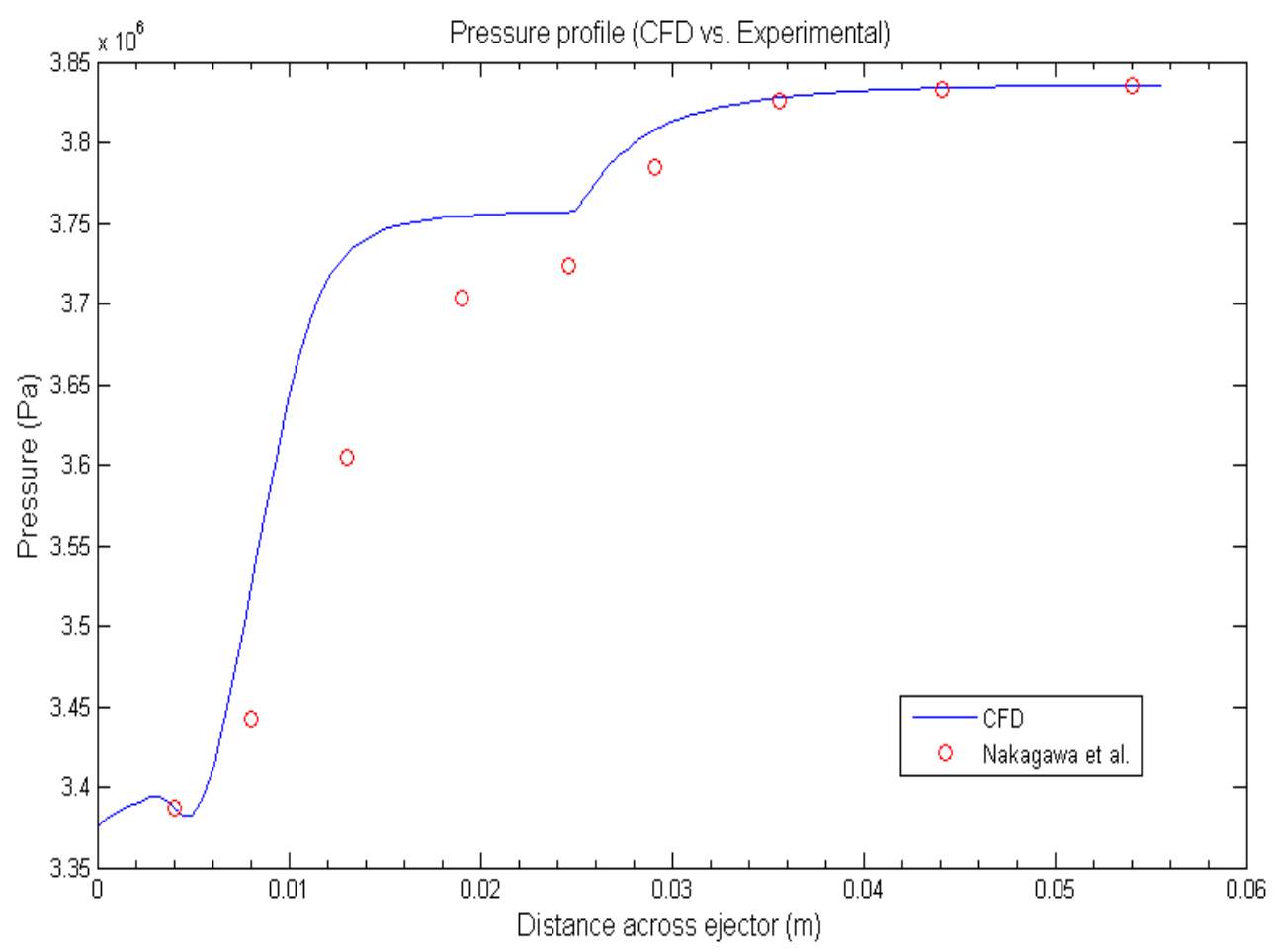

Figure 5.4. Comparison of CFD to experimental results of pressure profile across the nozzle. 
Figure 5.5 shows the mixing between the two streams. The instantaneous quality, $\mathrm{x}$, is displayed in the top half of the nozzle and the equilibrium quality, $\overline{\mathrm{x}}$, is shown in the bottom half. The two streams become well mixed by the end of the mixing section and in the diffuser. The very small difference between $\mathrm{x}$ and $\overline{\mathrm{x}}$ in the diffuser means that the flow in this section is near thermodynamic equilibrium. Changing the constant values in the relaxation model can have an effect on how fast the motive and suction streams will mix and reach equilibrium, and in the cases for the geometries and operating conditions in the presented work, the flow will be around thermodynamic equilibrium at the outlet.

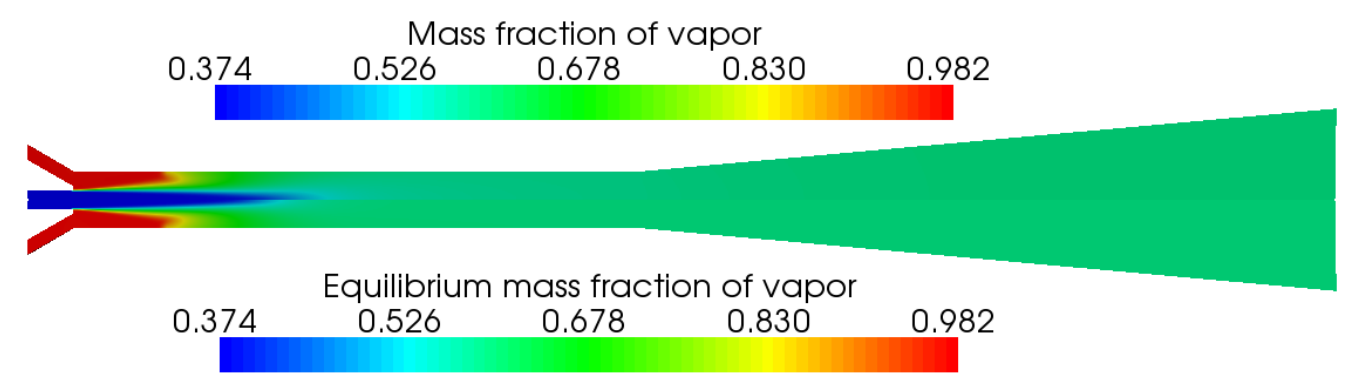

Figure 5.5. Instantaneous quality, $\mathrm{x}$, shown on the top half of the nozzle and equilibrium quality, $\overline{\mathrm{x}}$, is mirrored on the bottom half. The flow is near thermodynamic equilibrium in the diffuser section.

Figure 5.6 shows the velocity profile throughout the ejector. The velocity is at a maximum at the motive nozzle inlet. It can be seen that the mixing of the two streams and the occurring pressure rise cause the velocity to gradually decrease in the mixing section. The velocity continues to decrease in the diffuser (along with an increase in density), and the velocity at the outlet is about $3 \mathrm{~m} \mathrm{~s}^{-1}$. There is also a recirculation zone along the top wall a few millimeters into the mixing section. This can be seen in Figure 5.7. The recirculation can be attributed to the angle the suction nozzle stream enters the mixing section and that when the motive stream enters the mixing section, the flow fans 
out to the top wall just after the recirculation area. The part of the suction stream that is near the top wall flows into the motive stream that has a greater density, and causes the suction flow to recirculate in this section. The velocity of the flow in the recirculation area is less than $5 \mathrm{~m} \mathrm{~s}^{-1}$.

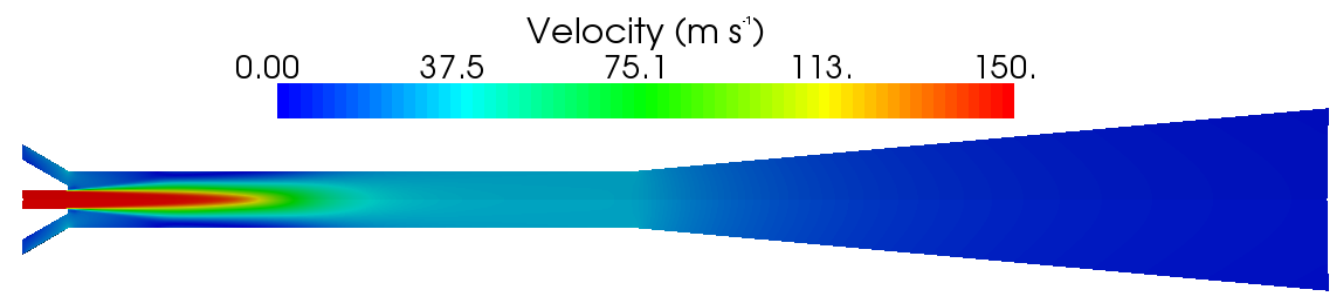

Figure 5.6. Velocity profile in the nozzle (mirrored over horizontal axis). The motive nozzle flow quickly decelerates in the mixing section.

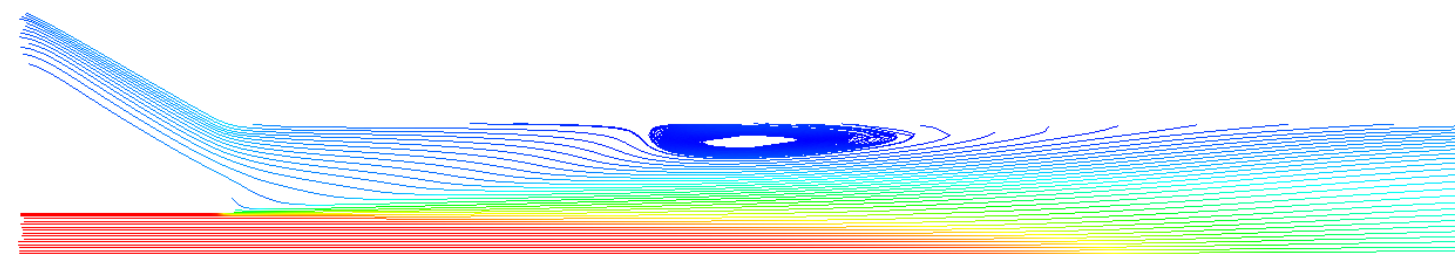

Figure 5.7. Stream lines show recirculation along the top wall of the mixing section. The stream lines are colored by velocity.

Turbulent kinematic viscosity, $v_{\mathrm{t}}$, can be seen in Figure 5.8. As expected, the viscosity is highest in the mixing section. This is because the streams have the most interaction in this area. The mixing of the two streams creates a high amount of turbulence, leading to an increase in turbulent viscosity. Turbulent viscosity is at a maximum slightly downstream of the recirculation zone. At the very beginning of the mixing section, the turbulent viscosity is lower (compared to the rest of the mixing section) because the motive and suction streams have not begun to mix Near the outlet, 
where the flow is less turbulent and is near thermodynamic equilibrium, the turbulent viscosity is at a minimum.

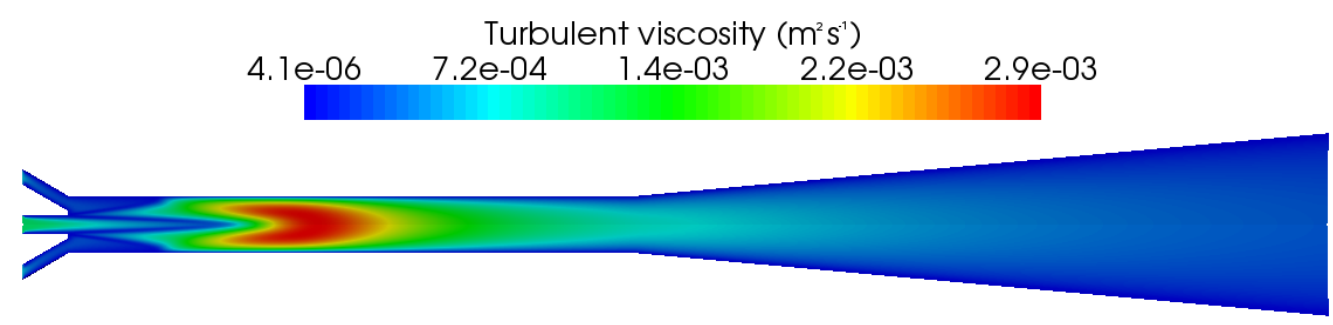

Figure 5.8. Turbulent kinematic viscosity is shown here (mirrored over horizontal axis), with the greatest amount of viscosity occurring in the mixing section.

\subsection{Mesh Quality}

A mesh quality study was done to test the accuracy of the meshes used in the previous sections of this chapter. Each of the three meshes was in the range of 6100 to 6750 cells $(6145$ cells for the nozzle with the $5 \mathrm{~mm}$ mixing section; 6549 for the $15 \mathrm{~mm}$; 6741 for the $25 \mathrm{~mm})$. The number of cells for the finer meshes is about double $(12,645$ for the $5 \mathrm{~mm} ; 12,296$ for the $15 \mathrm{~mm} ; 12,966$ for the $25 \mathrm{~mm}$ ). The eighteen cases were run again with the finer meshes and the difference in pressure recovery for 16 out of 18 cases was $\pm 2 \mathrm{kPa}$, which is less than $0.85 \%$ difference from the cases run with the coarser meshes (with most cases being under $0.5 \%$ difference). The two cases that had a greater difference were the ejector with the $25 \mathrm{~mm}$ mixing section and the gas cooler pressure set to $10.5 \mathrm{MPa}$, both for the cases considering the IHX and without the IHX. For the case without the IHX, the difference was $3 \mathrm{kPa}(0.75 \%$ difference in pressure recovery), and for the case with the IHX, the difference was $6 \mathrm{kPa}(1.12 \%$ difference). Since the finer meshes resulted in a very small change in pressure recovery, it can be concluded that the coarser meshes used in the previous sections of this chapter are acceptable. 
Looking at the finer mesh, there are some local differences in pressure in the region near the splitter where the two streams start to interact (Fig 5.9). In Figure 5.9, the ejector with the $5 \mathrm{~mm}$ mixing section is shown. A comparison is given, looking at the differences in pressure of the coarse and fine meshes, particularly around the splitter. The local differences in pressure with the finer mesh can be attributed to the fluctuations in turbulent viscosity in this area. The coarse mesh does not have enough cells to completely model the turbulence in this region.

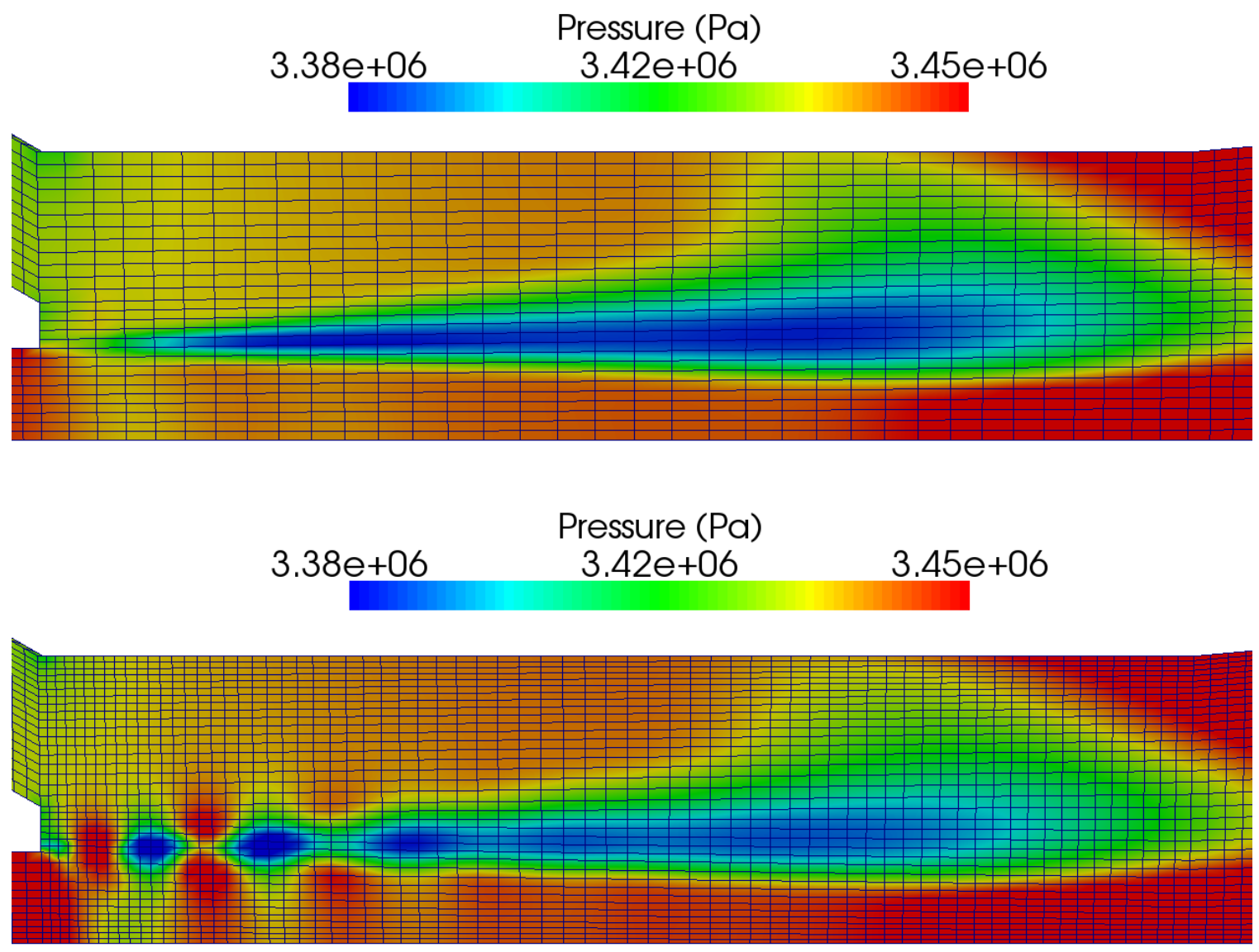

Figure 5.9. Difference in pressure in the mixing section of the ejector with the $5 \mathrm{~mm}$ mixing section for varying cell count. The coarser mesh with 6145 cells is on top and the mesh with 12,645 cells is on the bottom. 


\subsection{Comparison of Different Turbulence Models}

From the results in the previous sections of this chapter, it is noticed that the choice of turbulence model has an important role is predicting the pressure recovery. Along with the standard k-epsilon model that was used in the previous sections, three other RANS models were tested: realizable k-epsilon, RNG k-epsilon, and k-omega SST. Comparing these four models will provide a good initial study on the effects of applying different turbulence models.

All 18 cases were tested again with each of the other three turbulence models. Figure $5.10-5.12$ show the pressure recovery when using the realizable k-epsilon model, RNG model, and k-omega SST model, respectively. In these three figures, and Figure 5.2 , it is noticed that the nozzle with the greatest pressure recovery is the $15 \mathrm{~mm}$ mixing section length ejector with the use of the IHX and the nozzle with the lowest pressure recovery is the $5 \mathrm{~mm}$ mixing section length ejector without the use of the IHX. Comparing the turbulence models, the pressure recovery for the $15 \mathrm{~mm}$ mixing section length nozzle was least affected by the choice of turbulence model. The $5 \mathrm{~mm}$ mixing section length ejector was significantly affected by the turbulence model. This can be attributed to the change in the suction stream density at the inlet of the mixing section caused by the choice of turbulence model. A greater density would correlate with a greater pressure and thus a lower pressure recovery in the ejector. For any specific case with the $15 \mathrm{~mm}$ or $25 \mathrm{~mm}$ mixing section, the suction stream density at the mixing section entrance was almost unchanged for different turbulence models. Looking just at the $5 \mathrm{~mm}$ mixing section ejector, the realizable k-epsilon model predicts the lowest 
pressure recovery out of the four turbulence models, and the k-omega SST model predicts the greatest pressure recovery.

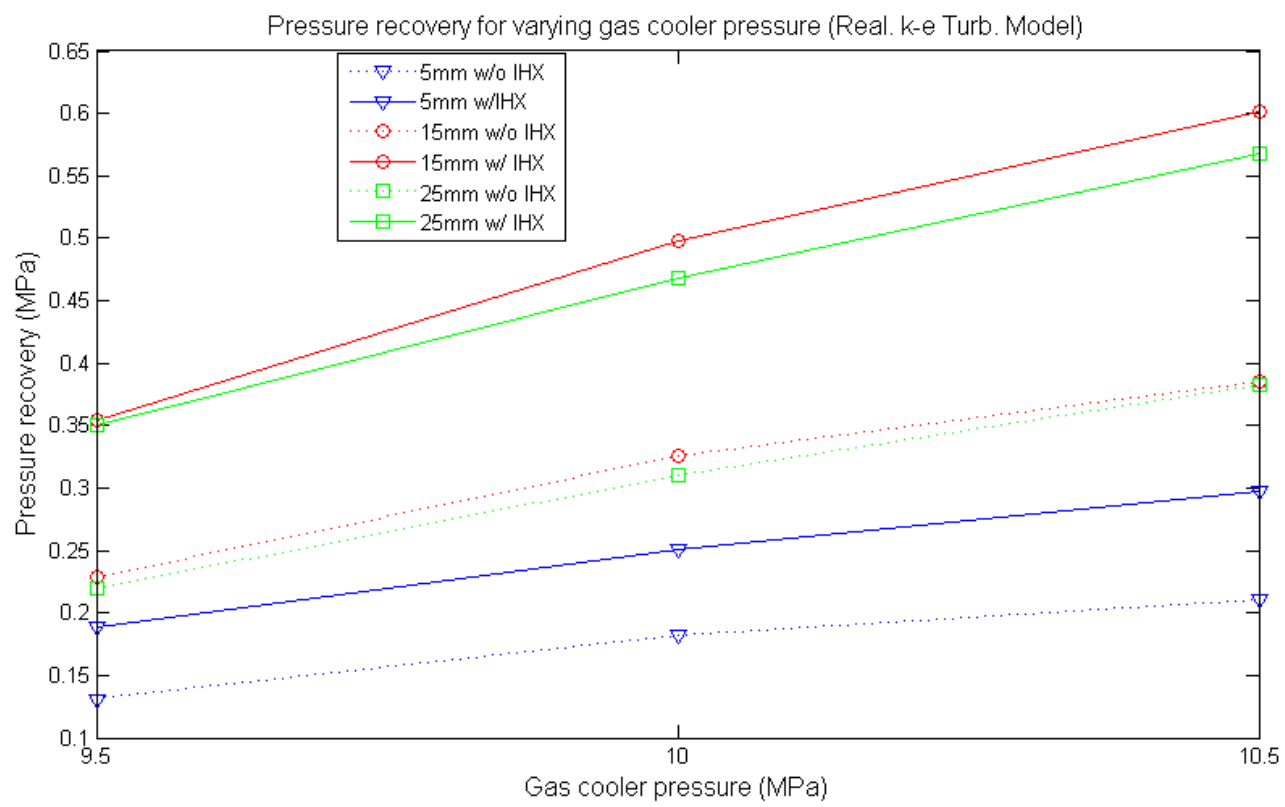

Figure 5.10. Using the realizable k-epsilon turbulence model, CFD results of pressure recovery for different mixing section lengths at varying gas cooler pressure.

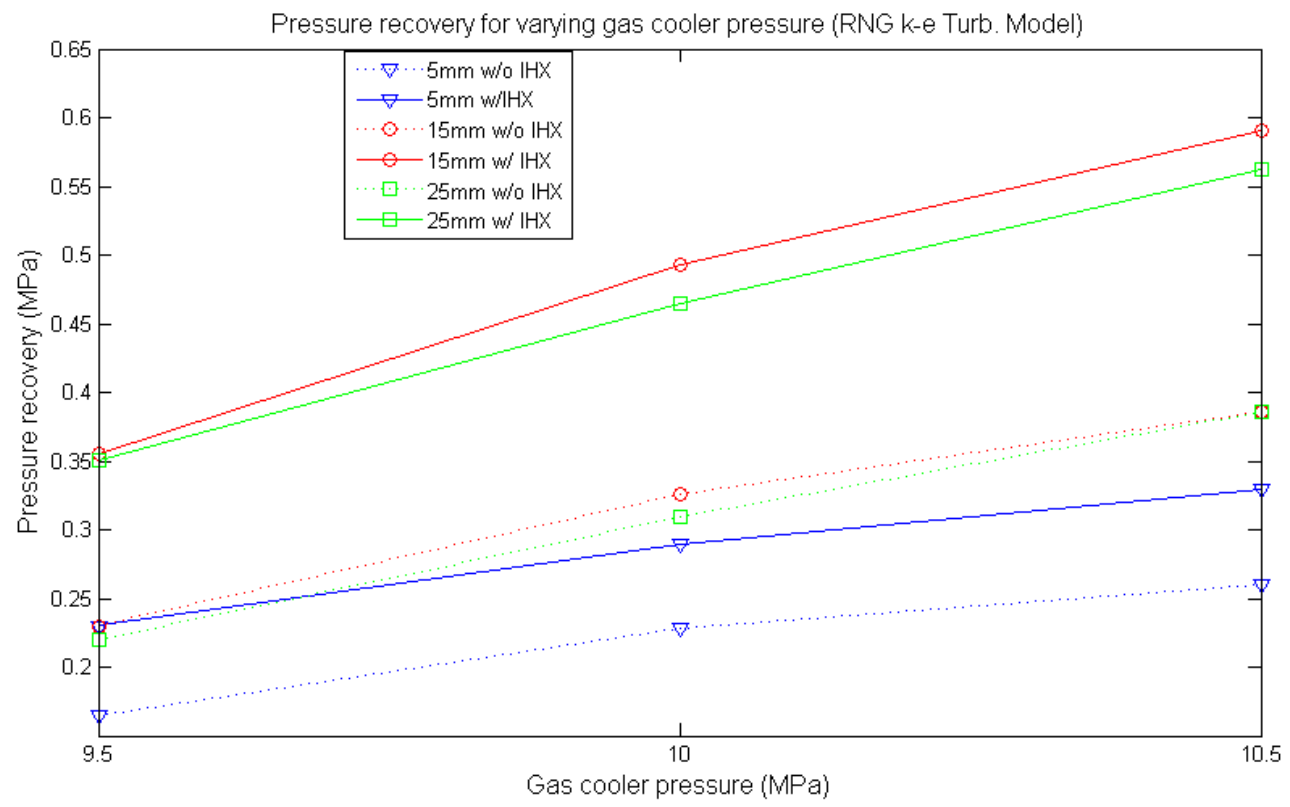

Figure 5.11. Using the RNG k-epsilon turbulence model, CFD results of pressure recovery for different mixing section lengths at varying gas cooler pressure. 


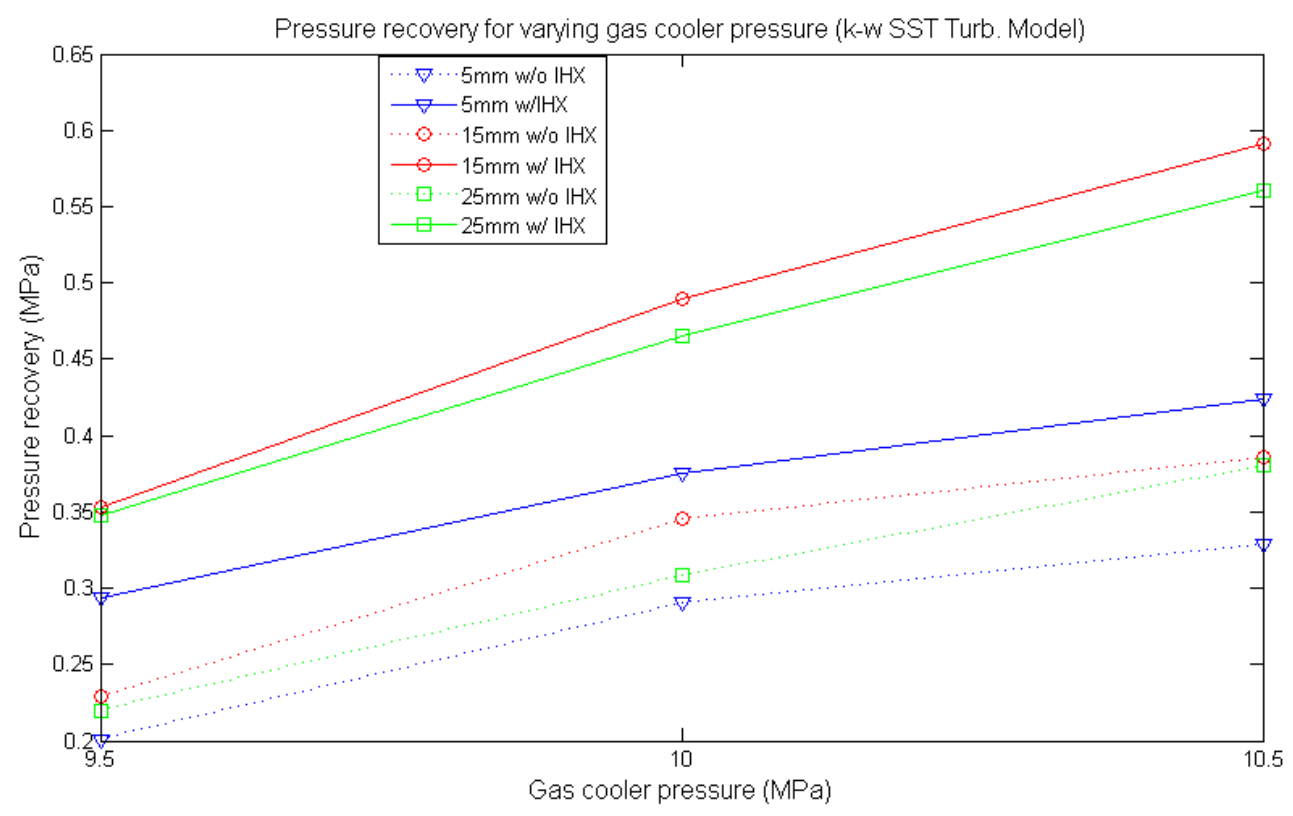

Figure 5.12. Using the k-omega SST turbulence model, CFD results of pressure recovery for different mixing section lengths at varying gas cooler pressure.

Tables $5.3-5.5$ show the difference in pressure recovery in the experimental work compared to the CFD results. Looking at each turbulence model, the average percent error for the 18 cases tested for each turbulence model ranged from $18 \%$ to $23 \%$ (18.6\% average error for standard k-epsilon; $18.8 \%$ for k-omega SST; $19.2 \%$ for RNG; $23.0 \%$ for realizable k-epsilon). It is interesting to note that in the experimental work of Nakagawa et al. [42], the pressure recovery in the ejector with the $5 \mathrm{~mm}$ mixing section length and the use of the IHX is less than the pressure recovery of the 15 and $25 \mathrm{~mm}$ mixing section ejectors that do not use the IHX. The realizable k-epsilon model is the only model out of the four that predicts this similar outcome, despite having the greatest average percent error to the experimental work. 
Table 5.3. Using the realizable k-epsilon turbulence model, pressure recovery difference between experimental and CFD results for varying gas cooler pressures of (a) $9.5 \mathrm{MPa}$,

(b) $10 \mathrm{MPa}$, and (c) $10.5 \mathrm{MPa}$.

\begin{tabular}{|c|c|c|c|c|c|}
\hline & \multicolumn{5}{|c|}{ Gas cooler pressure =9.5 MPa } \\
\hline Mixing section length (mm) & IHX? & Pressure increase (MPa) & & \\
\hline & & Nakagawa et al. & CFD & difference & $\%$ error \\
\hline 5 & no & 0.265 & 0.130 & 0.135 & 50.943 \\
\hline 5 & yes & 0.240 & 0.183 & 0.057 & 23.750 \\
\hline 15 & no & 0.375 & 0.228 & 0.147 & 39.200 \\
\hline 15 & yes & 0.397 & 0.345 & 0.052 & 13.098 \\
\hline 25 & no & 0.365 & 0.223 & 0.142 & 38.904 \\
\hline 25 & yes & 0.393 & 0.340 & 0.053 & 13.486 \\
\hline
\end{tabular}

\begin{tabular}{|c|c|c|c|c|c|}
\hline (b) & \multicolumn{5}{|c|}{ Gas cooler pressure = $10 \mathrm{MPa}$} \\
\hline Mixing section length (mm) & IHX? & Pressure increase (MPa) & & \\
\hline & & Nakagawa et al. & CFD & difference & \% error \\
\hline 5 & no & 0.291 & 0.179 & 0.112 & 38.488 \\
\hline 5 & yes & 0.256 & 0.240 & 0.016 & 6.250 \\
\hline 15 & no & 0.448 & 0.322 & 0.126 & 28.125 \\
\hline 15 & yes & 0.443 & 0.483 & -0.040 & -9.029 \\
\hline 25 & no & 0.432 & 0.306 & 0.126 & 29.167 \\
\hline 25 & yes & 0.454 & 0.450 & 0.004 & 0.881 \\
\hline
\end{tabular}

\begin{tabular}{|c|c|c|c|c|c|}
\hline (c) & \multicolumn{5}{|c|}{ Gas cooler pressure $=10.5 \mathrm{MPa}$} \\
\hline Mixing section length (mm) & IHX? & Pressure increase (MPa) & & \\
\hline & & Nakagawa et al. & CFD & difference & \% error \\
\hline 5 & no & 0.313 & 0.205 & 0.108 & 34.505 \\
\hline 5 & yes & 0.254 & 0.282 & -0.028 & -11.024 \\
\hline 15 & no & 0.496 & 0.378 & 0.118 & 23.790 \\
\hline 15 & yes & 0.487 & 0.580 & -0.093 & -19.097 \\
\hline 25 & no & 0.472 & 0.376 & 0.096 & 20.339 \\
\hline 25 & yes & 0.480 & 0.545 & -0.065 & -13.542 \\
\hline
\end{tabular}


Table 5.4. Using the RNG k-epsilon turbulence model, pressure recovery difference between experimental and CFD results for varying gas cooler pressures of (a) $9.5 \mathrm{MPa}$,

(b) $10 \mathrm{MPa}$, and (c) $10.5 \mathrm{MPa}$.

\begin{tabular}{|l|c|c|c|c|c|}
\hline & \multicolumn{5}{|c|}{ Gas cooler pressure =9.5 MPa } \\
\hline Mixing section length (mm) & IHX? & Pressure increase (MPa) & & \\
\hline & & Nakagawa et al. & CFD & difference & $\%$ error \\
\hline 5 & no & 0.265 & 0.169 & 0.096 & 36.226 \\
\hline 5 & yes & 0.240 & 0.221 & 0.019 & 7.917 \\
\hline 15 & no & 0.375 & 0.235 & 0.140 & 37.333 \\
\hline 15 & yes & 0.397 & 0.343 & 0.054 & 13.602 \\
\hline 25 & no & 0.365 & 0.245 & 0.120 & 32.877 \\
\hline 25 & yes & 0.393 & 0.340 & 0.053 & 13.486 \\
\hline
\end{tabular}

\begin{tabular}{|l|c|c|c|c|c|}
\hline (b) & \multicolumn{5}{|c|}{ Gas cooler pressure $10 \mathrm{MPa}$} \\
\hline Mixing section length (mm) & IHX? & Pressure increase (MPa) & & \\
\hline & & Nakagawa et al. & CFD & difference & $\%$ error \\
\hline 5 & no & 0.291 & 0.224 & 0.067 & 23.024 \\
\hline 5 & yes & 0.256 & 0.274 & -0.018 & -7.031 \\
\hline 15 & no & 0.448 & 0.321 & 0.127 & 28.348 \\
\hline 15 & yes & 0.443 & 0.473 & -0.030 & -6.772 \\
\hline 25 & no & 0.432 & 0.322 & 0.110 & 25.463 \\
\hline 25 & yes & 0.454 & 0.445 & 0.009 & 1.982 \\
\hline
\end{tabular}

\begin{tabular}{|l|c|c|c|c|c|}
\hline (c) & \multicolumn{5}{|c|}{ Gas cooler pressure $=10.5 \mathrm{MPa}$} \\
\hline Mixing section length (mm) & IHX? & \multicolumn{2}{|c|}{ Pressure increase (MPa) } & & \\
\hline & & Nakagawa et al. & CFD & difference & $\%$ error \\
\hline 5 & no & 0.313 & 0.252 & 0.061 & 19.489 \\
\hline 5 & yes & 0.254 & 0.308 & -0.054 & -21.260 \\
\hline 15 & no & 0.496 & 0.376 & 0.120 & 24.194 \\
\hline 15 & yes & 0.487 & 0.567 & -0.080 & -16.427 \\
\hline 25 & no & 0.472 & 0.381 & 0.091 & 19.280 \\
\hline 25 & yes & 0.480 & 0.535 & -0.055 & -11.458 \\
\hline
\end{tabular}


Table 5.5. Using the k-omega SST turbulence model, pressure recovery difference between experimental and CFD results for varying gas cooler pressures of (a) $9.5 \mathrm{MPa}$,

(b) $10 \mathrm{MPa}$, and (c) $10.5 \mathrm{MPa}$.

\begin{tabular}{|l|c|c|c|c|c|}
\hline & \multicolumn{5}{|c|}{ Gas cooler pressure = 9.5 MPa } \\
\hline Mixing section length (mm) & IHX? & Pressure increase (MPa) & & \\
\hline & & Nakagawa et al. & CFD & difference & $\%$ error \\
\hline 5 & no & 0.265 & 0.231 & 0.034 & 12.830 \\
\hline 5 & yes & 0.240 & 0.281 & -0.041 & -17.083 \\
\hline 15 & no & 0.375 & 0.261 & 0.114 & 30.400 \\
\hline 15 & yes & 0.397 & 0.345 & 0.052 & 13.098 \\
\hline 25 & no & 0.365 & 0.222 & 0.143 & 39.178 \\
\hline 25 & yes & 0.393 & 0.358 & 0.035 & 8.906 \\
\hline
\end{tabular}

\begin{tabular}{|l|c|c|c|c|c|}
\hline (b) & \multicolumn{5}{|c|}{ Gas cooler pressure $=10 \mathrm{MPa}$} \\
\hline Mixing section length (mm) & IHX? & Pressure increase (MPa) & & \\
\hline & & Nakagawa et al. & CFD & difference & $\%$ error \\
\hline 5 & no & 0.291 & 0.305 & -0.014 & -4.811 \\
\hline 5 & yes & 0.256 & 0.351 & -0.095 & -37.109 \\
\hline 15 & no & 0.448 & 0.351 & 0.097 & 21.652 \\
\hline 15 & yes & 0.443 & 0.464 & -0.021 & -4.740 \\
\hline 25 & no & 0.432 & 0.321 & 0.111 & 25.694 \\
\hline 25 & yes & 0.454 & 0.465 & -0.011 & -2.423 \\
\hline
\end{tabular}

\begin{tabular}{|l|c|c|c|c|c|}
\hline (c) & \multicolumn{5}{|c|}{ Gas cooler pressure $=10.5 \mathrm{MPa}$} \\
\hline Mixing section length (mm) & IHX? & \multicolumn{2}{|c|}{ Pressure increase (MPa) } & & \\
\hline & & Nakagawa et al. & CFD & difference & \% error \\
\hline 5 & no & 0.313 & 0.321 & -0.008 & -2.556 \\
\hline 5 & yes & 0.254 & 0.390 & -0.136 & -53.543 \\
\hline 15 & no & 0.496 & 0.391 & 0.105 & 21.169 \\
\hline 15 & yes & 0.487 & 0.553 & -0.066 & -13.552 \\
\hline 25 & no & 0.472 & 0.397 & 0.075 & 15.890 \\
\hline 25 & yes & 0.480 & 0.547 & -0.067 & -13.958 \\
\hline
\end{tabular}


An appendix is included that shows the pressure profile through the ejector for all the cases with each of the turbulence models and also the experimental results. For each of the cases, the minimum pressure occurs shortly after the beginning of the mixing section. This is where the suction stream reaches the recirculation zone. In each individual case, the recirculation area occurs closer to the beginning of the mixing section with the k-omega SST model; the recirculation area is furthest downstream with the realizable k-epsilon turbulence model. In general for each case, the CFD simulations predict a higher rate of pressure recovery in the early section of the ejector than the experimental results. In the first $10-15 \mathrm{~mm}$ of the ejector, the highest rate of pressure recovery is seen with the k-omega SST model, and the lowest rate of pressure recovery is seen with the realizable k-epsilon model. This is true for all cases. 


\section{CHAPTER 6}

\section{CONCLUSIONS}

The goal of this project was to use CFD to model fluid flow inside a two-phase ejector. One application for the ejector is to be put in a refrigeration cycle. A pressure rise is expected to occur in the nozzle, which will require less work from the compressor, thus resulting in a more efficient cycle. CFD is used to model the flow inside the ejector because many different operating conditions and geometries can be tested at a minimal cost. From the results shown in Chapters 4 and 5, some remarks can be made on the effectiveness of the HRM- $-\sum$-Y model.

The relaxation model is designed to bring the mixture towards equilibrium over a period of time. The value of this model is most significant when the enthalpy difference between the motive and suction streams is great. Adjusting the constants that determine the timescale does not have an effect on the pressure recovery, the key reason of using an ejector in a refrigeration cycle, but it has the ability to adequately show the nonthermodynamic equilibrium state of the fluid. Using the model constants from DownarZapolski et al. [49] may not be accurate for the cases with $\mathrm{CO}_{2}$ as the refrigerant (since water was used to determine the constants in Downar-Zapolski et al.), but it provides a preliminary start for future work that can look at how adjusting the relaxation model constants can affect how close the fluid is to thermodynamic equilibrium.

Carbon dioxide is a much better choice for a refrigerant than water. $\mathrm{CO}_{2}$ has become a more widely used refrigerant in recent experimental work. In the CFD results, cases with carbon dioxide led to more numerically stable simulations; the cases with water as the working fluid were not stable enough to include a compressibility term in the 
model. Because of this, and that the density gradient where the two streams meet near the splitter was lower for cases with $\mathrm{CO}_{2}$ as the working fluid, the CFD results were better when using $\mathrm{CO}_{2}$. A minor drawback of using $\mathrm{CO}_{2}$ is that the relaxation model constants are potentially mis-matched to the fluid.

The $\sum$-Y model has a dominant effect on the mixing of the streams and the overall pressure recovery in the nozzle. It controls almost all of the interaction between the motive and suction streams in the mixing section. Because interphase mixing is largely governed by the $\sum-Y$ model, improvements in this area would be particularly beneficial. The diffusion term used in the cases in the current work is based on Fick's law of mass diffusion; different diffusion models could be considered, such as a model used by Demoulin et al. [61] that accounts for large density fluctuations.

Turbulent viscosity is greatest in the mixing section. Because most of the mixing occurs in this section, the choice of RANS turbulence model has an important effect on pressure recovery since the pressure at the outlet is already specified and the inlet pressures are being predicted. None of the models chosen were significantly better than the rest. This is a reasonable outcome because the four models chosen are not greatly different from one another (as compared to other forms of turbulence models available). A more detailed turbulence study looking at different turbulence models, such as LES models and other RANS models, could be examined in the future.

The boundary conditions have a significant effect on the modeling of the ejector flow. In Chapter 4, the density at the inlets was set to a fixed value. This considered the fluid at each of the inlets to not be in thermodynamic equilibrium. This was modified in Chapter 5, where the density at the inlets was based on the enthalpy and the pressure 
solved in the previous time step. For these cases, the fluid at the motive and suction inlets are considered to be in thermodynamic equilibrium. This is a reasonable assumption since the difference between the instantaneous and equilibrium mass fraction of vapor is small in the sections of the motive and suction nozzle that are modeled in the CFD cases. Even though the difference is not great, the density and velocity of the motive nozzle flow have a significant effect on the pressure rise, so a change in the boundary conditions at the motive inlet can make a difference in the pressure recovery in the nozzle. Future investigation of how best to specify boundary conditions could be warranted.

The attempt to validate the HRM- $-\sum$-Y model to the experimental work of Nakagawa et al. [42] was a partial success. The error in pressure recovery was slightly higher than desired, but the CFD cases were tested against a variety of nozzle geometries and operating conditions. Similar trends were seen in the CFD results and the experimental work of Nakagawa et al. [42], so only minor adjustments to the HRM- $-\sum$ Y model may be necessary. Some of the ways to lower the CFD error have been mentioned earlier in this chapter, such as modifying the diffusion model in the $\sum$-Y code, changing the turbulence model, or modifying the boundary conditions. At this time, the code is not robust enough to accurately model a general set of operating conditions and nozzle geometries. 


\section{APPENDIX}

PRESSURE PROFILE FOR ALL CFD VALIDATION CASES

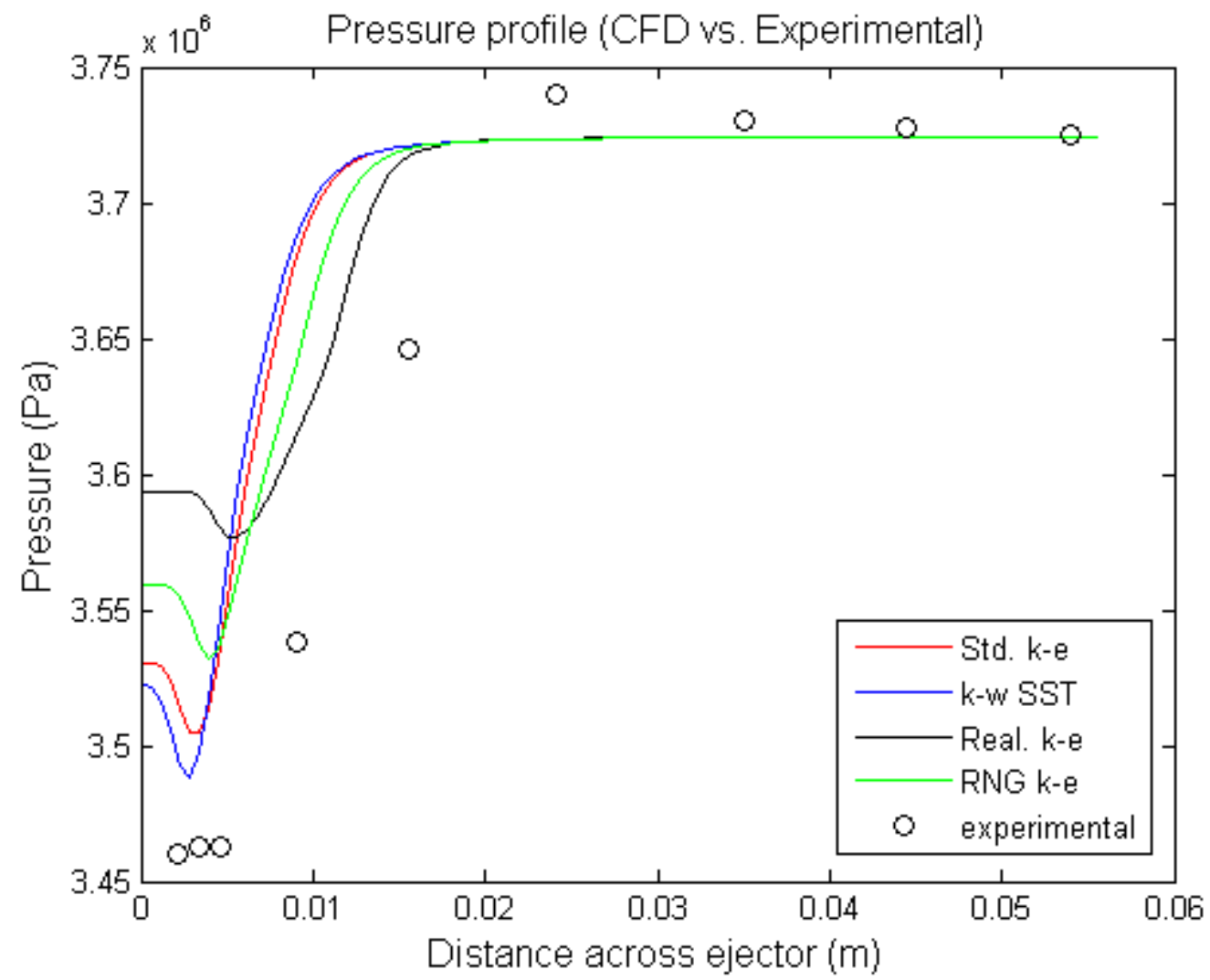

Figure A.1. Pressure through the ejector, comparing four turbulence models against experimental data. $5 \mathrm{~mm}$ mixing section length case without the IHX. Gas cooler pressure $=9.5 \mathrm{MPa}$. 


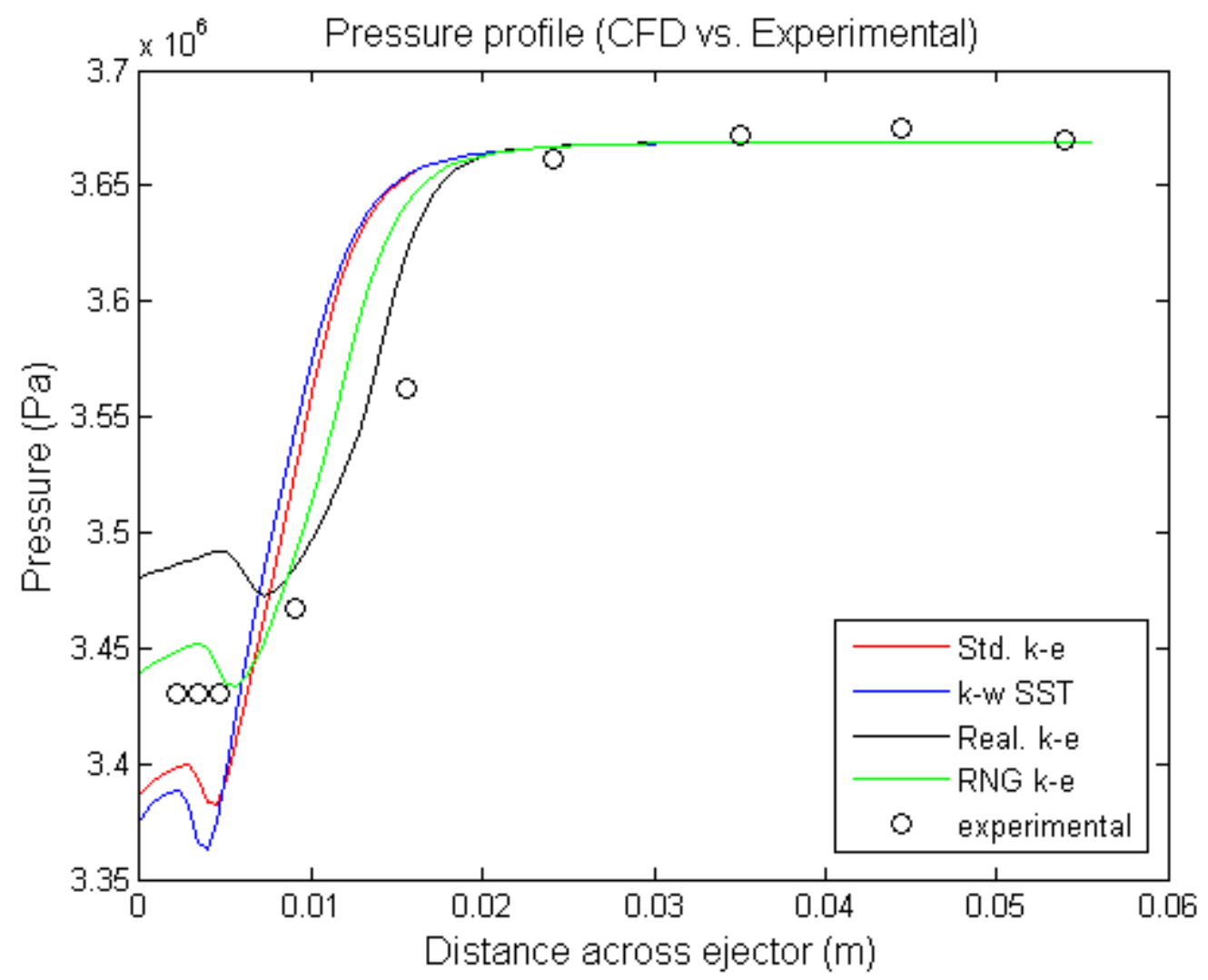

Figure A.2. Pressure profile for $5 \mathrm{~mm}$ mixing section length case with the IHX. Gas cooler pressure $=9.5 \mathrm{MPa}$. 


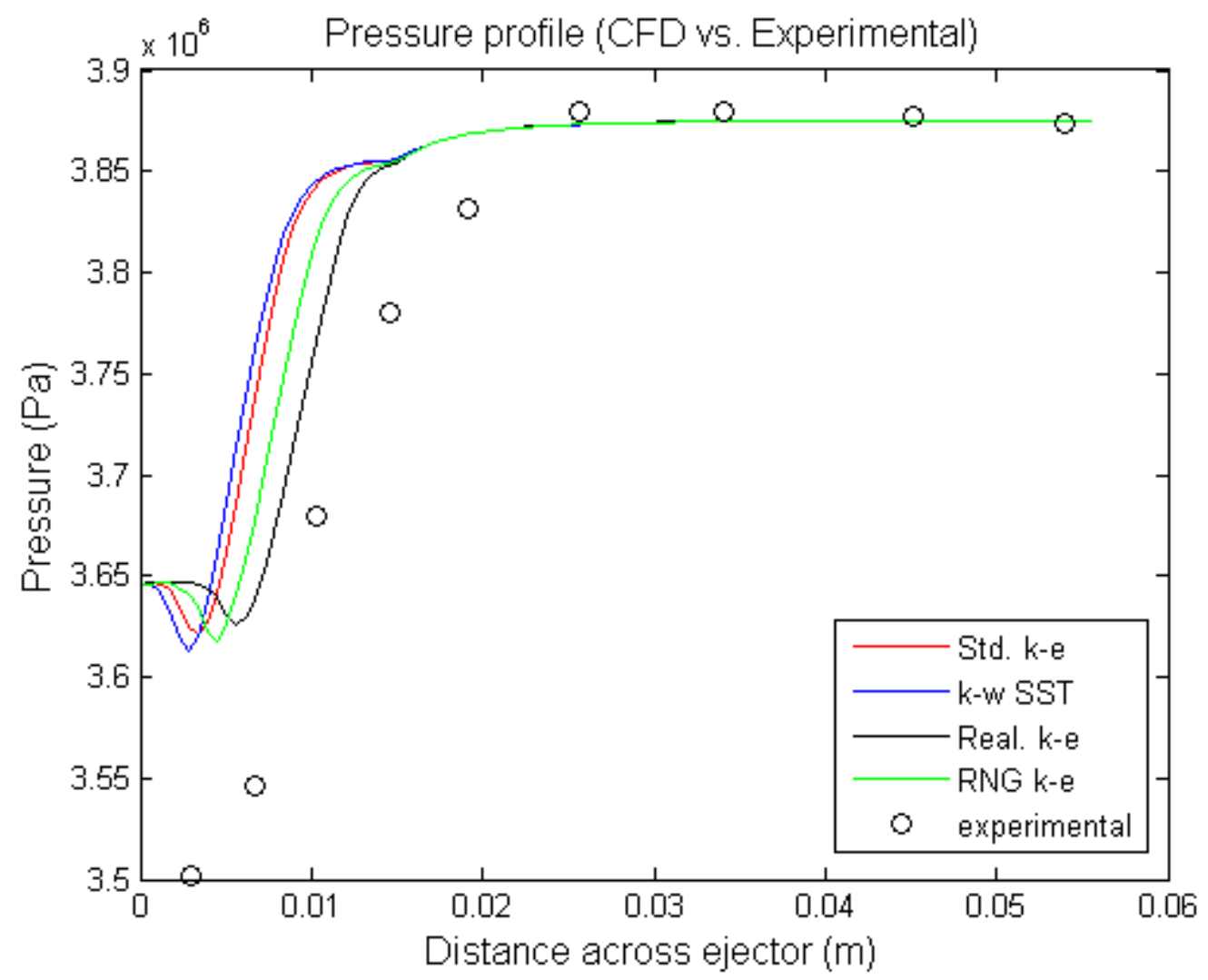

Figure A.3. Pressure profile for $15 \mathrm{~mm}$ mixing section length case without the IHX. Gas cooler pressure $=9.5 \mathrm{MPa}$. 


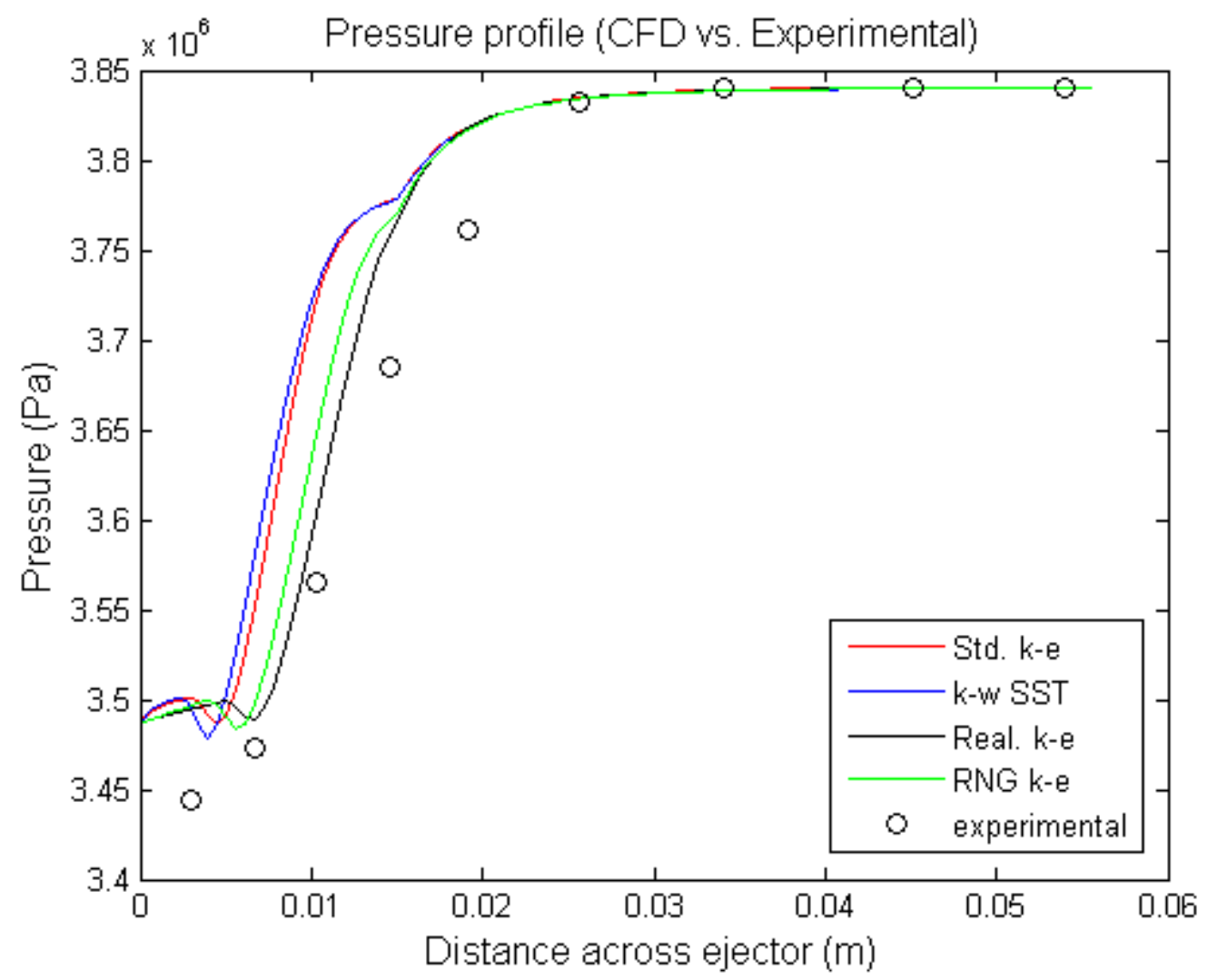

Figure A.4. Pressure profile for $15 \mathrm{~mm}$ mixing section length case with the IHX. Gas cooler pressure $=9.5 \mathrm{MPa}$. 


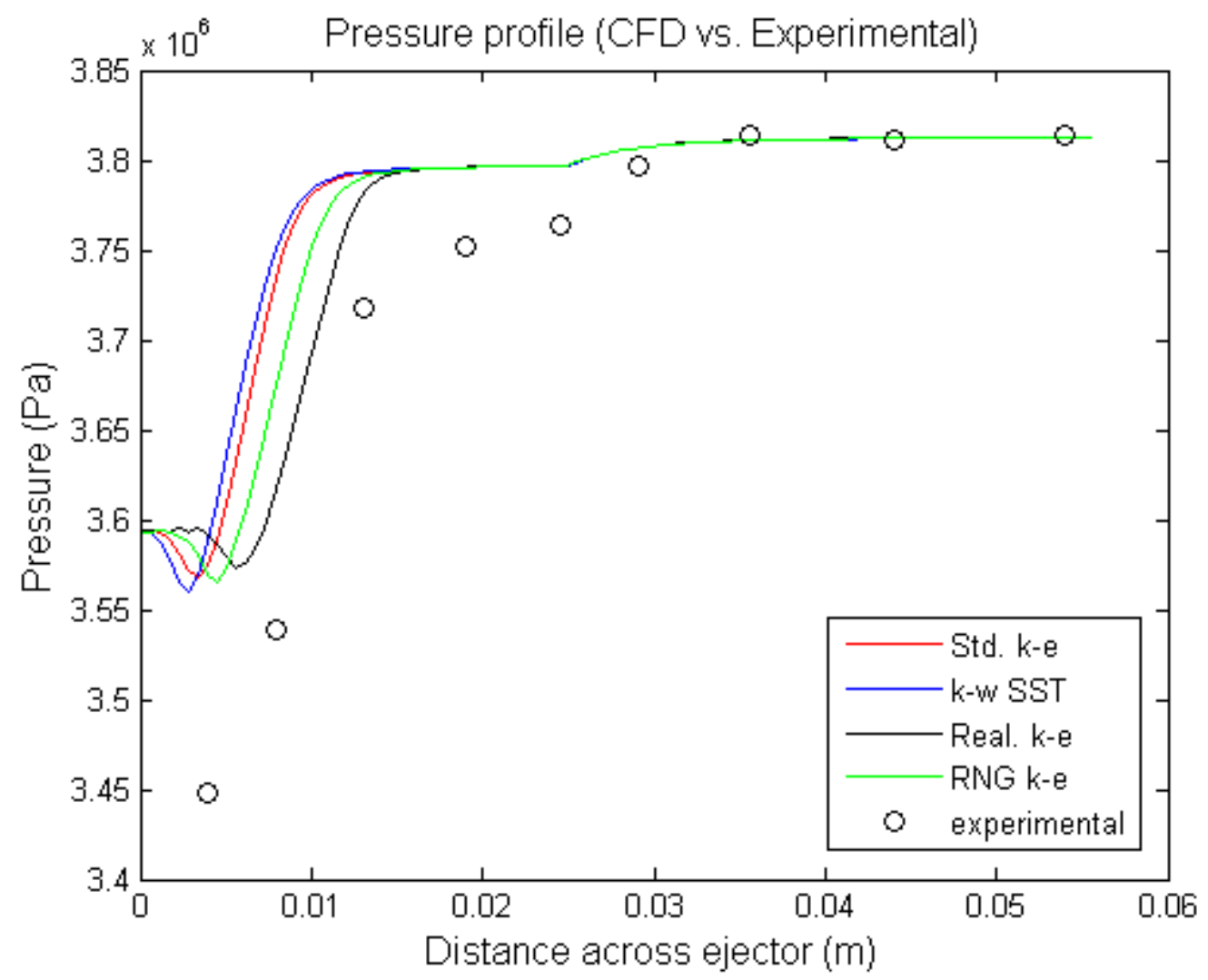

Figure A.5. Pressure profile for $25 \mathrm{~mm}$ mixing section length case without the IHX. Gas cooler pressure $=9.5 \mathrm{MPa}$. 


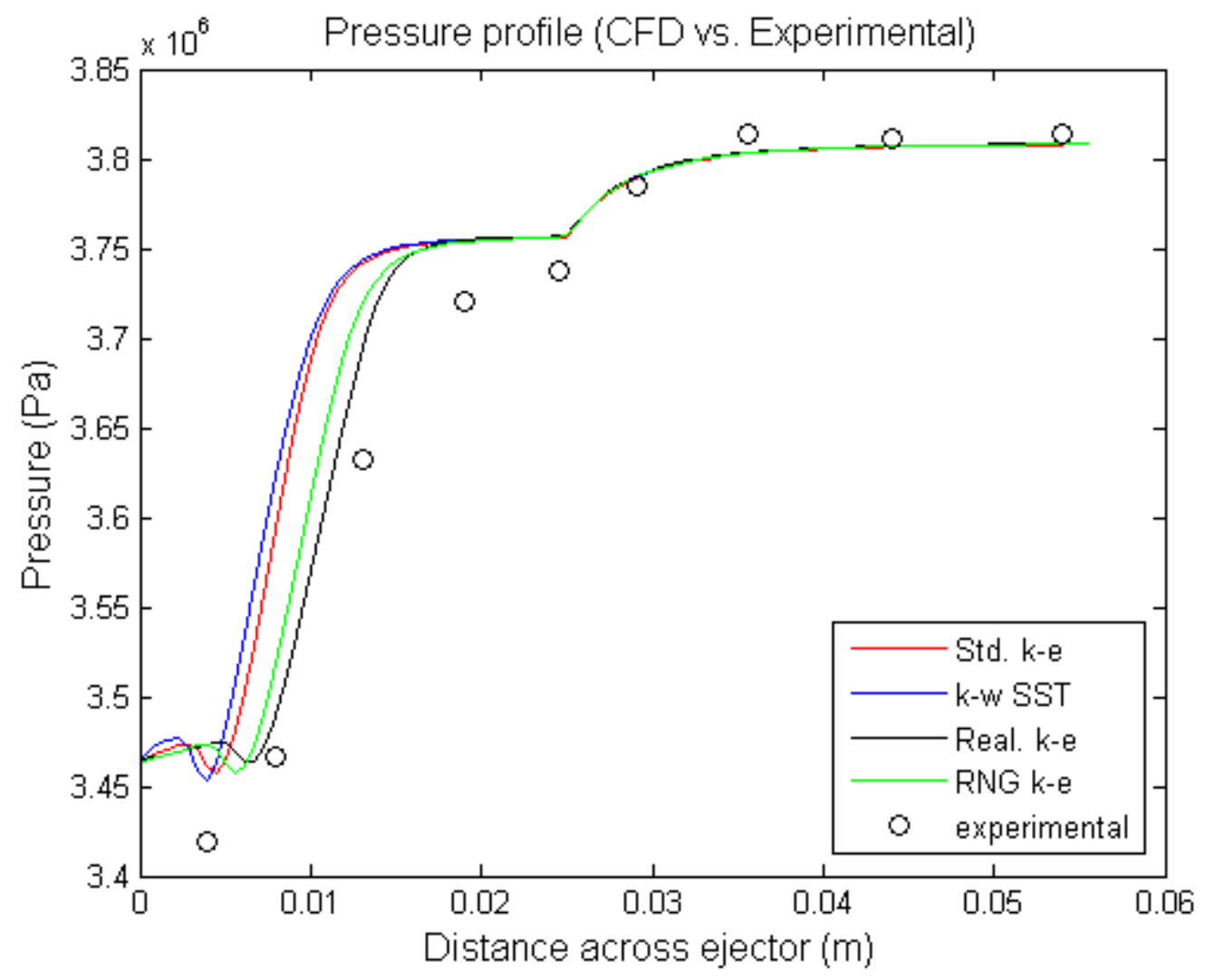

Figure A.6. Pressure profile for $25 \mathrm{~mm}$ mixing section length case with the IHX. Gas cooler pressure $=9.5 \mathrm{MPa}$. 


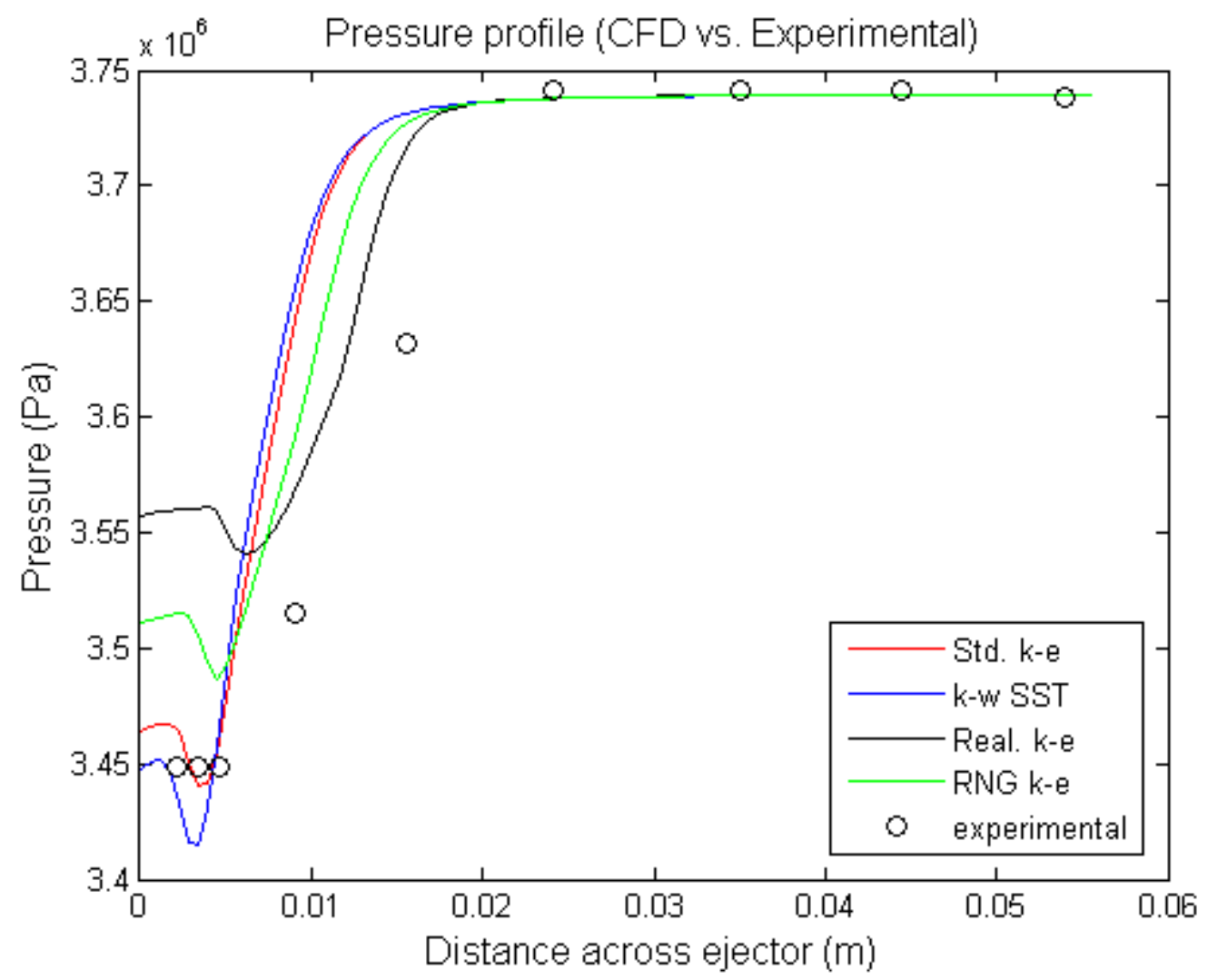

Figure A.7. Pressure profile for $5 \mathrm{~mm}$ mixing section length case without the IHX. Gas cooler pressure $=10 \mathrm{MPa}$. 


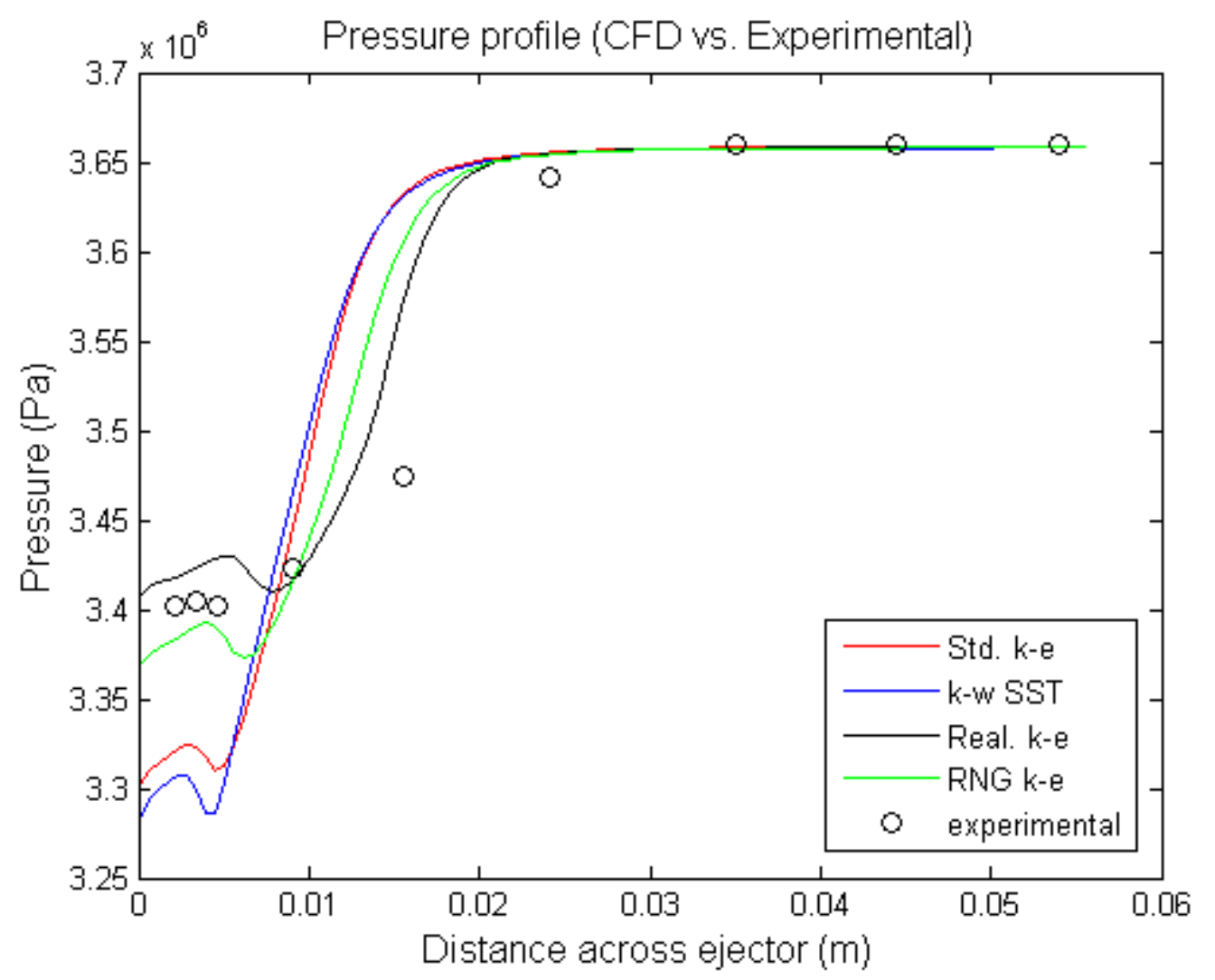

Figure A.8. Pressure profile for $5 \mathrm{~mm}$ mixing section length case with the IHX. Gas cooler pressure $=10 \mathrm{MPa}$. 


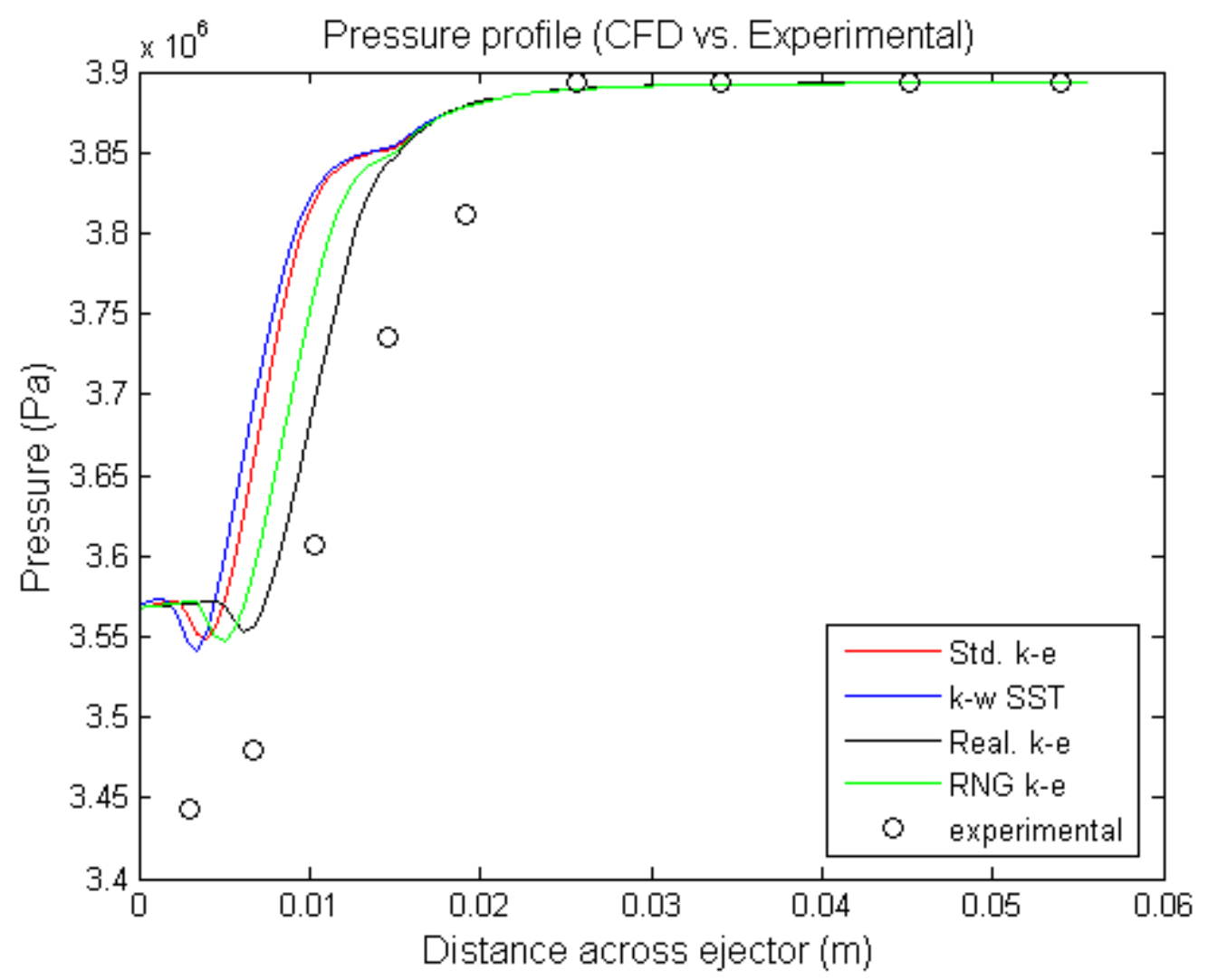

Figure A.9. Pressure profile for $15 \mathrm{~mm}$ mixing section length case without the IHX. Gas cooler pressure $=10 \mathrm{MPa}$. 


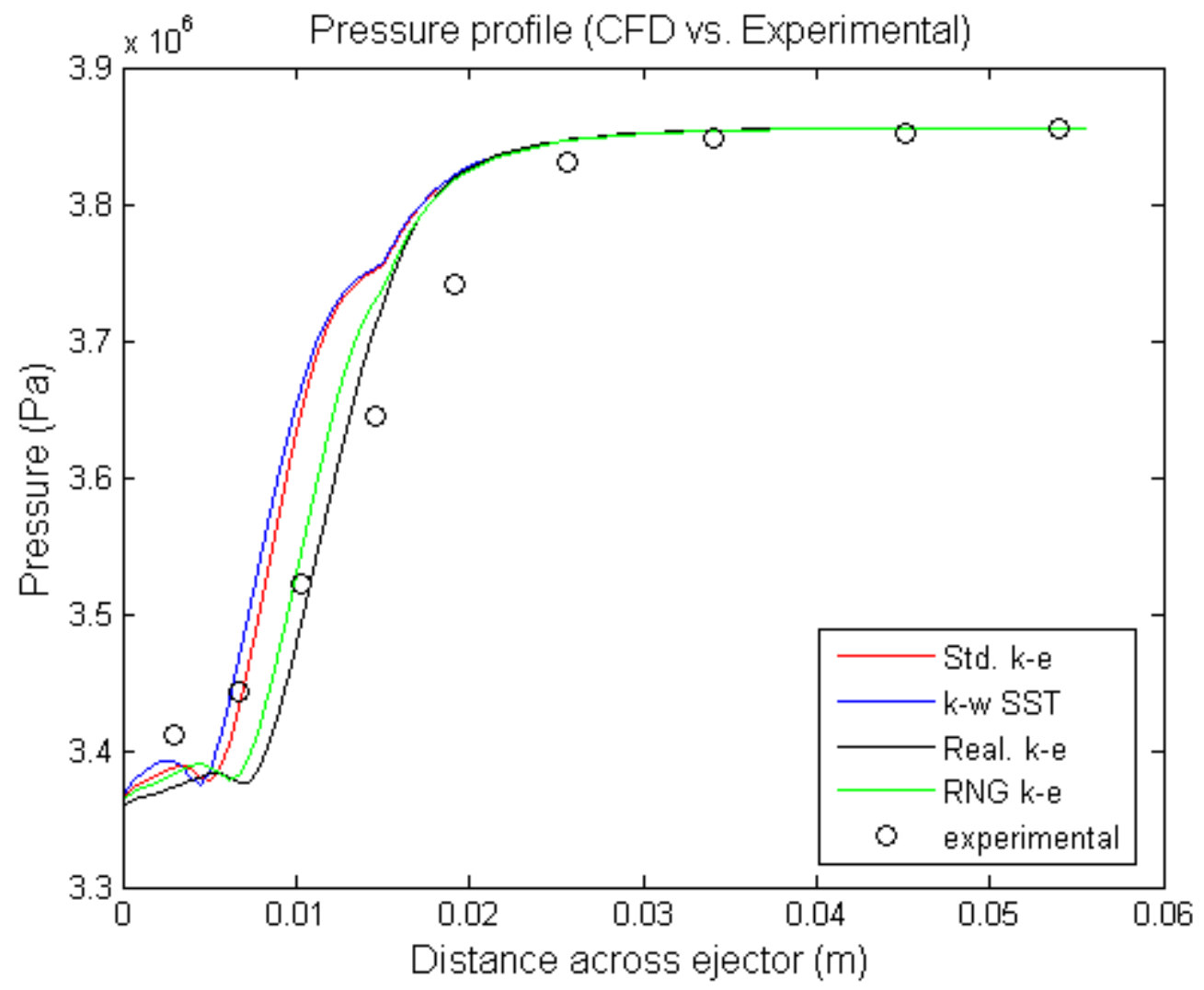

Figure A.10. Pressure profile for $15 \mathrm{~mm}$ mixing section length case with the IHX. Gas cooler pressure $=10 \mathrm{MPa}$. 


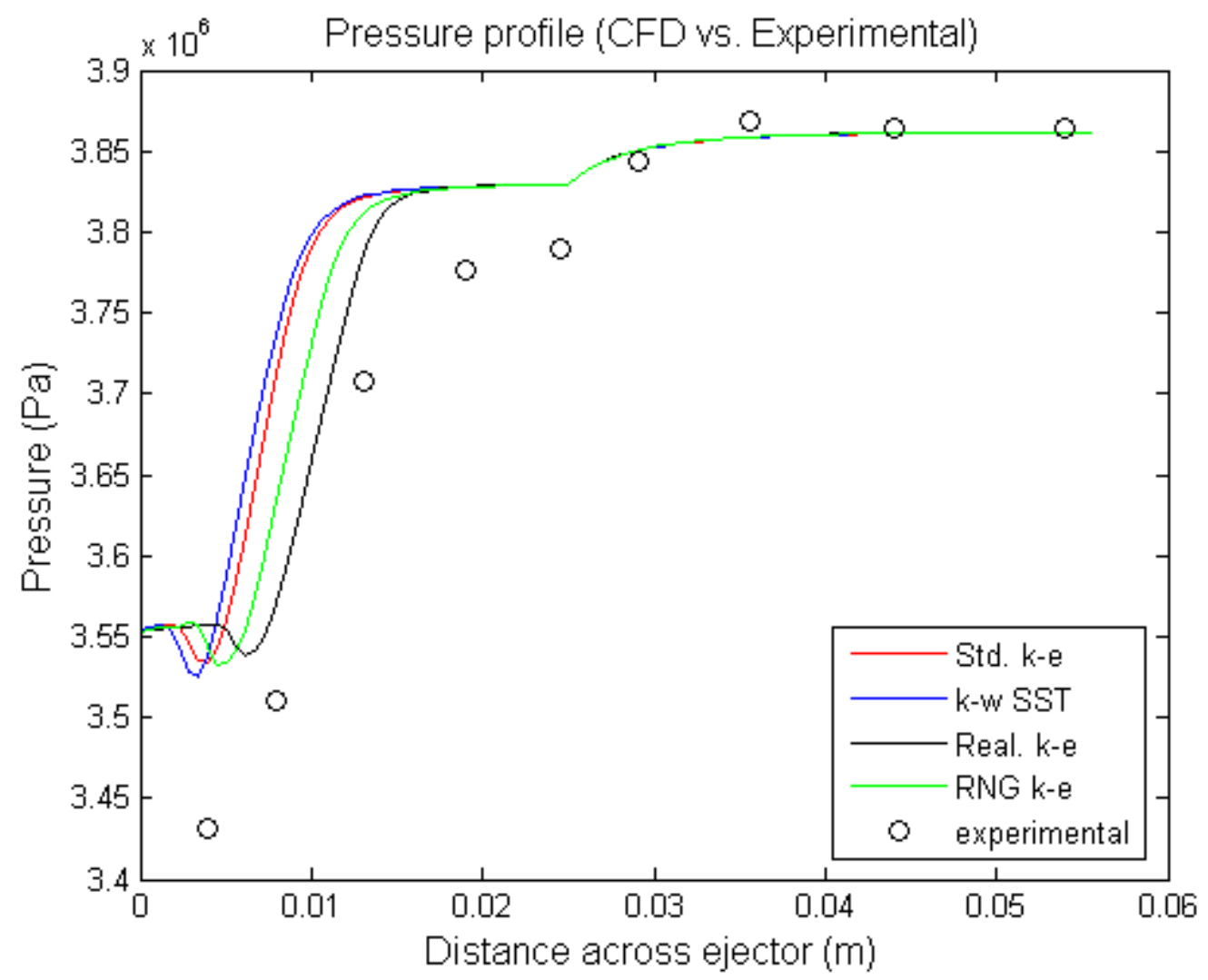

Figure A.11. Pressure profile for $25 \mathrm{~mm}$ mixing section length case without the IHX. Gas cooler pressure $=10 \mathrm{MPa}$. 


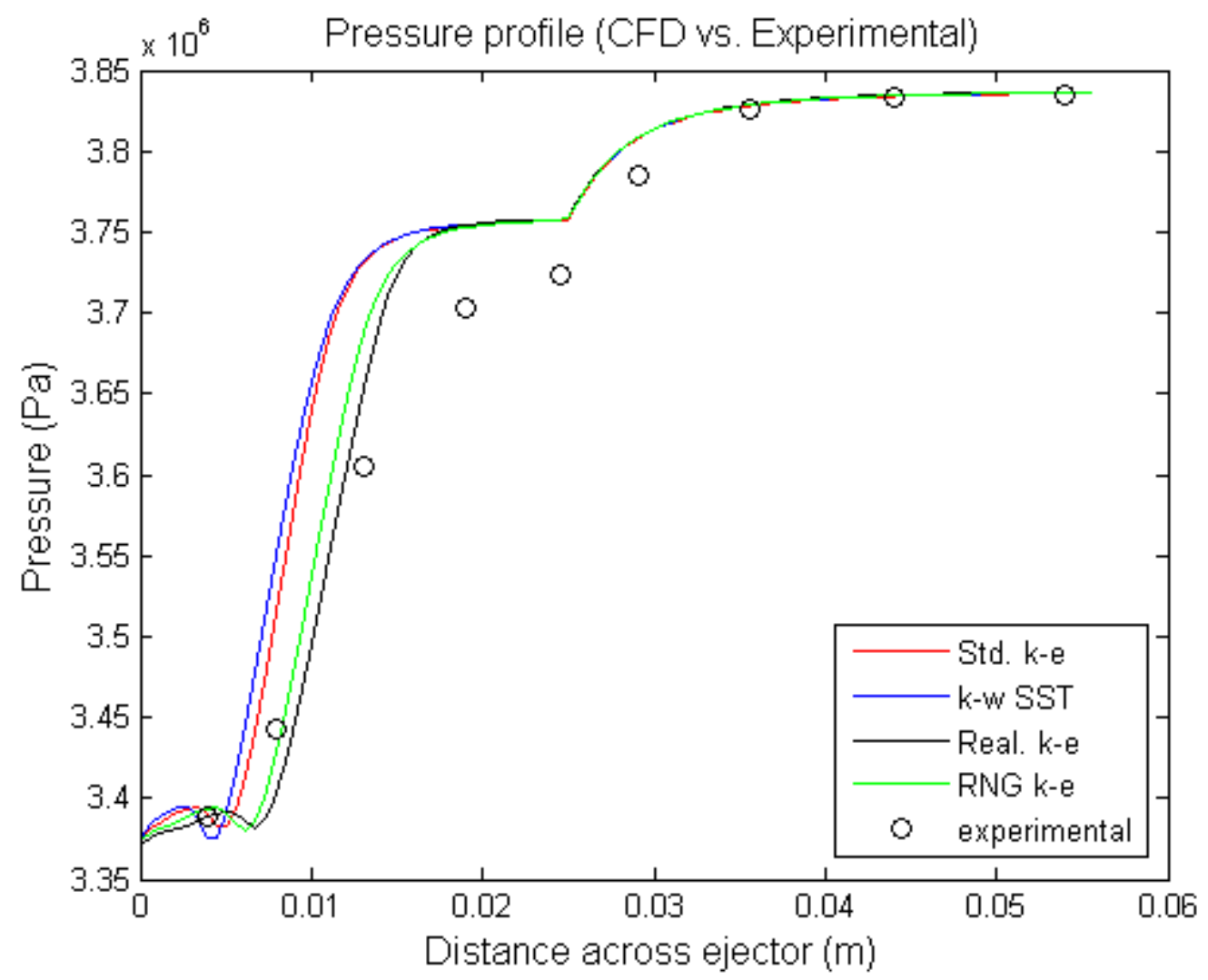

Figure A.12. Pressure profile for $25 \mathrm{~mm}$ mixing section length case with the IHX. Gas cooler pressure $=10 \mathrm{MPa}$. 


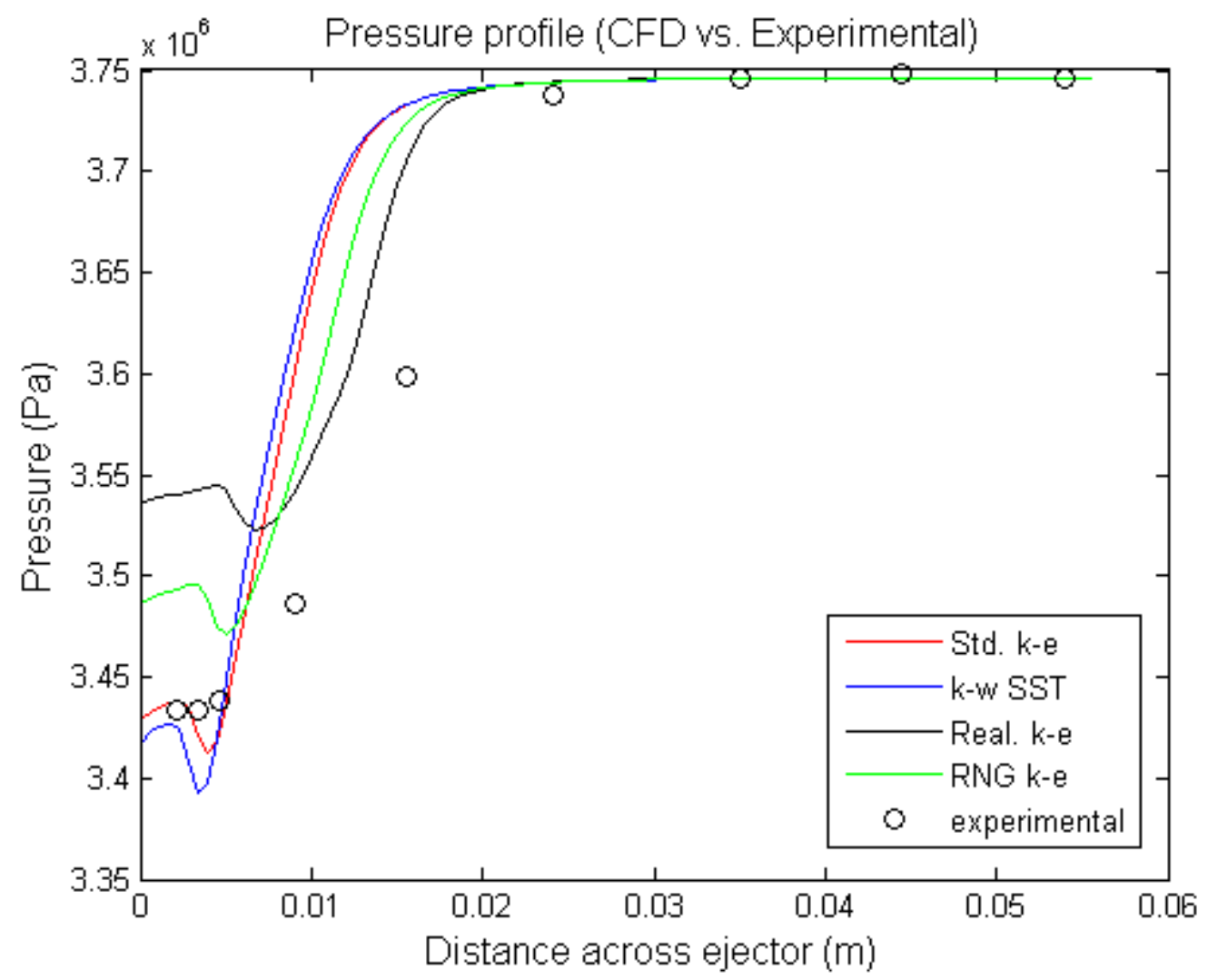

Figure A.13. Pressure profile for $5 \mathrm{~mm}$ mixing section length case without the IHX. Gas cooler pressure $=10.5 \mathrm{MPa}$. 


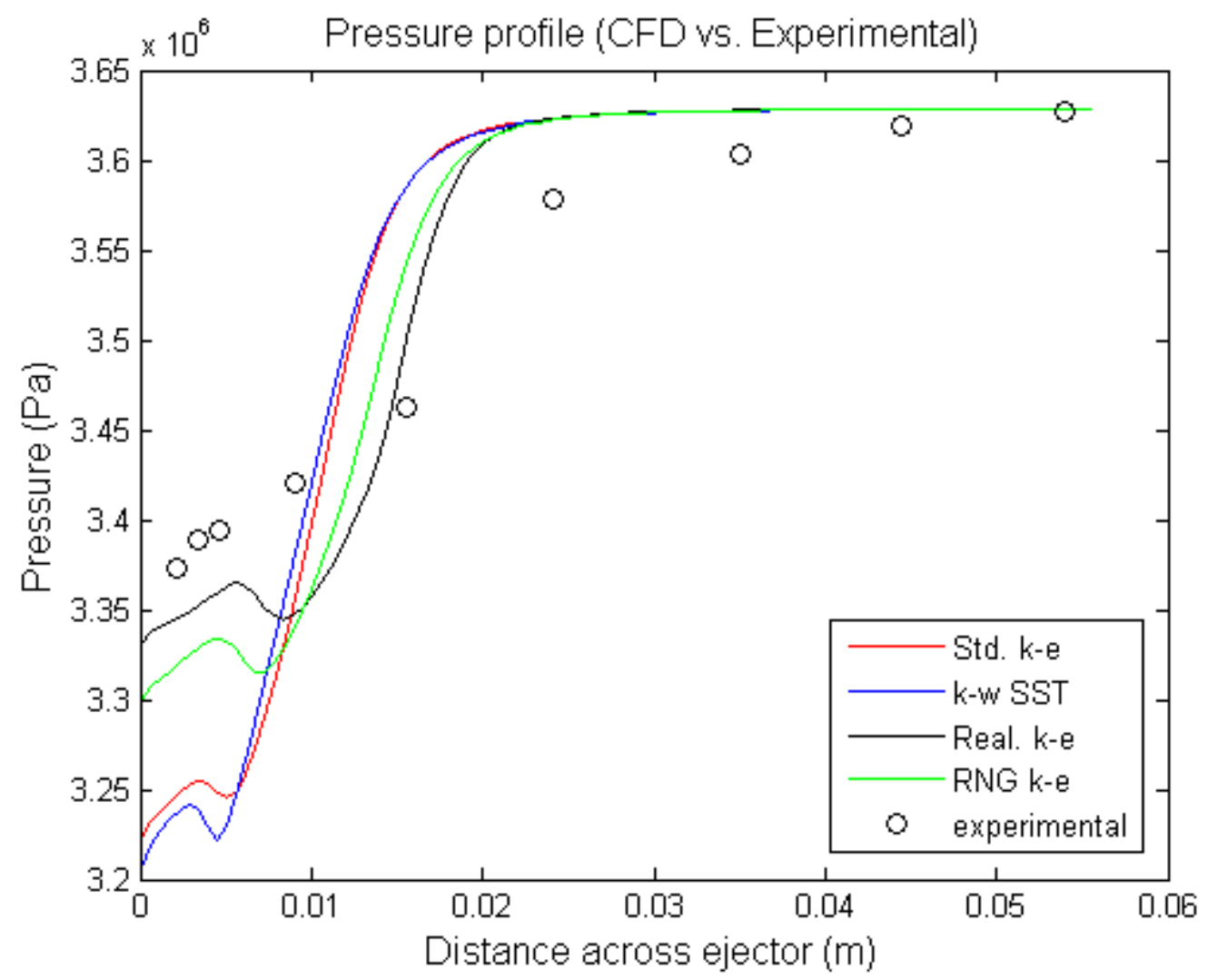

Figure A.14. Pressure profile for $5 \mathrm{~mm}$ mixing section length case with the IHX. Gas cooler pressure $=10.5 \mathrm{MPa}$. 


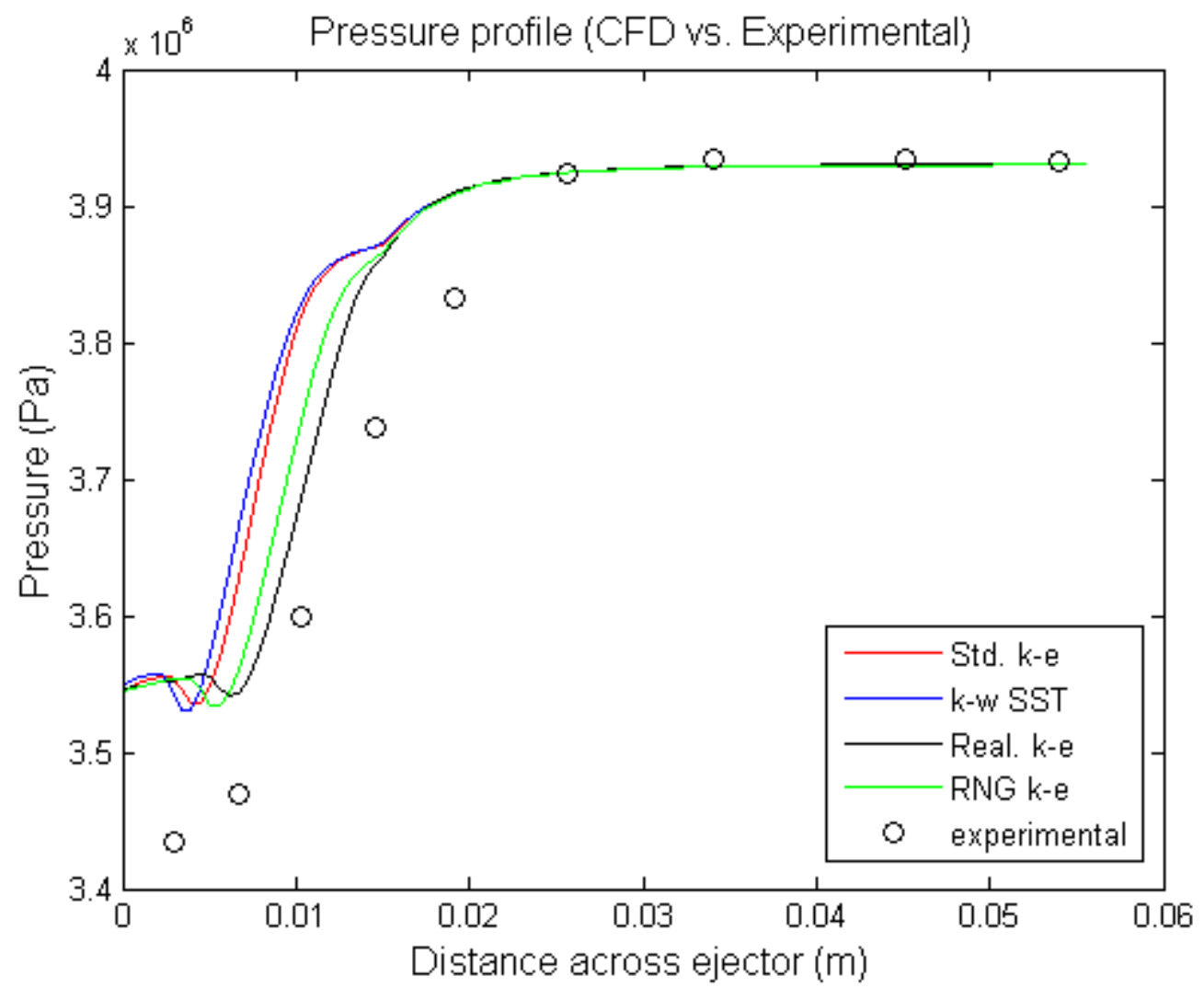

Figure A.15. Pressure profile for $15 \mathrm{~mm}$ mixing section length case without the IHX. Gas cooler pressure $=10.5 \mathrm{MPa}$. 


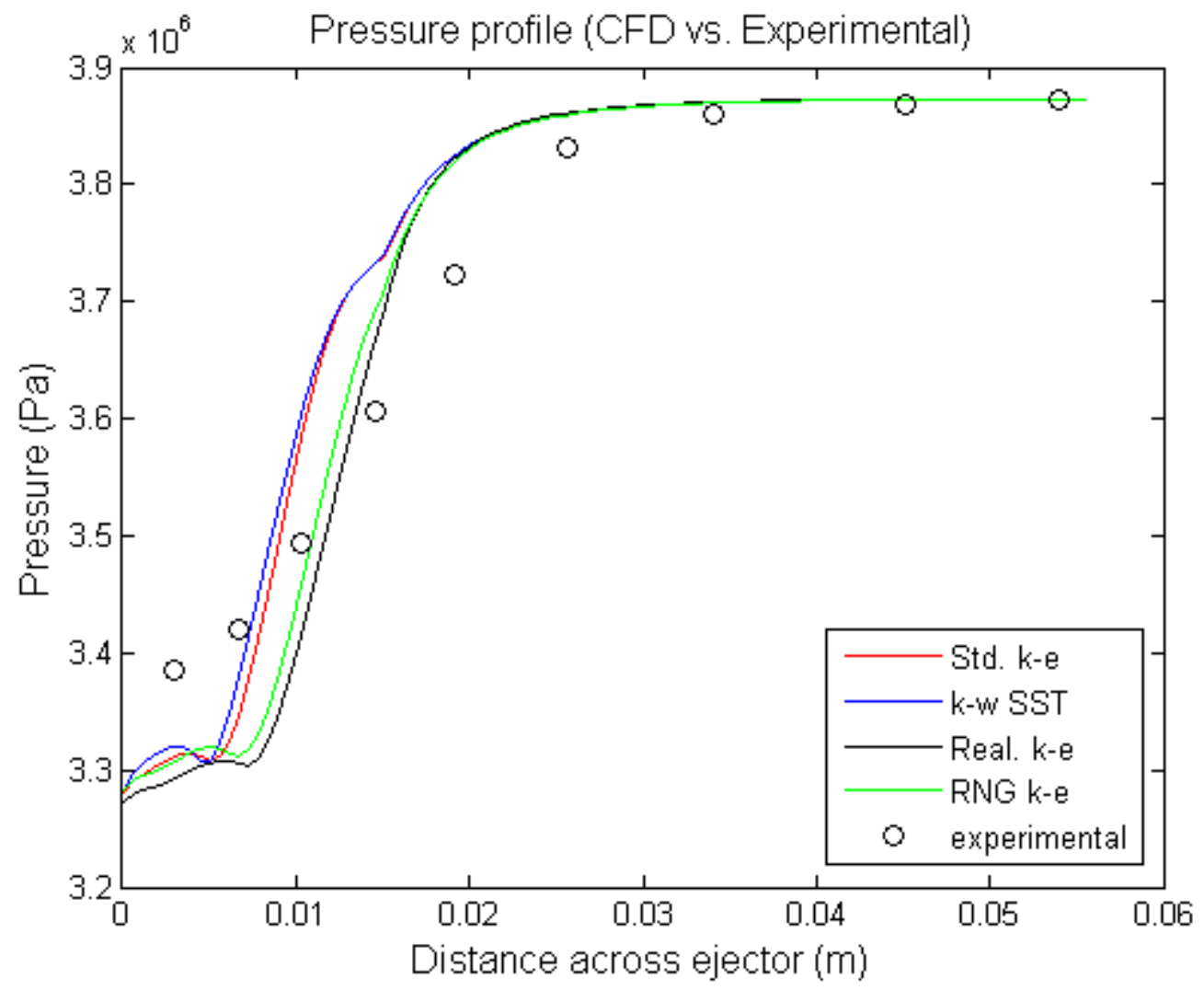

Figure A.16. Pressure profile for $15 \mathrm{~mm}$ mixing section length case with the IHX. Gas cooler pressure $=10.5 \mathrm{MPa}$. 


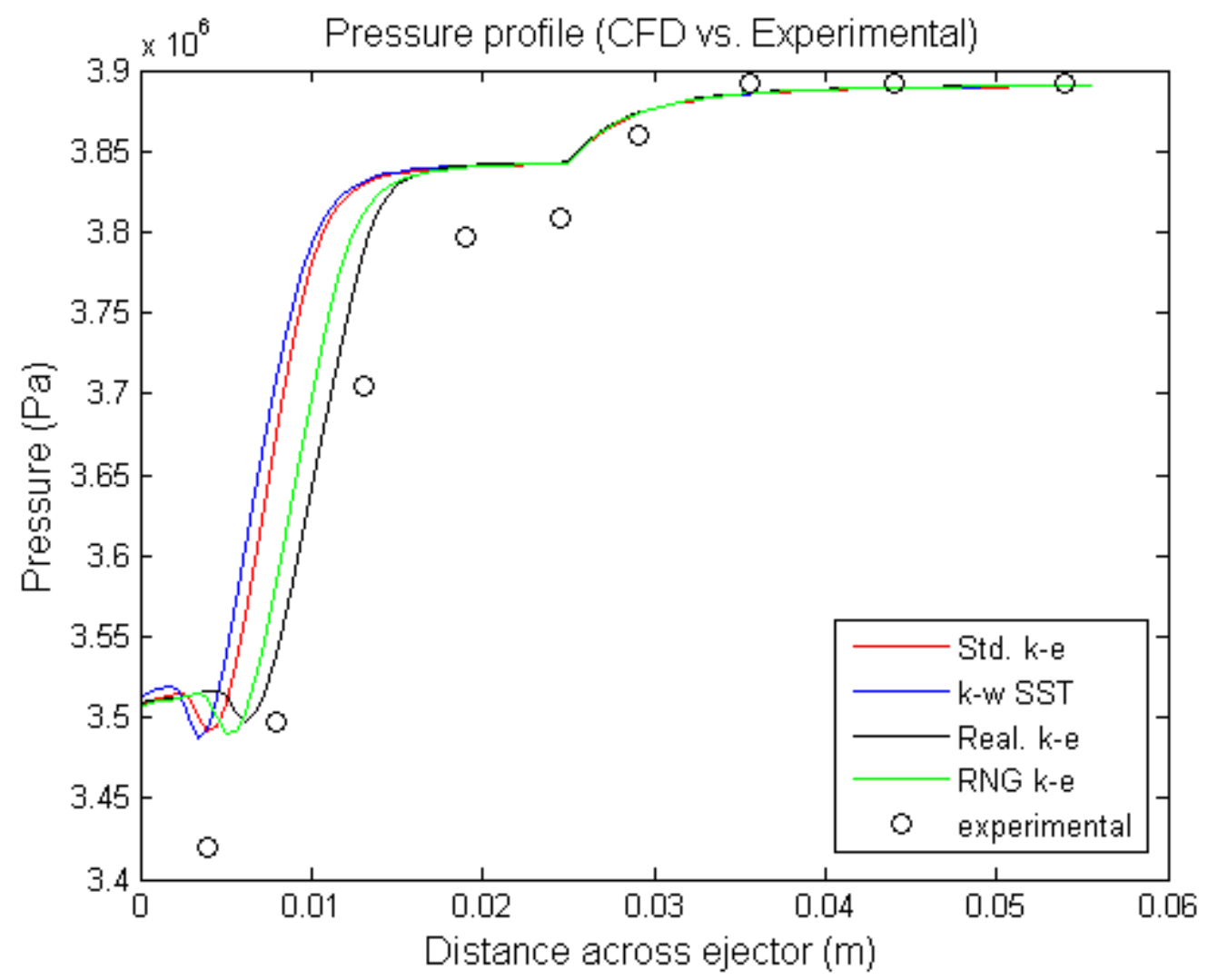

Figure A.17. Pressure profile for $25 \mathrm{~mm}$ mixing section length case without the IHX. Gas cooler pressure $=10.5 \mathrm{MPa}$. 


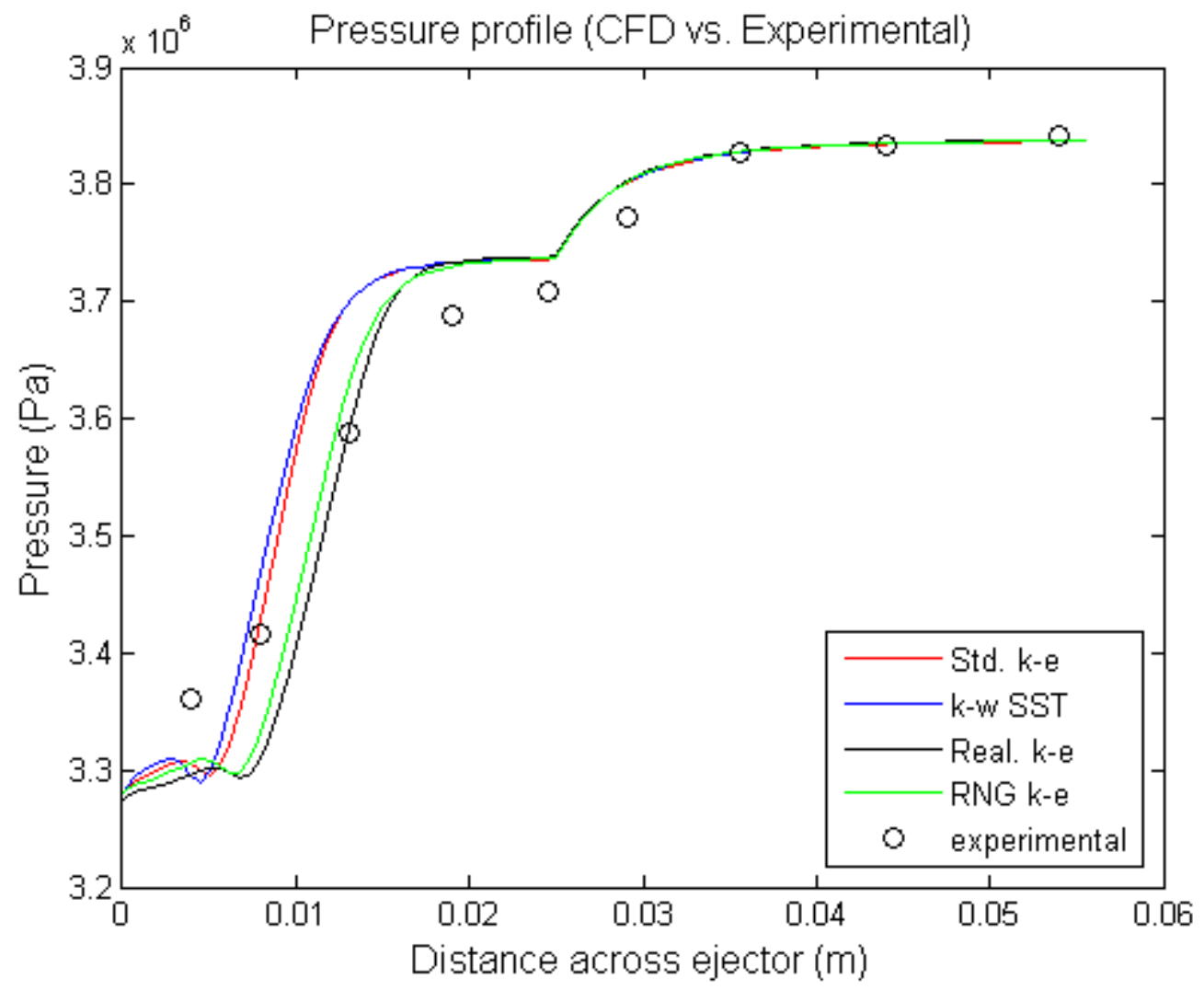

Figure A.18. Pressure profile for $25 \mathrm{~mm}$ mixing section length case with the IHX. Gas cooler pressure $=10.5 \mathrm{MPa}$. 


\section{REFERENCES}

1. Miguel J., Brown G.A.: An Analytical and Experimental Investigation of a Condensing Ejector with a Condensable Vapor, $1^{\text {st }}$ AIAA Annual Meeting, (1964), No. 64, 469.

2. Levy E.K.: Investigations of Liquid-Vapor Interactions in a Constant Area Condensing Ejector, Ph. D. Dissertation, Massachusetts Institute of Technology, (1967).

3. Bergander M.J.: Refrigeration Cycle with Two-Phase Condensing Ejector, International Refrigeration and Air Conditioning Conference at Purdue, 2006.

4. Menegay P., Kornhauser A.A.: Development of a Semi-Parabolic Two-Fluid Model for Two-Phase Ejectors, IECEC, 68(1995), 7-12.

5. Gay, N.H.: Refrigerating System, U.S. Patent No. 1,836,318, (1931).

6. Puzyrewski R., Gardzilewicz A., Baginska M.: Shock Waves in Condensing Steam Flowing Through a Laval Nozzle, Archives of Mechanics, 25(1973), No. 3, 393-409.

7. Hill P.: Condensation of Water Vapour During Supersonic Expansion in Nozzles, Journal Fluid Mechanics, 25(1966), No. 3, 593-620.

8. Menegay P.: A Computational Model for Two-Phase Ejector Flow, Ph. D. Dissertation, Virginia Polytechnic Institute and State University, (1997).

9. Bartosiewicz Y., Aidoun Z., Mercadier Y.: Numerical Assessment of Ejector Operation for Refrigeration Applications Based on CFD, Applied Thermal Engineering, 26(2006), 604-612.

10. Varga S., Oliveira A., Diaconu B.: Numerical Assessment of Steam Ejector Efficiencies Using CFD, International Journal of Refrigeration, 32(2009), 1203-1211.

11. Rusly E., Aye L., Charters W.W.S., Ooi A.: CFD Analysis of Ejector in a Combined Ejector Cooling System, International Journal of Refrigeration, 28(2005), 1092-1101.

12. Sriveerakul T., Aphornratana S., Chunnanond K.: Performance Prediction of Steam Ejector Using Computational Fluid Dynamics: Part 1. Validation of the CFD Results, International Journal of Thermal Sciences, 46(2007), 812-822.

13. Sriveerakul T., Aphornratana S., Chunnanond K.: Performance Prediction of Steam Ejector Using Computational Fluid Dynamics: Part 2. Flow Structure of a Steam Ejector Influenced by Operating Pressures and Geometries, International Journal of Thermal Sciences, 46(2007), 823-833. 
14. Grazzini G., Milazzo A., Piazzini S.: Prediction of Condensation in a Two Stage Steam Ejector for a Refrigeration System, Submitted to International Journal of Refrigeration.

15. Fisenko V.V.: The Fisonic Energy Device Physical Principals, Joint Power Conference, (1995).

16. Levy E.K., Brown G.A.: Liquid-Vapor Interactions in a Constant-Area Condensing Ejector, Journal of Basic Engineering, 94(1972), No. 1, 169-180.

17. Trela M., Kwidzinski R., Butrymowicz D.: Exergy Analysis of Losses in a TwoPhase Steam-Water Injector, Chemical and Process Engineering, 29(2008), No. 2, 453-464.

18. Kornhauser, A.A.: The Use of an Ejector as a Refrigerant Expander, Proceedings of the 1990 USNC/IIR-Purdue Refrigeration Conference, Purdue University, (1990).

19. Kermani M.J., Gerber A.G.: A General Formula for the Evaluation of Thermodynamic and Aerodynamic Losses in Nucleating Steam Flow, International Journal of Heat and Mass Transfer, 46(2003), 3265-3278.

20. Prandtl, L.: About Fully-Developed Turbulence (Über die ausgebildete Turbulenz), Z. Angew. Math. Mech., 5(1925), 136-139.

21. Avetissian A.R., Philippov G.A., Zaichik L.I.: Effects of turbulence and inlet moisture on two-phase spontaneously condensing flows in transonic nozzles, International Journal of Heat and Mass Transfer, 51(2008), No. 17-18, 4195-4203.

22. White A.J.: A comparison of Modelling Methods for Polydispersed Wet-Steam Flow, International Journal for Numerical Methods in Engineering, 57(2003), 819834.

23. Fakhari K.: Development of a Two-Phase Eulerian/Lagrangian Algorithm for Condensing Steam Flow, $44^{\text {th }}$ AIAA Aerospace Sciences Meeting, 10(2006), 71567167.

24. Simpson D.A., White A.J.: Viscous and Unsteady Flow Calculations of Condensing Steam in Nozzles, International Journal of Heat and Fluid Flow, 26(2005), 71-79.

25. Bilicki Z., Kestin J.: Physical Aspects of the Relaxation Model in Two-Phase Flow, Proc. Roy. Soc. London A., 428(1990), 379-397.

26. Clerc S., Agee L., Harrison J.: From Sub-Channel Analysis to Two-Phase Flow CFD: Improving Thermal-Hydraulics Analysis of Nuclear Reactor Cores, Proceedings of the ASME Heat Transfer Division, 366(2000), No. 4, 243-246. 
27. Richter, H.J.: Separated Two-Phase Flow Model: Application to Critical Two-Phase Flow, International Journal of Multiphase Flow, 9(1983), No. 5, 511-530.

28. Harrell, G.S.: Testing and Modeling of a Two-Phase Ejector, Ph.D. Dissertation, Virginia Polytechnic Institute and State University, (1997).

29. Chen J., Kevorkian V.: Mass Production of 300-Micron Water Droplets by AirWater Two-Phase Nozzles, Ind. Eng. Chem. Process Des. Dev., 7(1968), No. 4, 586590 .

30. Albagli D., Gany A.: High Speed Bubbly Nozzle Flow with Heat, Mass, and Momentum Interactions, International Journal of Heat and Mass Transfer, 46(2003), 1993-2003.

31. Young J.B.: Two-Dimensional, Nonequilibrium, Wet-Steam Calculations for Nozzles and Turbine Cascades, Journal of Turbomachinery, 114(1992), 569-579.

32. Senoo S., White A.J.: Numerical Simulations of Unsteady Wet Steam Flows with Non-Equilibrium Condensation in the Nozzle and the Steam Turbine, ASME Joint U.S.-European Fluid Engineering Summer Meeting, 1(2006), 757-767.

33. Riffat S.B., Gan G., Smith S.: Computational Fluid Dynamics Applied to Ejector Heat Pumps, Applied Thermal Engineering, 16(1996), No. 4, 291-297.

34. Chen F., Liu C.F., Yang J.Y.: Supersonic Flow in the Second-Throat EjectorDiffuser System, Journal of Spacecraft Rocket, 31(1994), No. 1, 123-129.

35. Wang J.J., Chen F.: On the Start Condition of a Second-Throat Ejector-Diffuser, Journal of Aeronautics, (1996), 321-326.

36. Aphornratana S.: Theoretical and Experimental Investigation of a Combined EjectorAbsorption Refrigerator, Ph. D. Dissertation, University of Sheffield, UK, 1994.

37. Huang B.J., Chang J.M., Wang C.P., Petrenko V.A.: A 1-D Analysis of Ejector Performance, International Journal of Refrigeration, 22(1999), 354-364.

38. Eames I.W.: A New Prescription for the Design of Supersonic Jet-Pumps: The Constant Rate of Momentum Change Method, Applied Thermal Engineering, 22(2002), 121-131.

39. Yapici R., Ersoy H.K.: Performance Characteristics of the Ejector Refrigeration System Based on the Constant Area Flow Model, Energy Conversion and Management, 46(2005), 3117-3135. 
40. Nakagawa M., Berana M., Kishine A.: Supersonic Two-Phase Flow of $\mathrm{CO}_{2}$ through Converging-Diverging Nozzles for the Ejector Refrigeration Cycle, International Journal of Refrigeration, 32(2009), 1195-1202.

41. Guangming C., Xiaoxiao X., Shuang L., Lixia L., Liming T.: An Experimental and Theoretical Study of a $\mathrm{CO}_{2}$ Ejector, International Journal of Refrigeration, 33(2010), 915-921.

42. Nakagawa M., Marasigan A.R., Matsukawa T., Kurashina A.: Experimental Investigation on the Effect of Mixing Length on the Performance of Two-phase Ejector for $\mathrm{CO}_{2}$ Refrigeration Cycle with and without Heat Exchanger, International Journal of Refrigeration, (2010), In Press.

43. Lee J., Kim Mo, Kim Mi.: Experimental Study on the Improvement of $\mathrm{CO}_{2}$ Air Conditioning System Performance Using an Ejector, International Journal of Refrigeration, (2010), In Press.

44. Deng J., Jiang P., Lu T., Lu W.: Particular Characteristics of Transcritical $\mathrm{CO}_{2}$ Refrigeration Cycle with an Ejector, Applied Thermal Engineering, 27(2007), 381388.

45. Elbel S., Hrnjak P.: Experimental Validation of a Prototype Ejector Designed to Reduce Throttling Losses Encountered in Transcritical R744 System Operation, International Journal of Refrigeration, 31(2008), 411-422.

46. Li D., Groll E.A.: Transcritical $\mathrm{CO}_{2}$ Refrigeration Cycle with Ejector-Expansion Device, International Journal of Refrigeration, 28(2005), 766-773.

47. Cebeci T.: Analysis of Turbulent Flows, 1(2004). Elsevier.

48. Schmidt D.P., Gopalakrishnan S., Jasak H.: Multi-dimensional simulation of thermal non-equilibrium channel flow, Int. J. Multiphase Flow, 36(2010), No. 4, 284-292.

49. Downar-Zapolski P., Bilicki Z., Bolle L., Franco J.: The Non-Equilibrium Relaxation Model for One-Dimensional Flashing Liquid Flow, IJMF, 22(1996), No. 3, 473-483.

50. Trask N., Perot J.B., Schmidt D.P., Meyer T., Lightfoot M., Danczyk S.: Modeling of the Internal Two-Phase Flow in a Gas-Centered Swirl Coaxial Fuel Injector, $48^{\text {th }}$ AIAA Aerospace Sciences Meeting, 2010.

51. Fluent 6.3 User's Guide, ANSYS, (2006).

52. Vallet A., Burluka A.A., Borghi R.: Development of a Eulerian Model for the "Atomization" of a Liquid Jet, Atomization and Sprays, 11(2001), 619-642. 
53. Launder B.E.: Heat and Mass Transport, Topics in Applied Physics 12 - Turbulence, (1978), Springer, Berlin.

54. Schlichting: Boundary Layer Theory (Grenzschicht-Theorie), 9(1997), Springer, Berlin.

55. Schmidt D.P., Corradini M.L., Rutland C.J.: A Two-Dimensional, Non-Equilibrium Model of Flashing Nozzle Flow, $3^{\text {rd }}$ ASME/JSME Joint Fluids Engineering Conference, 208(1999), No. 616.

56. Issa R.I.: Solution of the Implicitly Discretised Fluid Flow Equation by OperatorSplitting, Journal Comput. Phys., 62(1986), No. 1, 40-65.

57. Lemmon E.W., Huber M.L., McLinden M.O.: NIST Standard Reference Database 23: Reference Fluid Thermodynamic and Transport Properties-REFPROP, Version 8.0. National Institute of Standards and Technology, Gaithersburg, 2007.

58. Weller H.G., Tabor G., Jasak H., Fureby C.: A Tensorial Approach to Computational Continuum Mechanics Using Object-Oriented Techniques, Computers in Physics, 12(1998), No. 6, 620.

59. Koeltzsch K..: The Height Dependence of the Turbulent Schmidt Number within the Boundary Layer, Atmospheric Environment, 34(2000), No. 7, 1147-1151.

60. Tominaga Y., Stathopoulos T.: Turbulent Schmidt Numbers for CFD Analysis with Various Types of Flowfield, Atmospheric Environment, 41(2007), No. 37, 80918099.

61. Demoulin F., Beau P., Blokkel G., Mura A., Borghi R.: A New Model for Turbulent Flows with Large Density Fluctuations: Application to Liquid Atomization, Atomization and Sprays, 17(2007), 315-345. 